\title{
Emerging zero-dimensional to four-dimensional biomaterials for bone regeneration
}

\author{
Haoyu Fang ${ }^{1}$, Daoyu Zhu', Qianhao Yang ${ }^{1}$, Yixuan Chen ${ }^{1}$, Changqing Zhang ${ }^{1 *}$, Junjie Gao ${ }^{12^{*}}$ and \\ Youshui Gao ${ }^{1 *}$ (D)
}

\begin{abstract}
Bone is one of the most sophisticated and dynamic tissues in the human body, and is characterized by its remarkable potential for regeneration. In most cases, bone has the capacity to be restored to its original form with homeostatic functionality after injury without any remaining scarring. Throughout the fascinating processes of bone regeneration, a plethora of cell lineages and signaling molecules, together with the extracellular matrix, are precisely regulated at multiple length and time scales. However, conditions, such as delayed unions (or nonunion) and critical-sized bone defects, represent thorny challenges for orthopedic surgeons. During recent decades, a variety of novel biomaterials have been designed to mimic the organic and inorganic structure of the bone microenvironment, which have tremendously promoted and accelerated bone healing throughout different stages of bone regeneration. Advances in tissue engineering endowed bone scaffolds with phenomenal osteoconductivity, osteoinductivity, vascularization and neurotization effects as well as alluring properties, such as antibacterial effects. According to the dimensional structure and functional mechanism, these biomaterials are categorized as zero-dimensional, one-dimensional, twodimensional, three-dimensional, and four-dimensional biomaterials. In this review, we comprehensively summarized the astounding advances in emerging biomaterials for bone regeneration by categorizing them as zero-dimensional to four-dimensional biomaterials, which were further elucidated by typical examples. Hopefully, this review will provide some inspiration for the future design of biomaterials for bone tissue engineering.
\end{abstract}

Keywords: Zero/one/two/three/four-dimensional biomaterial, Tissue engineering, Bone regeneration

*Correspondence: zhangcq@sjtu.edu.cn; colingjj@163.com;

gaoyoushui@sjtu.edu.cn

1 Department of Orthopedic Surgery, Shanghai Jiao Tong University

Affiliated Sixth People's Hospital, Shanghai, China

Full list of author information is available at the end of the article

(c) The Author(s) 2022. Open Access This article is licensed under a Creative Commons Attribution 4.0 International License, which permits use, sharing, adaptation, distribution and reproduction in any medium or format, as long as you give appropriate credit to the original author(s) and the source, provide a link to the Creative Commons licence, and indicate if changes were made. The images or other third party material in this article are included in the article's Creative Commons licence, unless indicated otherwise in a credit line to the material. If material is not included in the article's Creative Commons licence and your intended use is not permitted by statutory regulation or exceeds the permitted use, you will need to obtain permission directly from the copyright holder. To view a copy of this licence, visit http://creativecommons.org/licenses/by/4.0/. The Creative Commons Public Domain Dedication waiver (http://creativeco mmons.org/publicdomain/zero/1.0/) applies to the data made available in this article, unless otherwise stated in a credit line to the data. 


\section{Graphical abstract}

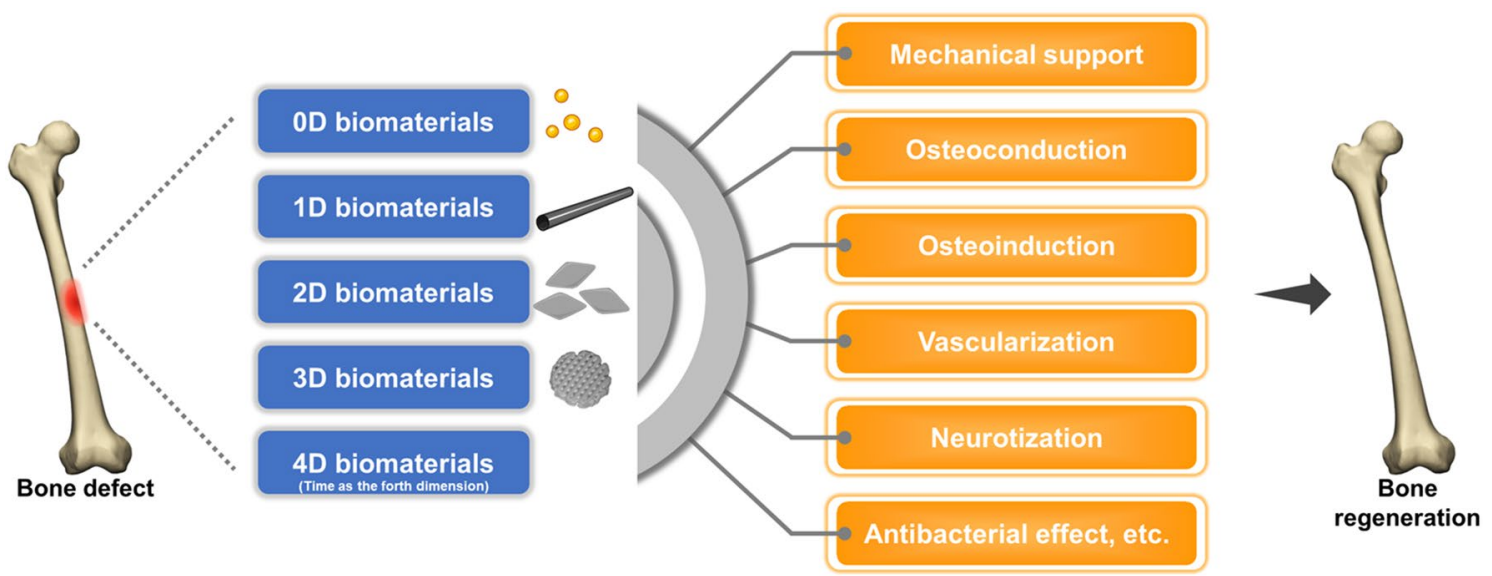

\section{Introduction}

Critical-sized bone defects resulting from trauma and other diseases remain a major challenge for orthopedic surgeons and appeal to the development of suitable bone grafts. Autologous bone grafts, which are generally regarded as the "gold standard" treatment for critical-sized bone defects, suffer from several disadvantages, such as quite limited source, prolonged operative time, and harvest site morbidity [1]. Therefore, artificial bone grafts emerge as alternative choices for bone tissue regeneration. A variety of biomaterials (e.g., polymer scaffolds, bioactive glasses, and hydrogels) have been intensively investigated as promising candidates for the effective reconstruction of bone defects.

The natural process of bone repair comprises a series of precisely-controlled synchronous and sequential events, which involve multiple cell populations, various biomolecules, extracellular matrices, and active interactions between all the components within the bone microenvironment [2]. To coordinate with the sophisticated process of bone regeneration, several characteristics and key parameters must be taken into account when designing biomaterials for bone tissue regeneration: (1) great biocompatibility and biodegradability to avoid potential inflammatory responses and rejection reactions; (2) proper surface properties to facilitate cell attachment and ingrowth, namely osteoconduction [3]; (3) a hierarchical interconnected porous structure to enable the ingrowth of vessels and neurons, and to permit the transport of nutrients and metabolites; (4) the capability of inducing pluripotent cells into osteogenic cell lineages via a process referred to as osteoinduction [3]; and (5) sufficient mechanical strength and structural integrity to sustain mechanical stress during bone remodeling.
In hopes of elucidating the correlation between material geometry and cell fate, we classified the biomaterials within the field of bone tissue regeneration according to the dimensional geometry and size in each dimension [i.e., number of dimensions that are confined to the nanoscale $(<100 \mathrm{~nm})]$. Specifically, nanoparticles with all three dimensions strictly confined to the nanoscale are defined as zero-dimensional biomaterials; one-dimensional biomaterials refer to nanomaterials with only two dimensions confined to the nanoscale; two-dimensional biomaterials have only one dimension within the nanoscale range; and all dimensions of three-dimensional biomaterials are greater than the nanoscale [4]. Fourdimensional biomaterials, which have emerged in recent years, integrate the concept of time as the fourth dimension [5].

\section{Zero-dimensional biomaterials}

As mentioned above, the classification system elucidated in this article is generally based on the dimensional geometry and size in each dimension [i.e., number of dimensions that are strictly confined to the nanoscale $(<100 \mathrm{~nm})]$.

Nanoparticles with all three dimensions strictly confined to the nanoscale are defined as zero-dimensional biomaterials [4]. Due to the high surface-to-volume ratio, zero-dimensional biomaterials exhibit several distinct physicochemical properties.

\section{Carbon-based zero-dimensional biomaterials}

During the past few decades, a variety of carbon-based zero-dimensional biomaterials have been fabricated, among which fullerene, nanodiamonds, and carbon dots are the most widely discussed. 


\section{Fullerene}

First discovered in 1985, fullerene $\left(C_{60}\right)$ has attracted considerable attention given its fascinating crystal structure, electronic properties, and physicochemical characteristics [6-8]. Geim [9] described fullerene as a wrapped form of a two-dimensional graphene sheet. Unlike graphene, however, the 60 carbon atoms contained in fullerene are arranged in a closed spherical form, which explains its significant diversity during aggregation [10, 11]. In other words, this unique morphological structure enables fullerene to assemble into one-, two-, and three-dimensional structures depending on the type of solvent mixture [12-14]. In 2015, Krishnan et al. [15] fabricated aligned fullerene nanowhiskers $\left(\mathrm{C}_{60} \mathrm{NWs}\right)$ via the vortex motion method, which were subsequently transferred onto glass substrates as a scaffold for cell culture. It turned out that MG-63 cells were highly oriented in accordance with the axis of the aligned $\mathrm{C}_{60} \mathrm{NWs}$. In addition, it has been reported that polyhydroxylated fullerene not only supported the proliferation of human adiposederived stem cells (hADSCs), but also facilitated the process of osteogenic differentiation and biomineralization, of which the mechanism has not been fully explored yet [16]. The production of cytotoxic reactive oxygen species (ROS) by photoexcited fullerene, however, may hinder the further application of fullerene as a friendly biomaterial for bone regeneration [17].

\section{Nanodiamonds}

Another carbon-based nanomaterial that deserves attention is nanodiamonds (NDs), which are defined as nanocrystalline diamonds with a diameter of 5-8 $\mathrm{nm}$. Due to the high surface-to-volume ratio, NDs, which are chemically inert, could be easily surface-functionalized with a variety of chemically reactive moieties such as - $\mathrm{COOH}$. Many efforts have been made to apply NDs to biomaterial scaffolds in the last two decades, given the unique and superior properties of NDs, such as extreme hardness, superior mechanical strength, high thermal conductivity, great chemical stability and surface reactivity, and excellent biocompatibility [18].

A study showed that nanostructured nanocrystalline diamond (NCD) films provide better support for the adhesion, metabolic activity and osteogenic differentiation of MG-63 cells compared to the control polystyrene culture dish [19]. Astonishingly, even a small quantity (e.g., $10 \% \mathrm{wt}$ ) of octadecylamine-functionalized nanodiamond (ND-ODA) incorporated in poly(L-lactic acid) (PLLA) could result in remarkable potentiation in the mechanical performance of the composite scaffold (e.g., Young's modulus, strain at failure, tensile strength, and hardness) [20, 21]. Furthermore, due to the high surface reactivity of NDs, ND-ODA/PLLA scaffolds interact with a variety of moieties and ions in the simulated body fluid and facilitate the deposition of bone-like apatite, which showed excellent mineralization capability and could be of great benefit for bone regrowth [21]. The addition of NDs into poly(lactic-co-glycolic acid) (PLGA) nanofibrous scaffolds remarkably promoted its mechanical performance in rupture tests, and the composite scaffold also exhibited great biocompatibility to enable the adhesion, spreading, and proliferation of MG-63 cells without evoking considerable inflammatory reactions of RAW 264.7 macrophages and MG-63 cells [22]. In addition, intrinsic fluorescence emitted by NDs under certain wavelengths of light could be of great value for in vivo monitoring of ND-ODA/PLLA-based internal fixation devices during surgery and during the process of bone healing [20]. In summary, NDs exhibit a great diversity of fascinating properties (i.e., superior mechanical strength, great chemical stability and surface reactivity, excellent biocompatibility, favorable effects on cell proliferation and differentiation, remarkable mineralization capability, and strong intrinsic fluorescence), which makes ND-based scaffolds promising biomaterials for bone regenerative engineering.

\section{Carbon dots}

As emerging carbon-based zero-dimensional nanomaterials, Carbon dots (C-dots) have drawn widespread attention since their emergence $[23,24]$. The most distinguishing feature of $\mathrm{C}$-dots is their excitation wavelength dependent photoluminescence spectra, with emissions ranging from the visible wavelength to the near-infrared wavelength [24]. Interestingly, the photoluminescence of C-dots exhibits strong resistance to photobleaching, which makes $\mathrm{C}$-dots an ideal tracer for monitoring the progress of scaffold biodegradation. In addition, several in vitro and in vivo studies have elucidated that C-dots have great biocompatibility with minimal cytotoxicity when applied at appropriate concentrations (e.g., $10 \mu \mathrm{g} /$ ml) [25-31], whereas high concentrations of C-dots (i.e., higher than $50 \mu \mathrm{g} / \mathrm{ml}$ ) could exert an inhibitory effect on cell proliferation $[25,27]$.

Numerous studies have demonstrated that C-dots alone could substantially facilitate the osteogenic differentiation of mesenchymal stem cells (MSCs), which was corroborated by enhanced ALP activity and up-regulation of osteogenic gene markers [e.g., runt-related transcription factor 2 (Runx2), osteopontin (OPN), bone sialoprotein (BSP), and osteocalcin (OCN)] [25-28]. On the other hand, the addition of $\mathrm{C}$-dots to hydroxyapatite (HA) and polymers has been reported to improve the mechanical performance, osteoconductivity, and osteoinductivity of composite biomaterials [32-36]. For example, Khajuria 
et al. [33] found that HA nanoparticles conjugated with nitrogen-doped C-dots exhibited a more favorable influence on the proliferation, osteogenic differentiation, and calcium mineralization of MC3T3-E1 cells compared with HA nanoparticles alone, presumably via the internalization of the conjugates into osteoblasts and thus activating the bone morphogenetic protein (BMP) signaling pathway. Furthermore, this conjugate significantly accelerated bone metabolism and mineralization in the zebrafish jawbone regeneration model. However, another study discovered that doping of C-dots in calcium phosphate nanorods induced ectopic chondrogenesis rather than osteogenesis in a rat subcutaneous model, presumably by activating the HIF- $\alpha /$ SOX-9 signaling pathway [37].

It is also worth noting that, aside from the unique photoluminescence and osteoinductive capability, C-dots exhibit several other intriguing characteristics as biomaterials for bone regeneration. It has been reported that the superior photothermal effect made C-dots a promising candidate for osteosarcoma ablation, suppressing tumor growth or even eradicating the tumor. On the other hand, the excellent osteoinductive capability of C-dots could expedite the process of subsequent bone tissue regeneration after photothermal tumor ablation is accomplished. Moreover, chitosan/nanohydroxyapatite scaffolds possessed better antibacterial properties when doped with $\mathrm{C}$-dots and irradiated under near-infrared (NIR) irradiation due to the photothermal effect of C-dots [34]. Regarding primary and metastatic tumors in the bone tissue, biomaterials with superior photothermal effect and excellent osteoinductivity would have incomparable advantages in eradicating tumors and facilitating the repairing process of critical-sized bone defects arising from tumor ablation. As for the treatment of infective bone defects (e.g., infected nonunion), biomaterials with potent antibacterial property and excellent osteoinductive capability could effectively clear the persistent bacterial infection and facilitate the reconstruction of bone defects.

\section{Other zero-dimensional biomaterials}

Aside from carbon-based zero-dimensional nanoparticles, a variety of inorganic nanoparticles have shown incredible potential for promoting MSC proliferation as well as facilitating the process of osteogenic differentiating and biomineralization.

Metallic nanoparticles (e.g., gold nanoparticles and silver nanoparticles) and metallic oxide nanoparticles (e.g., iron oxide nanoparticles) have been reported to influence MSC fate and direct MSC differentiation toward the osteogenic lineage, mainly by causing intracellular mechanical stress. For example, Yi et al. [38] discovered that gold nanoparticles (AuNPs) co-cultured with MSCs could exert mechanical stress on stem cells to activate p38 MAPK signaling pathway and subsequently upregulate the expression of osteogenesis-related genes, which resulted in elevated ALP activity and promoted mineralization rates. In addition, silver nanoparticles (AgNPs) encapsulated in collagen favored MSC proliferation, osteogenic differentiation, and calcium mineralization, which was corroborated in a mouse femoral fracture model [39]. As for metallic oxide nanoparticles, it has been reported that iron oxide nanoparticles (IONPs) exhibited excellent biocompatibility as well as promotive effects on MSC osteogenic differentiation and biomineralization, resulting from the activation of MAPK pathway and the subsequent up-regulation of downstream genes that are related to osteogenesis (e.g., Runx2 and BMP-2) [40]. Of note, not only can AuNPs interact with MSCs and facilitate osteogenesis, but they can also serve as cellular probes for MSC tracking in vivo. In 2016, Wan et al. [41] fabricated AuNPs@SiO ${ }_{2}$-TS by modifying silica-coated AuNPs with DNA Transfectin 3000 (TS), in which silica was incorporated to promote biocompatibility and TS was incorporated to enhance the cellular uptake of the composite nanoparticles. While exhibiting no adverse effect on cell viability and multi-directional differentiation capability of MSCs with concentrations lower than $100 \mu \mathrm{g} / \mathrm{ml}$ in vitro, AuNPs@SiO ${ }_{2}$-TS could be uptaken by MSCs effectively and retained in MSCs for more than 14 days. Using dual-energy computer tomography (DECT) and proper decomposition methods, MSCs labeled by AuNPs@SiO ${ }_{2}$-TS could be clearly visualized and distinguished from the surrounding bone tissue in a rabbit femoral bone defect model, indicating that AuNPs@SiO $\mathrm{Si}_{2}$-TS could serve as a noninvasive probe for the real-time tracking of MSCs in vivo.

In recent years, magnetic nanoparticles have also emerged as promising zero-dimensional biomaterials for bone tissue engineering. For example, Liu et al. [42] incorporated magnetic $\mathrm{SrFe}_{12} \mathrm{O}_{19}$ nanoparticles into bioglass/chitosan scaffolds to fabricate multi-functional hybrid scaffolds for photothermal tumor therapy and subsequent bone regeneration. The excellent photothermal conversion property of $\mathrm{SrFe}_{12} \mathrm{O}_{19}$ endowed the hybrid scaffolds with great efficiency in killing osteosarcoma cells, which was corroborated in a nude rat subcutaneous MNNG tumor model. On the other hand, thanks to the superior saturation magnetization and coercivity of $\mathrm{SrFe}_{12} \mathrm{O}_{19}$, the magnetic field produced by the hybrid scaffolds could significantly promote MSC proliferation and up-regulate the expression of osteogenesis-related genes, presumably by activating BMP-2/Smad/Runx2 signaling pathway. The exceptional bone regeneration 
capability of the hybrid scaffolds was also confirmed in a rat critical-sized calvarial defect model.

In summary, the high surface-to-volume ratio of zerodimensional biomaterials endows them with exceptional properties, such as great mechanical strength, thermal conductivity, electric properties, and surface reactivity (modulating cell fate and facilitating bone mineralization). Incorporation of zero-dimensional biomaterials with other substrates could provide multifunctional platforms for the treatment of bone diseases that could cause bone defects (e.g., osteosarcoma) to serve as stepwise countermeasures to treat the aforementioned bone diseases and facilitate subsequent bone regeneration. Zerodimensional nanoparticles are generally incorporated with other biomaterials to cater to the needs for bone defect repair, given that zero-dimensional nanoparticles alone lack the prerequisite structural integrity and stability for bone regeneration. However, the interaction mechanism between zero-dimensional biomaterials and MSCs, as well as the potential cytotoxicity of these nanoparticles, have yet to be further elucidated. Selective examples of zero-dimensional biomaterials for bone tissue engineering are briefly provided in Table 1 .

\section{One-dimensional biomaterials}

One-dimensional biomaterials refer to nanomaterials with only two dimensions confined to the nanoscale $(<100 \mathrm{~nm})$, which can be further subdivided into nanowires, nanotubes, etc. [4]. Due to the unique morphology (e.g., high length-to-diameter ratio) and nanotopography, one-dimensional biomaterials have an extremely high degree of anisotropy, which results in various distinct properties. Moreover, numerous one-dimensional biomaterials have served as the basic building block for fabricating higher-dimensional biomaterials.

\section{Nanowires}

Nanowires are defined as solid nanomaterials with lengths longer than $100 \mathrm{~nm}$ and diameters confined to the nanoscale. The length-to-diameter ratio is the key characteristic of nanowires, and this feature plays an essential role in influencing cell fates [43]. Early in 2007, the biocompatibility of the vertically aligned silicon nanowire $(\mathrm{SiNW})$ array on a Si wafer was corroborated in several mammalian cell lines [44]. In 2013, it was reported that the interaction between MSCs and vertically aligned SiNW arrays on silicon substrates preferentially resulted in osteogenic and chondrogenic differentiation of MSCs, apart from the significant improvement in cell adhesion and proliferation [45]. Mechanical stimulation during MSCs-SiNW interaction triggers cytoskeletal reorganization and transiently activates $\mathrm{Ca}^{2+}$ channels, which subsequently initiate the Ras/Raf/MEK/ERK signaling pathway to modulate cell adhesion, proliferation, and differentiation. Furthermore, various mechanosensitive pathways (e.g., Akt, insulin, TGF- $\beta / B M P$, MAPK/ ERK, integrin, and Wnt signaling pathways) also play essential roles in activating Ras/Raf/MEK/ERK cascades and initiating the process of osteogenesis and chondrogenesis when MSCs were co-cultured with the vertically aligned SiNW array [46]. In addition to SiNW, bioactive glass nanofibers (BG-NFs) [47] and nanofibers composed of poly(lactide-co-glycolide) and nanohydroxyapatite (PLGA/nHA-NFs) [48] have also shown great potential for the osteoinduction of MSCs.

\section{Nanotubes}

Nanotubes are hollow cylindrical nanostructures that have drawn considerable attention due to their extraordinary mechanical, chemical, and electrical properties. The nanotube biomaterials currently used for bone regeneration mainly include titanium dioxide nanotubes $\left(\mathrm{TiO}_{2}\right.$-NTs) and carbon nanotubes (CNTs).

\section{Titanium dioxide nanotubes $\left(\mathrm{TiO}_{2}-\mathrm{NTS}\right)$}

The length and diameter of $\mathrm{TiO}_{2}$-NTs could be precisely controlled over a wide range via electrochemical anodization, which enables researchers to explore the relationship between the morphology/nanotopography of $\mathrm{TiO}_{2}-\mathrm{NTs}$ and stem cell fate [49]. Numerous studies have demonstrated that the diameter of vertically oriented $\mathrm{TiO}_{2}-\mathrm{NTs}$ on $\mathrm{Ti}$ substrates determines the intrinsic properties of the biomaterial (e.g., hydrophilia), thus influencing cell adhesion, spreading, proliferation, and differentiation [50-54]. Specifically, small $\mathrm{TiO}_{2}$-NTs (diameter ranging from 15 to $30 \mathrm{~nm}$ ) augmented MSC adhesion and proliferation, whereas such cell activities were severely impaired on $\mathrm{TiO}_{2}-\mathrm{NTs}$ with a diameter greater than $50 \mathrm{~nm}[50,52,53]$. In addition, larger $\mathrm{TiO}_{2}$-NTs (diameter ranging from 70 to $100 \mathrm{~nm}$ ) could trigger MSC elongation and osteogenic differentiation, presumably by inducing cytoskeletal stress [52, 54]. Thanks to such unique diameter-dependent MSC behavior, osteogenic differentiation of MSCs could be precisely modulated by altering the diameter of vertically oriented $\mathrm{TiO}_{2}-\mathrm{NTs}$ on Ti substrates, offering a promising route for bone regeneration.

\section{Carbon nanotubes (CNTs)}

As indicated by Geim [9], carbon nanotubes (CNTs) can be considered as single or several layers of graphene sheet(s) rolling into a seamless cylindrical nanostructure. CNTs are further subdivided into single-walled CNTs (SWCNTs) and multi-walled CNTs (MWCNTs). SWCNTs have a better-defined diameter between 0.4 and $2 \mathrm{~nm}$, whereas the outer diameter of MWCNTs ranges 


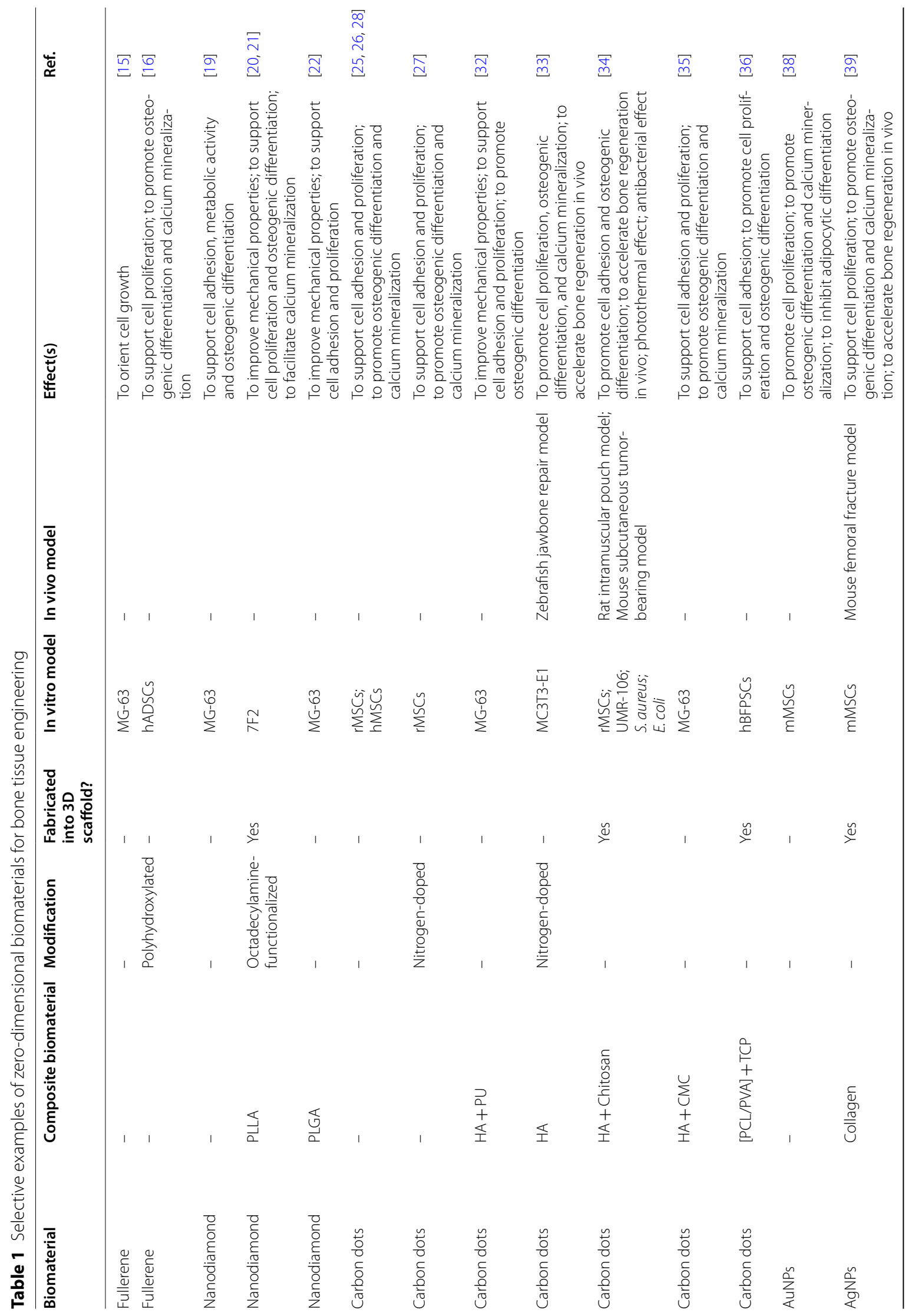




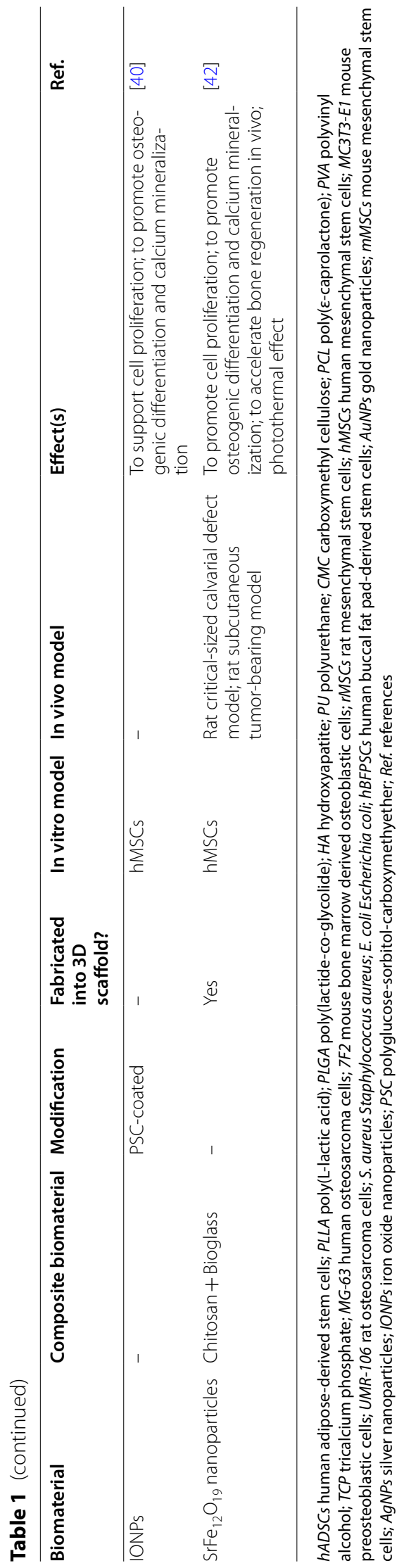


from 2 to $100 \mathrm{~nm}[55,56]$. SWCNTs and MWCNTs are up to a few microns in length, resulting in an extremely high aspect ratio (L/D) and large interfacial area. Due to their unique structure and nanotopography, CNTs exhibit great mechanical strength and chemical stability, as well as exceptional electrochemical and thermal properties [57]. These excellent properties have led to the wide application of CNTs in a variety of fields, including electrochemical devices [58], field emission devices [59], energy storage [60], probes [61], and medical applications [62].

Numerous studies have shown that CNTs alone could act as cores for initiating the crystallization of apatite/ $\mathrm{HA}$ and accelerate the process of mineralization [63, 64]. High cell viability, strong adhesiveness, and an elevated proliferation rate were observed when osteoblastic cells were cultured in CNT-coated dishes [65]. It was indicated that the unique rough nanostructure of CNTs increased the surface roughness of the CNT-coated dishes, which up-regulated the expression of vinculin and resulted in better cell adhesion and viability. In another in vivo study [66], CNTs facilitated the process of bone formation and were eventually incorporated into the newly formed osseous tissue without causing any evident rejection reaction or inflammatory response, which corroborated the exceptional bone-tissue compatibility of CNTs. Notably, CNTs have been widely utilized as reinforcing agents for improving the structural integrity and mechanical properties of the biomaterials, including hardness, elastic modulus, tensile strength, bending strength, and compressive strength, as well as reducing the wear debris from composites [67-75]. In regard to tricomponent composite biomaterials, CNTs could serve as interfaces to increase the interfacial bonding between the other components [e.g., HA, bioactive glass (BG), polysaccharides, polymers, and mineral trioxide aggregate (MTA)] [75-79]. More importantly, the addition of CNTs into biomaterials (e.g., HA [68-70, 73, 80, 81] and polymers $[67,72,74,82-85])$ substantially facilitated cell adhesion, proliferation, migration, mineralization, osteoinduction, and bone regeneration. For example, CNT-coated polycaprolactone-polylactic acid scaffolds combined with insulin-like growth factor-1 triggered osteogenic differentiation of MSCs, inhibited cellular senescence, and accelerated bone regeneration in a rat femoral defect model (Fig. 1) [85]. Moreover, due to the electrical conductivity of CNTs, the poly-DL-lactide (PLA)/CNTs composite scaffold exhibited favorable effects on osteoblast proliferation, extracellular mineralization, and osteogenic differentiation under electrical stimulation $[86,87]$.

Despite numerous exceptional properties, one factor that might hamper the application of CNTs is the underlying cytotoxicity. It has been reported that CNTs dispersed in solution could impair MSC proliferation, osteogenic differentiation, mineralization, and adipogenic differentiation via the Smad-dependent BMP signaling pathway [88]. As indicated above, pristine CNTs dispersed in the solution could elicit cytotoxicity and hinder cell activities, presumably by the production of ROS and activation of inflammatory reactions. However, CNTs bound to a surface exhibit minimal cytotoxicity, which suggests that surface functionalization might be critical to eliminating the potential cytotoxicity of CNTs. For example, PEGylated SWCNTs exhibit reduced ROSmediated cytotoxic potency compared with uncoated SWCNTs [89]. In general, a more profound understanding of the cytotoxicity of CNTs is needed such that an optimal surface functionalization strategy can be designed to mitigate the hazard that might be associated with the application of CNTs.

In general, one-dimensional biomaterials (e.g., nanowires and nanotubes) exhibit unique nanotopography and a large length-to-diameter ratio, which exerts a great influence on cell behavior and calcium biomineralization. The diameter and orientation of aligned nanowires/nanotubes potentially represent the key parameters for MSC differentiation, which surely deserves more investigation. Moreover, the linear morphology of nanowires and nanotubes could be utilized to guide neovascularization and innervation, which may represent a hotspot of future research. Selective examples of one-dimensional biomaterials for bone tissue engineering are briefly presented in Table 2.

\section{Two-dimensional biomaterials}

The definition of a two-dimensional biomaterial arises from the fact that only one dimension of it is within the nanoscale range $(<100 \mathrm{~nm})$ [4]. Based on the definition, two-dimensional biomaterials are characterized by a high diameter-to-thickness ratio, resulting in exceptional properties such as great absorption capacity.

\section{Graphene and its derivatives}

Graphene, a monolayer of dense honeycomb lattice formed by carbon atoms, is considered the building block for other carbon allotropes (e.g., fullerenes and CNTs) [9]. Since the experimental discovery of graphene in 2004 [90], graphene and its derivatives, including graphene oxide (GO) and reduced graphene oxide ( $\mathrm{rGO}$ ), have received tremendous attention for their potential application in tissue engineering [91].

The peculiar hexagonal lattice nanostructure and one atomic thickness endow graphene with a large surface area, excellent mechanical properties, exceptionally high electronic conductivity, great thermal conductivity, superior charge carrier mobility, and impermeability to gases 


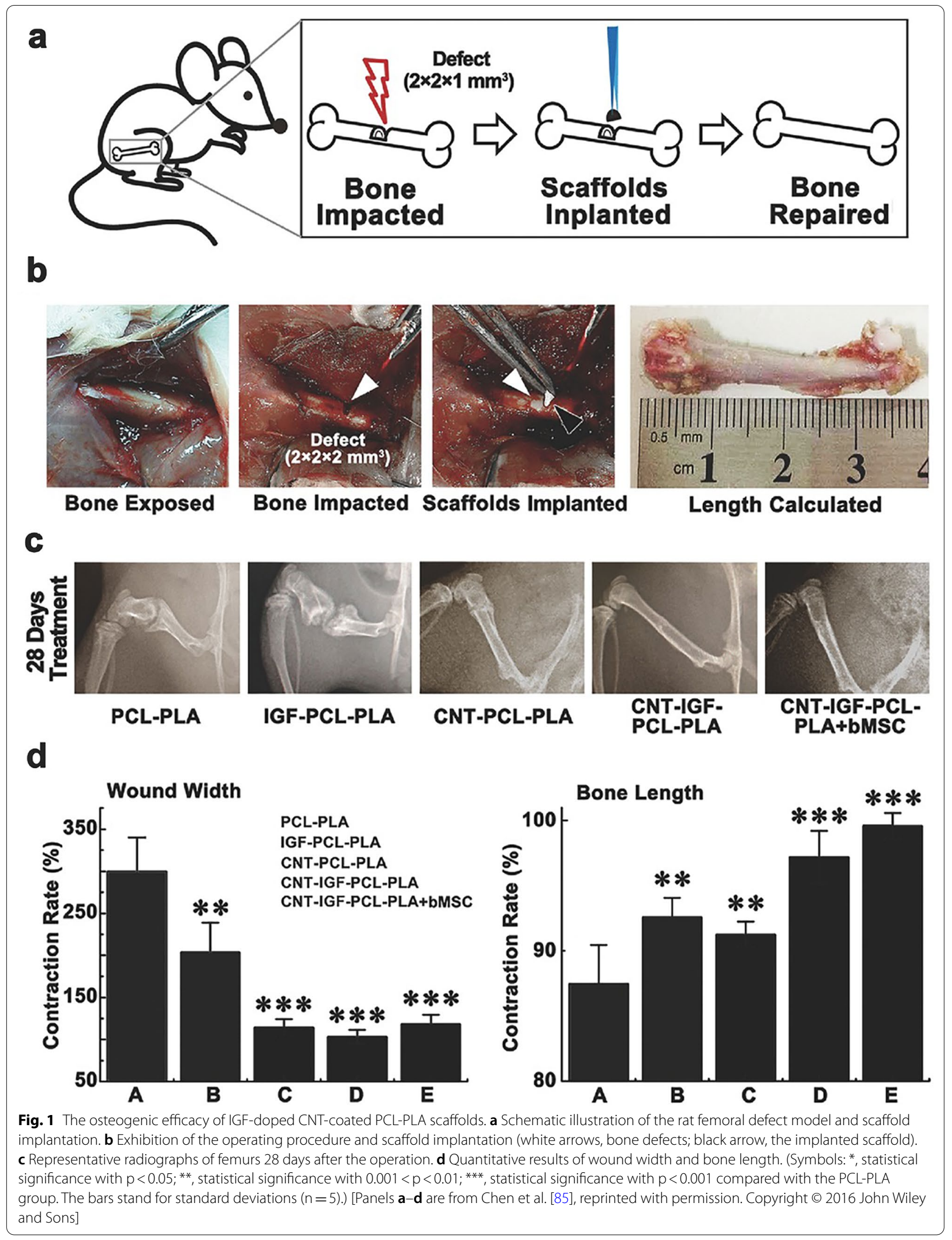




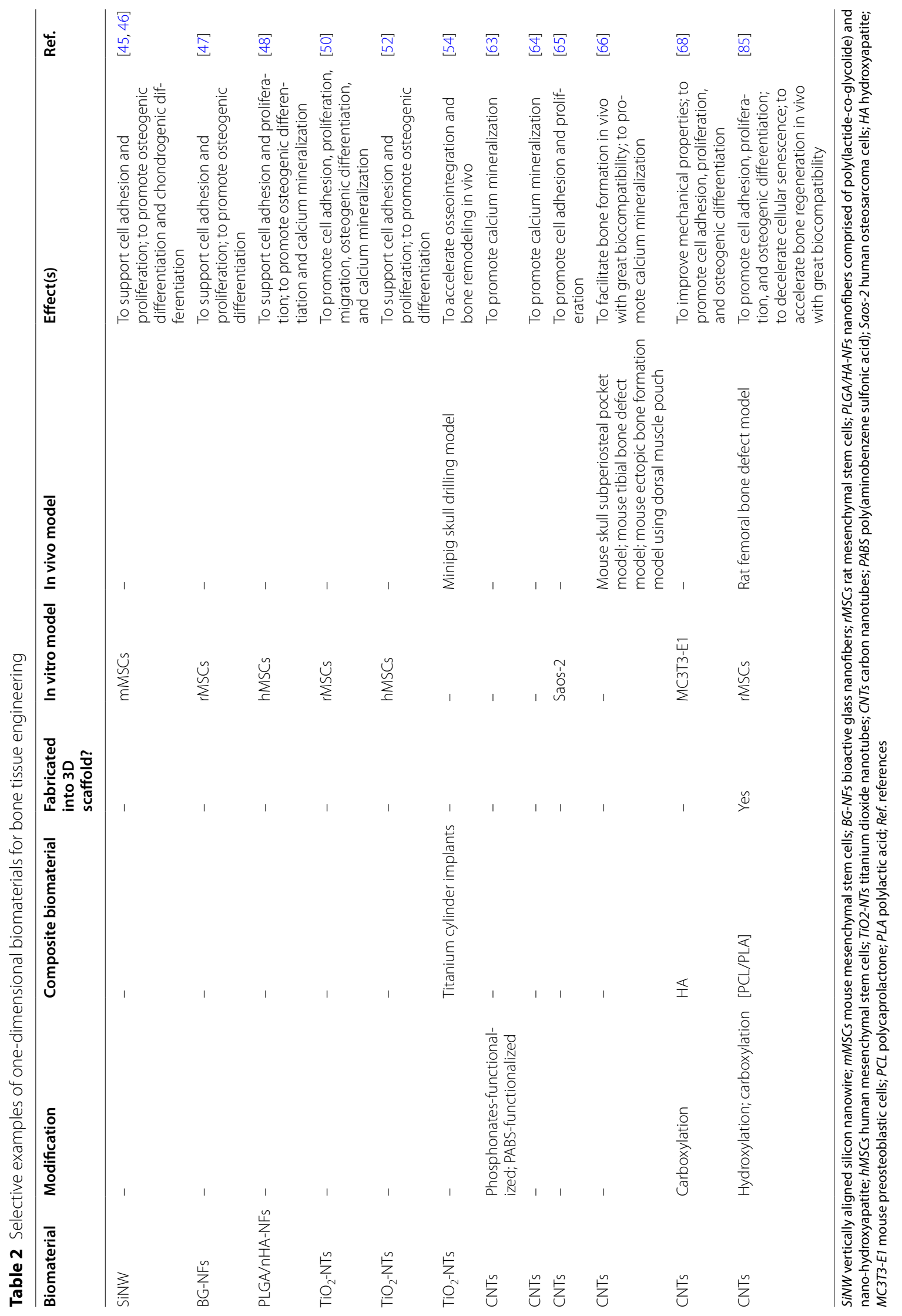


[91, 92]. Advances in the large-area synthesis of uniform graphene via chemical vapor deposition (CVD) have made it feasible to explore the potential biomedical applications of graphene [93]. Numerous studies have elucidated that CVD-grown graphene on different substrates (e.g., soda lime glass, polydimethylsiloxane (PDMS), polyethylene terephthalate (PET), oxidized silicon wafer $\left(\mathrm{SiO}_{2} / \mathrm{Si}\right.$ stack), and stainless steel) exhibited favorable effects on cell adhesion $[94,95]$, proliferation $[94,95]$, and osteogenic differentiation of MSCs [96-98]. For instance, Nayak et al. [97] discovered that the osteogenic differentiation rate of MSCs co-cultured with graphene was comparable to that achieved by introducing the common growth factor BMP-2 (Fig. 2). It has also been reported that three-dimensional graphene foams exhibit great potential for maintaining MSC viability and inducing spontaneous osteogenic differentiation without extrinsic osteogenic inducers [98]. The exceptional osteoinductive property of graphene is attributed to its superior noncovalent binding ability, which allows graphene to serve as a preconcentration platform for osteogenic inducers [96]. Specifically, $\pi-\pi$ stacking among the aromatic rings endows graphene with an extremely high absorption capacity of dexamethasone and $\beta$-glycerophosphate, which promote MSC differentiation toward the osteogenic lineage. Moreover, graphene was composited with other materials (e.g., BG and HA) as hybrid biomaterials [99-101]. The addition of graphene not only substantially enhanced the mechanical properties of these hybrid scaffolds (e.g., compressive strength and tensile strength), but also showed favorable biocompatibility and osteoinductivity in both in vitro and in vivo experiments.

Graphene oxide (GO) generally refers to the oxidized form of graphene, which incorporates diverse oxygencontaining functional groups (e.g., hydroxyl and epoxide groups on the basal plane, and carboxyl groups on the edge) within a single-atom-thick nanostructure [96, 102]. In addition to the active reaction sites provided by a variety of oxygen-containing groups, the regular distribution of these functional groups provides GO with

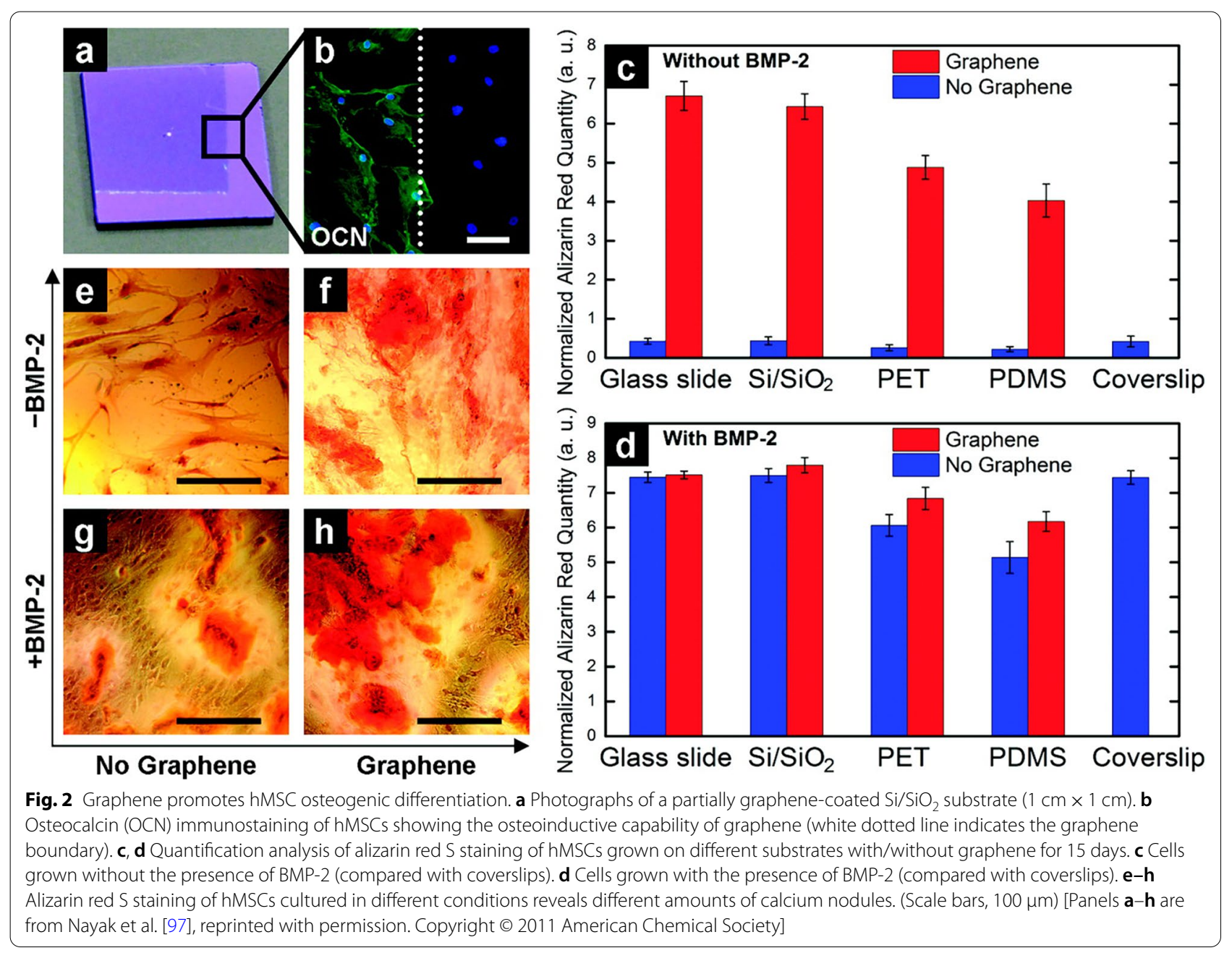


both hydrophilic and hydrophobic parts along with the remaining carbon-carbon $\mathrm{sp}^{2}$ domains, all of which enable GO to have more active interactions with biomolecules via covalent, noncovalent, electrostatic, and hydrogen bonding. It has been reported that GO and surface-modified GO are capable of enhancing cell adhesion and proliferation, as well as facilitating HA mineralization and osteogenic differentiation [96, 103-107]. As mentioned above, the distinct structure endows GO with exceptionally high absorption capacity for various molecules, which explains its substantial influence on cell differentiation. According to Lee et al. [96], GO could concentrate dexamethasone via the remaining $\pi-\pi$ stacking among the aromatic rings, and absorb ascorbic acid via hydrogen bonding, thus accelerating osteogenic differentiation of MSCs. In addition, the hydrogen bonding and electrostatic interactions between GO and insulin help with the focal enrichment of insulin while preserving the insulin protein structure, thus promoting adipogenic differentiation of MSCs in adipogenic medium [96]. However, it has also been suggested that the physical stress derived from the topographic features of GO may act as another essential parameter in promoting osteogenic differentiation, presumably by affecting cytoskeletal tension and inducing cytoskeletal reorganization [103]. The incorporation of GO with other biomaterials has been the focus of intensive research in the past few years. As might be expected, even a tiny amount of GO (e.g., 1 $w t \%)$ could boost the mechanical strength of the composites to a large extent [108-122], whereas excess GO may jeopardize the mechanical performance presumably by forming agglomerates and increasing porosity $[108,114$, $115,121]$. The hydrophilicity and water retention ability of the composite scaffolds are also improved by the incorporation of GO [110, 111, 114, 117, 118, 122, 123], which partially contributes to the improved cell adhesion strength and molecule absorption affinity of the composites. During the fabrication of some tricomponent or tetracomponent composite biomaterials, GO also serves as an interface phase to facilitate the interfacial binging of the other components (e.g., polymers and bioceramics) $[111,112,116,118,120,122]$. Most importantly, the GO-incorporated hybrid scaffolds exhibited great biocompatibility [108-113, 116-118, 120-129], antibacterial activity $[110,127]$, and osteoinductivity $[109,111$, $112,114,116,117,123,125-128,130]$ both in vitro and in vivo, which was corroborated by elevated ALP activity, calcium mineralization, and osteogenic gene expression. For instance, Zhang et al. [128] designed a novel bifunctional bioceramic scaffold by incorporating $\mathrm{Fe}_{3} \mathrm{O}_{4}$ nanoparticles into GO-modified $\beta$-tricalcium phosphate $\left(\beta\right.$-TCP) scaffold. As magnetic particles, $\mathrm{Fe}_{3} \mathrm{O}_{4}$ endowed the composite scaffolds with excellent magnetothermal effects under a magnetic field, which could be precisely controlled by altering the magnetic field intensity and the content of $\mathrm{Fe}_{3} \mathrm{O}_{4}$ nanoparticles. In vitro experiments demonstrated that the prominent magnetothermal effect of the composite scaffolds reduced the cell viability of osteosarcoma cells (MG-63) by 75\%, whereas GO and continuously released $\mathrm{Fe}^{3+}$ ions could synergistically accelerate osteogenic differentiation of MSCs and facilitate new bone formation. Of note, various bioactive molecules (e.g., osteogenic inducers [113, 122, 129, 131] and antibacterial nanoparticles [113]) have been immobilized into many GO-incorporated hybrid scaffolds to further improve the performance of the composite scaffolds. Given its active interactions with biomolecules, GO served as an effective carrier in these drug-loading scaffolds to achieve large loading dose and sustained release of the bioactive molecules, with preservation of the bioactivity of the molecules.

As implied by the name, reduced graphene oxide (rGO) is basically produced by reducing $\mathrm{GO}$ via different reduction techniques, such as chemical reduction and thermal reduction. During the reduction process, the quantities of oxygen-containing functional groups would be reduced to varying extents depending on the reduction methods, which results in modulated electrical conductivity, thermal stability, and hydrophilicity [132, 133]. Numerous studies have reported that rGO exhibited a favorable capability of supporting cell proliferation and adhesion, as well as promoting biomimetic mineralization and osteogenic differentiation [103, 134-137]. Inspired by its excellent capability of augmenting osteogenesis, rGO has also been incorporated with many other biomaterials (e.g., HA and polymer) to fabricate novel hybrid materials with superior biocompatibility and osteoinductivity [138-141].

Similar to any other carbon-based material, the cytotoxicity of graphene and its derivatives has always been a topic of great interest. Pristine graphene dispersed in the solution was reported to accumulate on the cell membrane and cause cytotoxicity, presumably by increasing intracellular oxidative stress and inducing apoptosis [142]. High concentrations of GO in the solution could also attenuate cell viability in a dose-dependent manner $[143,144]$. However, graphene films coated onto different substrates exhibited superior biocompatibility without any appreciable cytotoxicity [95]. In addition, no acute or chronic toxicity was observed after mice were intravenously injected with PEGylated graphene at a dose of $20 \mathrm{mg} / \mathrm{kg}$, which was corroborated by hematological and histological analyses [145]. Based on the discussion above, we may arrive at the conclusion that surface functionalization or immobilization of graphene and its derivatives might mitigate or even eliminate the potential 
cytotoxic effect. Moreover, the size and dose of graphene and its derivatives might also represent essential parameters to influence their biocompatibility and cytotoxicity.

\section{Other thin film coatings on biomaterials}

Aside from graphene and its derivatives, a great number of two-dimensional nanofilm coatings have been applied to traditional biomaterials to facilitate more intense integration of biomaterials and the biological environment, and thus to expedite the process of bone regeneration.

After clean glass surfaces were modified with amino ($\mathrm{NH}_{2}$ ), MSCs cultured on these modified surfaces could spontaneously differentiate toward the osteogenic lineage even without the presence of extrinsic osteogenic inducers [146]. In another study, calcium phosphate coatings on substrates exerted a potent effect on triggering the spontaneous osteogenic differentiation of human MSCs without osteogenic additives, presumably by modulating the behavior of focal adhesions [147]. It has also been reported that $\mathrm{TiO}_{2}-\mathrm{HA}$ nanocomposite coatings favor MSC proliferation, adhesion, osteogenic differentiation, and extracellular matrix mineralization [148].

Black phosphorus (BP) nanofilms have emerged as promising bioactive coatings for numerous applications due to their high photothermal conversion efficiency and fine osteoinductivity. Yang et al. [149] constructed a bifunctional therapeutic platform by incorporating BP nanofilm into the $3 \mathrm{D}$-printed BG scaffold. The presence of BP nanofilms endowed the hybrid scaffold with excellent photothermal performance for the ablation of osteosarcoma, as well as escalated osteoconduction and osteoinduction performance to facilitate subsequent bone regeneration, which was corroborated both in vitro and in vivo (Fig. 3). One way to explain the exceptional bone regeneration performance of $\mathrm{BP}$ nanosheets is that exposure to the oxygen and water could lead to the rapid biodegradation of $\mathrm{BP}$ and result in the release of abundant $\mathrm{PO}_{4}^{3-}$, which rapidly extracts $\mathrm{Ca}^{2+}$ ions and accelerates the formation of calcium phosphate to facilitate the process of biomineralization and bone regeneration.

In general, two-dimensional nanosheets and nanofilms usually serve as coatings and layer-by-layer building blocks for the modification and fabrication of composite scaffolds. The large diameter-to-thickness ratio of twodimensional nanofilm coatings endows them with great potential for altering the intricate surface properties of biomaterials, such as surface chemistry and charge, which subsequently influence cell behavior and cell fate in a profound way. Selective examples of two-dimensional biomaterials for bone tissue engineering are briefly summarized in Table 3.

\section{Three-dimensional biomaterials}

Biomaterials with all dimensions larger than the nanoscale are defined as three-dimensional biomaterials, and most of the clinically used implants fall into this category. With tunable spatial structure and biochemical properties, three-dimensional biomaterials could act as imitated extracellular matrices to regulate cell behavior. It is worth mentioning that zero-, one-, and two-dimensional biomaterials are usually incorporated into three-dimensional scaffolds to combine their exceptional biological effects. Metallic scaffolds, bioceramic scaffolds, polymer scaffolds, and hydrogels are the most investigated three-dimensional biomaterials for bone regeneration.

\section{Metal-based scaffolds}

Due to their great biocompatibility and superior mechanical strength, metal alloys (e.g., stainless steel, titanium alloys, and cobalt-chromium) have been widely utilized as plates for internal fixation of fractures and as protheses for joint replacement. Given the poor biodegradability of metal alloys, it would be difficult for newly formed osseous tissue to resorb and replace solid metal implants, which may hinder their application in bone tissue engineering. In fact, secondary surgery is usually required to remove the implanted metal plates after fracture healing is completed. On the other hand, metal ions and wear debris could be released from some metal implants via corrosion in the electrolytic body fluid, potentially resulting in local or systematic toxicity [150]. Of note, the elastic modulus of some metal implants is much higher than that of natural bone, which may elicit the stress

\footnotetext{
(See figure on next page.)

Fig. 3 In vivo bone regeneration effect and photothermal effect of BP-BG scaffolds. $\mathbf{a}-\mathbf{h}$ Micro-CT images and quantitative analysis of the harvested crania from SD rats after 8 weeks of implantation. a Micro-CT 3D reconstructed imaging of the harvested cranium. Micro-CT images of the BP-BG group ( $\mathbf{b}, \mathbf{c})$ and BG group $(\mathbf{d}, \mathbf{e})$ were obtained by contrasting with black $(\mathbf{b}, \mathbf{d})$ and white $(\mathbf{c}, \mathbf{e})$ substrates, respectively, to visualize the newly formed osseous tissue. $\mathbf{f}-\mathbf{h}$ Quantitative parameters indicating the bone regeneration effect of BG and BP-BG scaffolds, including bone volume/tissue volume (f), bone mineral density $(\mathbf{g})$, and total porosity $(\mathbf{h})$. i-m Photothermal tumor ablation induced by BP-BG scaffolds under NIR irradiation. $\mathbf{i}$ Infrared thermographic images of the tumor-bearing nude mice in different groups. Mice were implanted with BG or BP-BG scaffolds and subsequently treated with NIR irradiation for varied time intervals. $\mathbf{j}$ Real-time temperature in tumor sites corresponding to (i). $\mathbf{k}$ The average body weight of nude mice in different groups. I The average tumor volume of nude mice in different groups. The results demonstrated that the photothermal effect of BP-BG scaffolds was efficient in suppressing tumors. $\mathbf{m}$ Gross view of osteosarcoma-bearing nude mice in different groups on the 14th day. (Symbols: ${ }^{*}$, statistical significance with $\mathbf{p}<0.05$. Data is presented as mean \pm SD.) [Panels $\mathbf{a}-\mathbf{m}$ are from Yang et al. [149], reprinted with permission. Copyright @ 2018 John Wiley and Sons]
} 

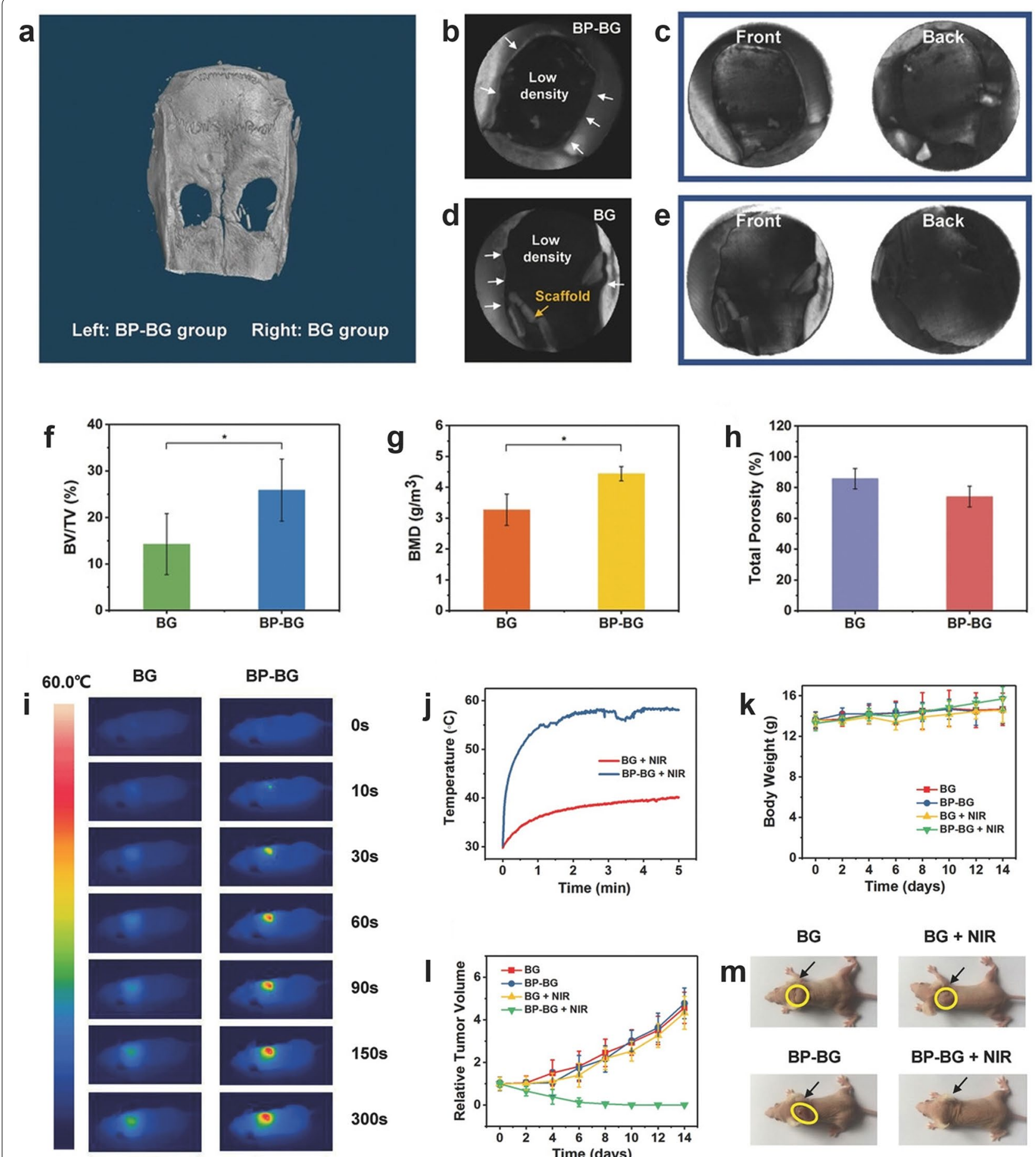

BP-BG

$25.0^{\circ} \mathrm{C}$
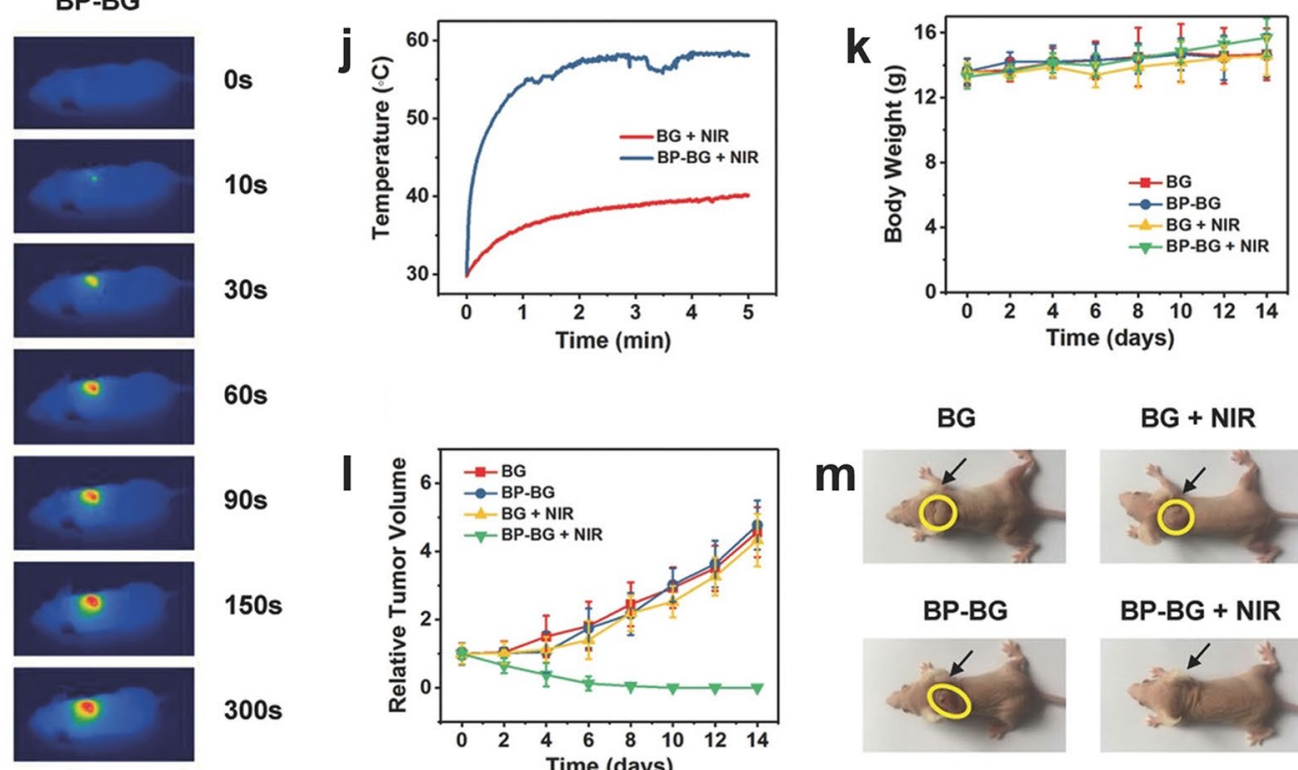

$60 s$
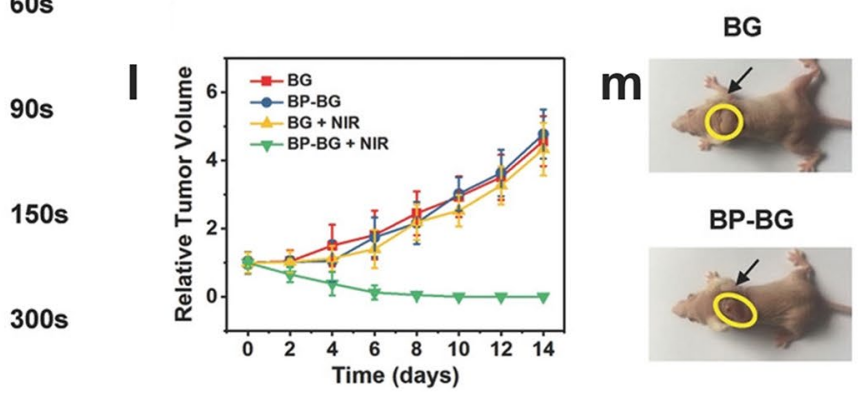

$B G+N I R$

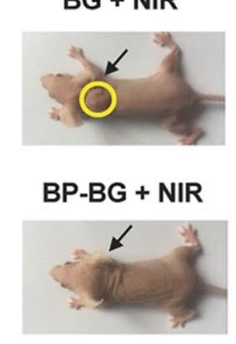

Fig. 3 (See legend on previous page.)

shielding effect and subsequently result in osteopenia and even fracture recurrence [151]. To overcome these limitations, many porous metal-based scaffolds that resemble cancellous bone in microstructure have been fabricated via different methods (e.g., rapid prototyping, stack sintering, and 3D inkjet printing) [152-155]. In vitro and in vivo analyses revealed that the interconnected micropores and macropores of these scaffolds 


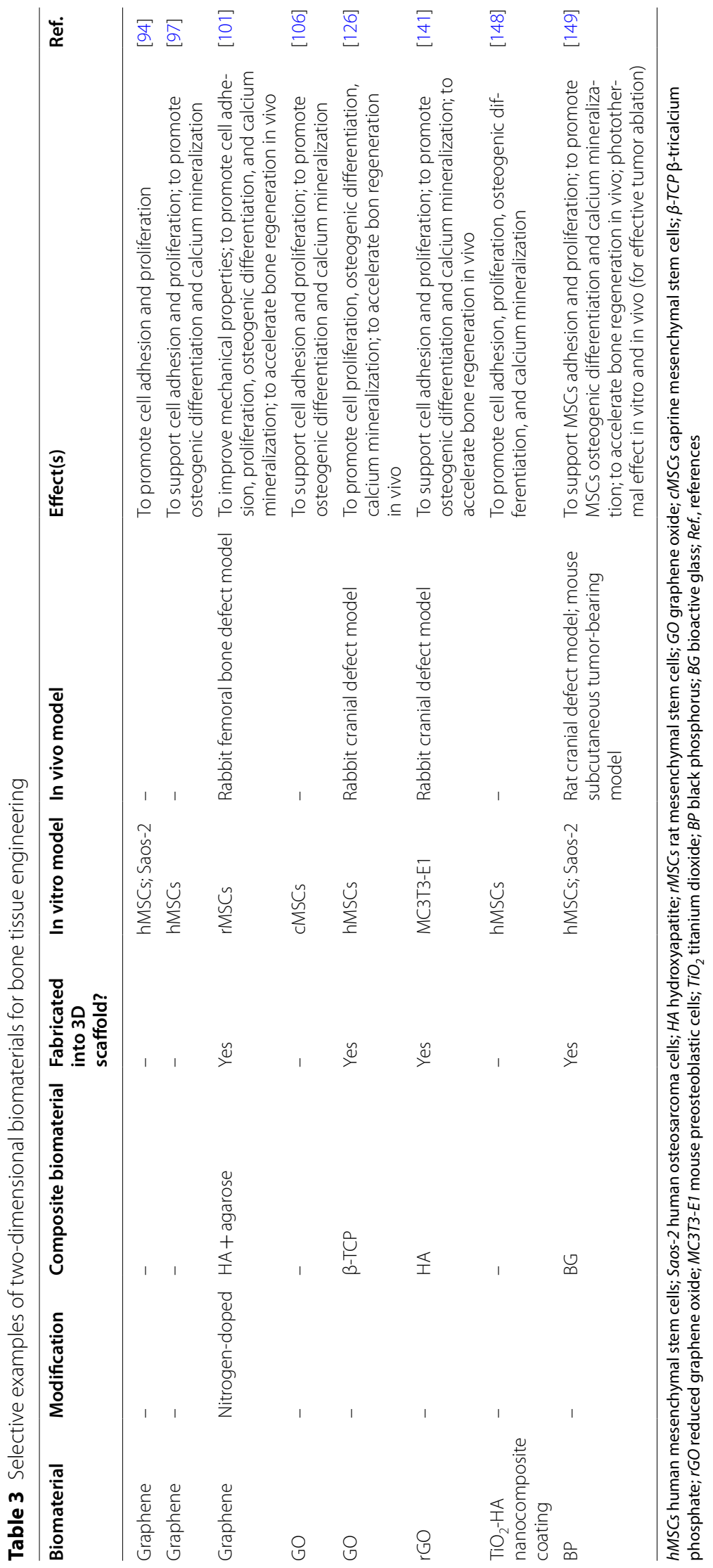


were favorable for cell proliferation, cell adhesion, cell migration, mineralization, and adsorption of proteins, indicating excellent osteoconductivity and osteoinductivity [152-155]. The highly porous structure allowed for cell infiltration, which made it possible for these metalbased scaffolds to be integrated into the newly formed bone [154]. Moreover, the tunable porosity makes it feasible to modify the mechanical strength of these scaffolds and thus to mitigate the stress shielding effect [154]. In addition to the aforementioned studies, considerable effort has been devoted to exploiting the surface modification of metal-base implants. For example, Vaithilingam et al. [156] functionalized $\mathrm{Ti}_{6} \mathrm{Al}_{4} \mathrm{~V}$ titanium alloy with phosphonic acid self-assembled monolayers, which subsequently served as an interphase to immobilize biomolecules and drugs, such as paracetamol, onto the alloy. In another study, Gopi et al. [157] found that strontiumsubstituted $\mathrm{HA} / \mathrm{ZnO}$ duplex-layer coatings on magnesium alloy significantly improved its corrosion resistance in simulated body fluid.

\section{Bioceramic scaffolds}

Bioceramics are defined as ceramic biomaterials for biological applications. With favorable biocompatibility, surface reactivity, corrosion resistance, mechanical stiffness, and cost effectiveness, bioceramics have been widely utilized within clinical orthopedics, such as bioceramic coatings on joint replacement protheses and bioceramic granules/powders for filling osseous defects [158-160]. However, the brittleness and poor fatigue resistance of bioceramics, which could worsen with the increasing porosity, limit their utility as load-bearing scaffolds [158, 161]. Bioceramics are subdivided into bioactive bioceramics (e.g., calcium phosphate $(\mathrm{CaP})$, bioactive glass (BG), calcium sulfate, and calcium silicate) and bioinert bioceramics (e.g., zirconia and alumina) based on whether chemical bonding could be formed between the bioceramics and living tissues after implantation [160]. Among these bioceramics, calcium phosphate $(\mathrm{CaP})$ and bioactive glass (BG) are most commonly used for orthopedic and dental applications.

\section{Calcium phosphate (CaP)}

Calcium phosphates (CaPs) mainly include hydroxyapatite (HA), amorphous calcium phosphate (ACP), dicalcium phosphate (DCP), tricalcium phosphate (TCP), octacalcium phosphate (OCP), and biphasic calcium phosphates (BCPs) [159]. These CaPs can be manufactured in various forms, including powders, granules, coating layers, and bulk with tunable porosity and density. CaP-based biomaterials have the capability of integrating with the bone tissue without forming fibrous connective tissues or adipose tissues, indicating great bioactivity and osteoconductivity [162]. In fact, the chemical composition and structure of CaPs resemble those of native bon tissues, which also contribute to their excellent bioactivity and biocompatibility.

Hydroxyapatite (HA), which is typically denoted as $\mathrm{Ca}_{10}\left(\mathrm{PO}_{4}\right)_{6}(\mathrm{OH})_{2}$, is present in natural bone and teeth as an inorganic component of bone matrix. Up to $70 \%$ of the wet weight of human bone consists of HA, which intersperses in the collagen matrix as mosaics of microcrystallites [163]. As an intrinsic component of bone tissue, pure HA has drawn widespread attention for its application in bone tissue engineering. As a bioactive ceramic, HA forms strong chemical bonds with bone tissue, enabling active interactions with cells/biomolecules and regulation of cell fate. Aside from supporting cell adhesion and proliferation, HA-based scaffolds accelerate cell infiltration, expedite the process of mineralization, elevate ALP activity, upregulate the expression of osteogenic genes, and facilitate the process of angiogenesis, all of which indicate excellent biocompatibility, osseointegration, osteoconductivity, osteoinductivity, and angiogenic effects [164-171]. For example, Calabrese et al. [171] found that collagen/Mg-doped HA scaffolds could induce MSC differentiation toward the osteogenic lineage even in the absence of extrinsic osteogenic inducers (Fig. 4). Compared with other CaPs, HA has a relatively slow degradation rate, which may result in prolonged retention time in vivo (e.g., even up to several years). Given its brittleness and insufficient mechanical strength, HA minimally sustain mechanical stress during bone remodeling, which hinders its application in repairing large osseous defects $[158,161]$. To address these limitations, biodegradable polymers have been incorporated with HA to improve the mechanical performance, reduce the brittleness, and modulate the biodegradability of composite scaffolds $[164,166,169,170,172]$. It is also worth mentioning that the addition of polymers into

\section{(See figure on next page.)}

Fig. 4 Collagen/Mg-doped HA scaffolds induce hADSCs osteogenic differentiation with/without extrinsic osteogenic inducers. a-h Representative immunohistochemical staining images of osteogenesis-related gene markers after hADSCs were cultured on scaffolds in different media for various time intervals. i Corresponding quantitative analysis of the percentage of positive cells for different osteogenic gene markers. (Symbols: ${ }^{*}$, significant difference when comparing osteogenic and expansion medium groups at the same time points; 1, significant difference compared with the 1-week group in the same medium; 2, significant difference compared with the 2-week group in the same medium; 3, significant difference compared with the 4-week group in the same medium; 4, significant difference compared with the 8-week group in the same medium) [Panels $\mathbf{A}-\mathbf{E}$ are from Calabrese et al. [171]. Copyright @ 2016 Calabrese et al.] 


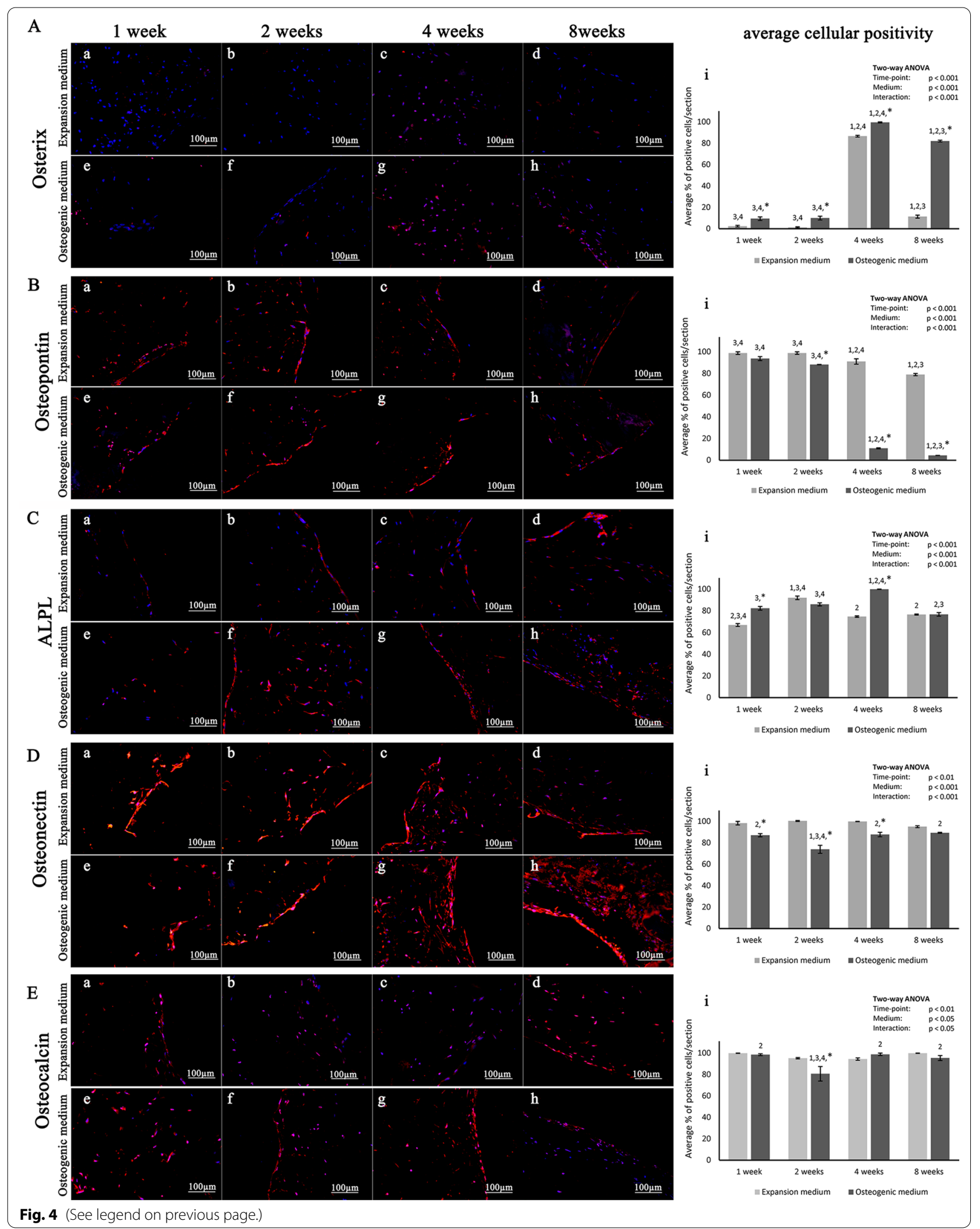


HA might endow the composite biomaterial with some additional beneficial properties, such as the capability to deliver biomolecules [166].

Tricalcium phosphate $\left(\mathrm{Ca}_{3}\left(\mathrm{PO}_{4}\right)_{2}\right)$, which is abbreviated as TCP, can be subdivided into several polymorphs (i.e., $\beta$-TCP, $\alpha$-TCP, and $\alpha^{\prime}$-TCP) depending on the atomic arrangement $[173,174]$. TCP has a calcium-tophosphorus $(\mathrm{Ca} / \mathrm{P})$ ratio of 1.50 , which is rather close to that of natural human bone tissue [175-177]. It has been reported that porous TCP scaffolds are highly bioactive, biocompatible, osteoconductive, and osteoinductive [178]. Compared with HA, TCP is much more resorbable and degradable, which could serve as an abundant source of calcium and phosphorus and thus facilitate the process of bone regeneration [175]. However, the brittleness, poor mechanical strength, excessive solubility, and high degradability of TCP hampered its application in load-bearing sites. A variety of polymers (e.g., alginate, polylactic acid (PLA), polycaprolactone (PCL), and collagen) were incorporated with TCP for modulating the biodegradation rate, as well as improving mechanical properties and osteoinductive performance of the composite scaffolds [179-182]. For instance, a novel type of injectable 3D scaffold with favorable mechanical strength and biological performance was fabricated by combining $\mathrm{CaCl}_{2}$-coated $\beta$-TCP beads with alginate hydrogels [179]. The instantaneous crosslinking between the alginate hydrogel and $\mathrm{CaCl}_{2}$ also endowed the composite with high injectability to form the custom-tailored shapes for osseous defects.

Another type of $\mathrm{CaP}$ that has been the focus of extensive research is biphasic calcium phosphate (BCP), which refers to an intimate mixture of two different CaPs. Generally, the most commonly used BCPs consist of HA and $\beta$-TCP in varying proportions [159]. As mentioned above, HA was relatively 'stable' with low biodegradability, whereas $\beta$-TCP undergoes biodegradation and dissolution at a much faster rate and results in an ionic-rich environment. The combination of HA and $\beta$-TCP would bring together the advantages of both, such as superior bioactivity, osteoconductivity, and osteoinductivity. Moreover, better control over the biodegradability and mechanical properties could also be achieved by altering the $\mathrm{HA} / \beta-\mathrm{TCP}$ ratio of $\mathrm{BCP}$, so as to yield a balance between bioactivity and mechanical stability.

In general, CaP-based biomaterials possess many advantages, such as superior biocompatibility, bioactivity, osteoconductivity, osteoinductivity, and cost effectiveness, all of which make them promising candidates for bone tissue engineering. On the other hand, more efforts are required to overcome the limitations of $\mathrm{CaPs}$, namely brittleness, poor mechanical strength, presence of impurities, etc. More insights are also required to finely modulate the biodegradability and solubility of CaPbased biomaterials, which are determined by a variety of parameters (e.g., composition, microstructure, porosity, crystallinity, particle size range, and fabrication method).

\section{Bioactive glass (BG)}

Bioactive glass $(B G)$ is considered a peculiar subgroup of ceramic biomaterials, typically with the composition of $\mathrm{SiO}_{2}-\mathrm{Na}_{2} \mathrm{O}-\mathrm{CaO}-\mathrm{P}_{2} \mathrm{O}_{5}[183,184]$. Since it was first fabricated by Professor Larry Hench in the late 1960s, BG has been extensively researched as one of the most promising biomaterials for tissue regeneration [184]. BG exhibits various clinical utilities, especially in the field of orthopedic and maxillofacial surgery, such as BG-based ossicular prostheses for the reconstruction of the ossicular chain [185] and BG-based bone substitutes for spinal fusion in the treatment of adolescent idiopathic scoliosis [186]. Generally, BG can be subdivided into three groups depending on the main component present in the composition, namely silicate $\left(\mathrm{SiO}_{2}\right)$ glass, borate $\left(\mathrm{B}_{2} \mathrm{O}_{3}\right)$ glass, and phosphate $\left(\mathrm{P}_{2} \mathrm{O}_{5}\right)$ glass [187]. In addition, 45S5 Bioglass ${ }^{\circledR}$ (45 wt\% $\mathrm{SiO}_{2}, 24.5 \mathrm{wt} \% \mathrm{CaO}, 24.5 \mathrm{wt} \% \mathrm{Na}_{2} \mathrm{O}, 6$ wt\% $\mathrm{P}_{2} \mathrm{O}_{5}$ ) is the first and most famous BG originally synthesized by Hench and resembles human cancellous bone in terms of elemental composition and interconnected porous structure [184].

One of the biggest bright spots of BG is its fabulous surface reactivity and bioactivity, from which its name is derived. As elucidated by Hench [184, 188], the surface reaction of implanted BG could be summarized as follows: rapid release of soluble ions, formation of hydrated silica and hydroxy carbonate apatite bilayer on the surface, crystallization of $\mathrm{HA}$, interaction and bonding with collagen fibrils produced by osteoblasts, enhanced adsorption and desorption of biomolecules, modulated cell behavior of macrophage and osteogenic cell line, all of which synthetically facilitate the process of mineralization and bone regeneration to a great extent. Incorporation of other oxides alters the performance of $B G$ in various ways, such as the incorporation of $\mathrm{AgO}$ for the antibacterial effect and $\mathrm{Al}_{2} \mathrm{O}_{3}$ for strengthening the mechanical properties [187, 189]. As reported by several research groups, the addition of $\mathrm{ZnO}$ endowed $\mathrm{BG}$ with elevated bioactivity and mineralization rates, as well as favorable effects on the viability and differentiation of osteoblastic cell lines [190,191]. Even a small variation in composition or a change in the proportion of each oxide could tremendously alter the physicochemical properties and biological performance of BG. It should also be emphasized that different manufacturing methods of BG, mainly including the melt-quenching route and sol-gel technique, may result in differences in uniformity, porous 
texture, dissolution rate, bioactivity, and mineralization ability [192, 193].

Despite all the merits, such as superior bioactivity and osteoinductivity, the inherent brittleness of BG could result in fast porous structure collapse, presenting as a major obstacle in the context of bone tissue regeneration. It has been reported that polymer impregnation into BG allows better manipulation of mechanical properties and biodegradation rates, which subsequently guarantees the structural integrity and stability of composite biomaterials while facilitating bone regeneration [194, 195]. The combination of polymers with BG would bring together the advantages of both, facilitating improved bioactivity, mechanical properties, mineralization capability, osteoconductivity, and osteoinductivity. Another emerging biomaterial is mesoporous bioactive glass (MBG) with the pore size between 2 and $50 \mathrm{~nm}$. Zhang et al. [196] fabricated MBG via a simple powder processing technique, yielding preferable compressive strength over MBG synthesized via the traditional polyurethane foam template method. They also discovered that aminofunctionalized MBG scaffolds (N-MBGS) exerted more favorable effects on MSC adhesion, proliferation, and osteogenic differentiation than unfunctionalized MBGS and carboxylic-functionalized MBGS, which was further corroborated in the rabbit femoral defect model (Fig. 5). The improved bioactivity, biocompatibility, osteoconductivity, and osteoinductivity of N-MBGS was ascribed to its positively charged surface and decreased degradation rate. Due to the extraordinary drug loading capacity of MBG, a variety of drugs (e.g., ipriflavone and gentamicin sulfate) were immobilized onto MBG to achieve a large loading dose and controlled release, which could endow MBG with anti-osteoporotic and antibiotic abilities [197, 198]. To meet the demands for custom-tailored bone graft substitutes, injectable BG cement was designed by mixing borate BG particles and chitosan-based bonding solution, yielding excellent mechanical strength, biocompatibility, and osteoinductive effects both in vitro and in vivo [199-201]. Moreover, Ding et al. [199] incorporate vancomycin into injectable borate BG cement as a multifunctional platform for the treatment of osteomyelitis in the rabbit tibia (Fig. 6).

\section{Polymer scaffolds}

Biocompatible polymers are considered promising candidates for bone tissue engineering due to their excellent biocompatibility and design flexibility. The degradability of a polymer scaffold is determined by various factors, such as the composition of the polymer and the porosity of the polymer scaffold. According to the origin, polymers can be roughly categorized into two groups, namely natural polymers and synthetic polymers [202].
Natural polymers utilized for bone tissue regeneration mainly include collagen, chitosan, hyaluronic acid, silk, alginate, etc. One potential advantage of natural polymers is that they may contain some biological recognition sites, which would help with the specific interaction with cells and therefore modulate cell behavior [203]. However, the potential presence of immunogen and pathogenic impurities, the poor cost effectiveness and unsatisfactory batch-to-batch replicability may hinder the application of natural polymers in bone tissue regeneration [202]. Moreover, the suboptimal processability of natural polymers proves to be an obstacle as well, which only allows limited control over the mechanical properties and degradation rates. A wide range of crosslinking techniques have been intensively explored to reinforce the mechanical strength of natural polymers, such as the use of chemical crosslinking reagents [204], enzymatic reaction of lysyl oxidase [205], and photocrosslinking method [206]. In addition to crosslinking, fiber orientation is another significant parameter for reinforcing the structural integrity of natural polymer-based scaffolds [207].

Synthetic polymers within the field of bone tissue engineering include polylactic acid (PLA), poly(glycolic acid) (PGA), poly(lactic-co-glycolic acid) (PLGA), poly(ethylene glycol) (PEG), polycaprolactone (PCL), etc. Synthetic polymers have received considerable attention in bone regeneration applications, which could be ascribed to their favorable effect on supporting cell attachment and propagation as well as their ability to promote MSC differentiation toward the osteogenic lineages and accelerate calcium biomineralization [208-211]. Compared with natural polymers, synthetic polymers are replicable and could be more easily tailored in terms of the microstructure, hydrophilicity, pore size, porosity, mechanical characteristics, and degradability [208-213]. As indicated in many studies, pore size and porosity are two of the key parameters for modulating the mechanical properties of synthetic polymer-based scaffolds [210-213]. Advanced fabrication techniques such as rapid prototyping and electrospinning were applied to construct the interconnected porous microstructure of polymer-based scaffolds with great precision $[165,214$, 215]. Furthermore, a variety of soluble particles, known as porogens, could be imbedded into polymers to form porous structures upon dissolution, of which the pore size and porosity can be altered by changing the size and amount of porogens [210, 211, 213, 216, 217]. However, some synthetic polymers exhibit unsatisfactory hydrophilicity without secondary modification, which may hinder cell attachment and lead to poor biological performance [209]. Moreover, although various synthetic polymers are biocompatible and biodegradable, the release of 


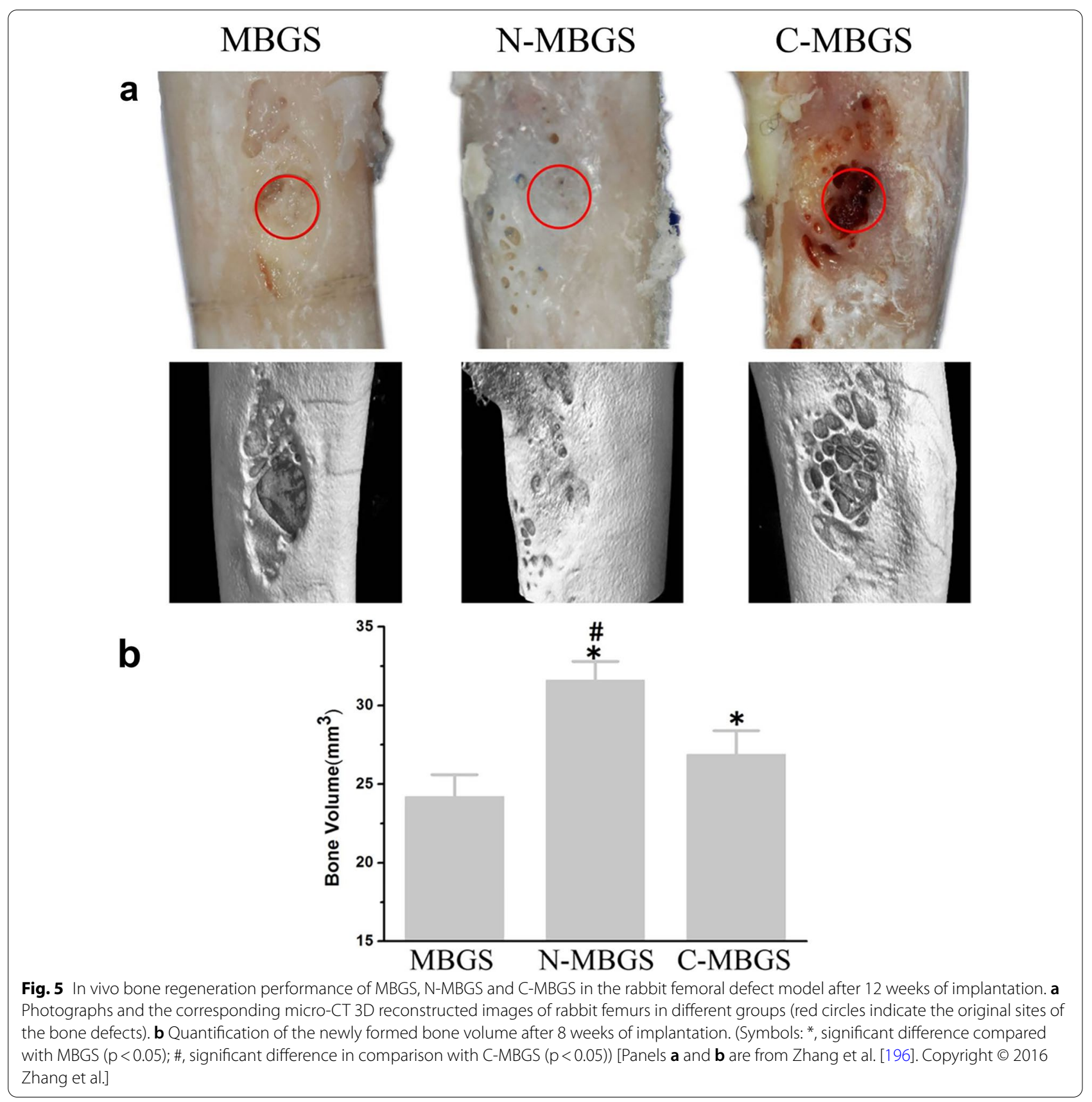

degradation byproducts and wear debris might still elicit inflammatory responses and rejection reactions [218].

Generally, both natural and synthetic polymer scaffolds with high porosity exhibit relatively inferior loading-bearing capacity compared with metallic biomaterials. To circumvent the possible mechanical failure of polymer-based scaffolds, calcium phosphate and bioactive glass were incorporated into the polymer matrix to fabricate composite scaffolds, resulting in improved biological performance and osteoinductive effects $[165,213,214,216,219-224]$. For instance, Sheikh et al. [221] demonstrated that incorporation of silk and HA nanoparticles into PLGA-based scaffolds could impart optimized stress-bearing capacity and hydrophilicity to the hybrid scaffolds along with better biocompatibility and bioactivity to facilitate cell growth and infiltration. In vivo results from rat cranial defect models showed that, when compared with the other scaffolds, silk-HA-PLGA composite scaffolds induced relatively more complete intramembranous 

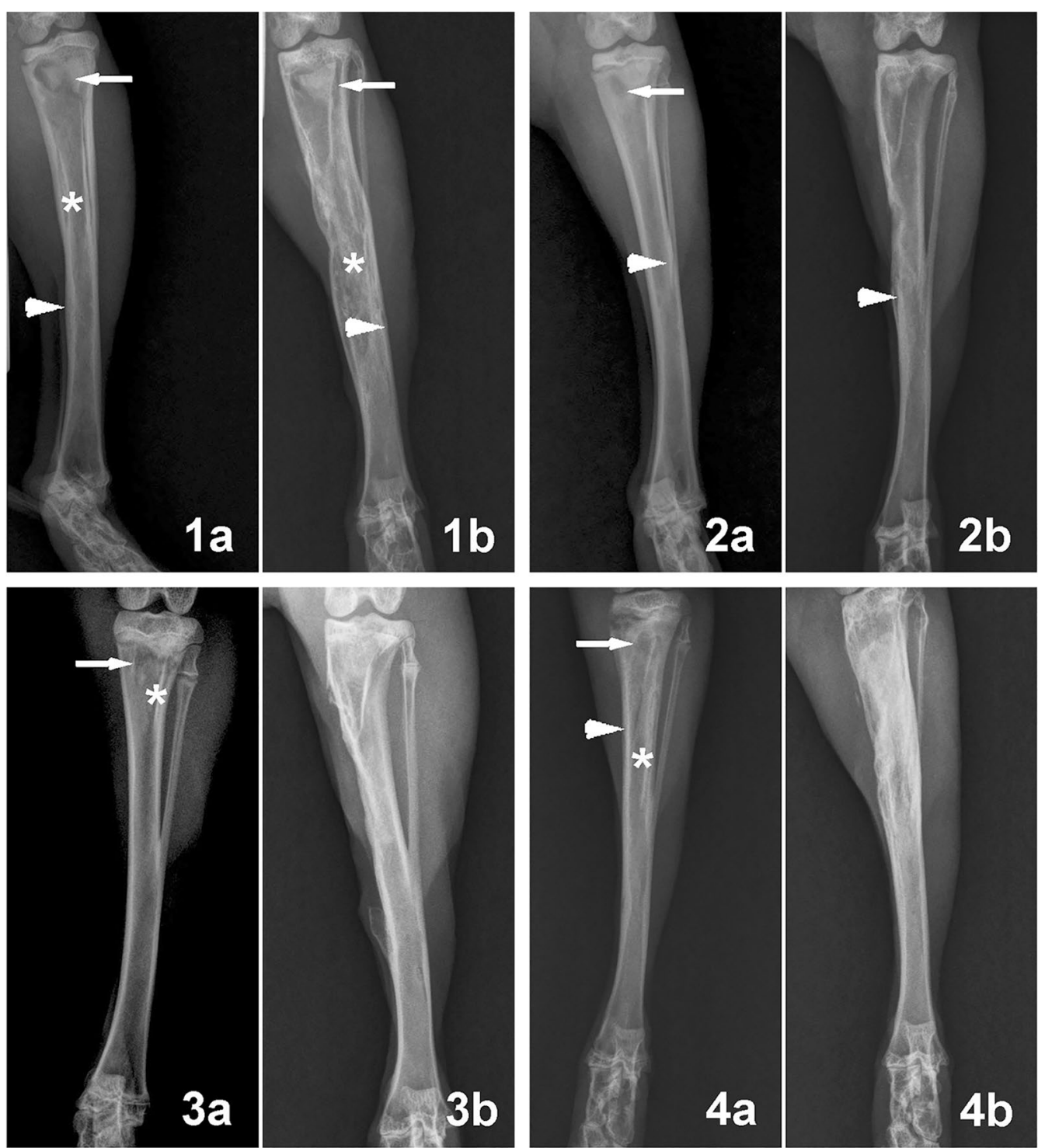

Fig. 6 Representative radiographs of rabbit tibial osteomyelitis in different groups before surgery (1a, $\mathbf{2 a}, \mathbf{3 a}, \mathbf{4 a})$ and at 2 months after surgery (1) $\mathbf{2 b}, \mathbf{3 b}, \mathbf{4 b}$ ). (Group 1, control group without any treatment; Group 2, debridement + daily intravenous administration of vancomycin for a month; Group 3, debridement + implantation of vancomycin-loaded calcium sulfate cement; Group 4, debridement + implantation of vancomycin-loaded borate BG cement.) In Group 1, the destroyed bone (arrows), periosteal newly formed osseous tissue (arrowhead), and sequestral bone formation $\left(^{*}\right)$ in the postoperative radiographs indicated the deterioration of osteomyelitis. The osteomyelitis in Group 2 was partly controlled, whereas osteomyelitis in Group 3 and Group 4 healed. [Panels 1a-4b are from Ding et al. [199]. Copyright @ 2014 Ding et al.]

ossification 4 weeks after implantation with no sign of inflammation or rejection (Fig. 7). Surface modification of polymer scaffolds with biomolecules, such as plasma deposition and Arg-Gly-Asp tripeptide (RGD), could substantially promote cell attachment and colonization $[217,225]$. It is also worth noting that polydopamine (PDA) coating on the PLA scaffolds not only enhanced MSC adhesion, proliferation, and osteogenic differentiation, but also enabled the composite scaffolds to exhibit superior antibacterial effects and angiogenic effects (Fig. 8) [226].

\section{Hydrogels}

Hydrogels are a group of hydrophilic polymeric materials that are able to absorb a vast amount of water and keep it retained, which could be ascribed to their crosslinked three-dimensional networks. Due to their hydrophilic nature and high water content, hydrogels 


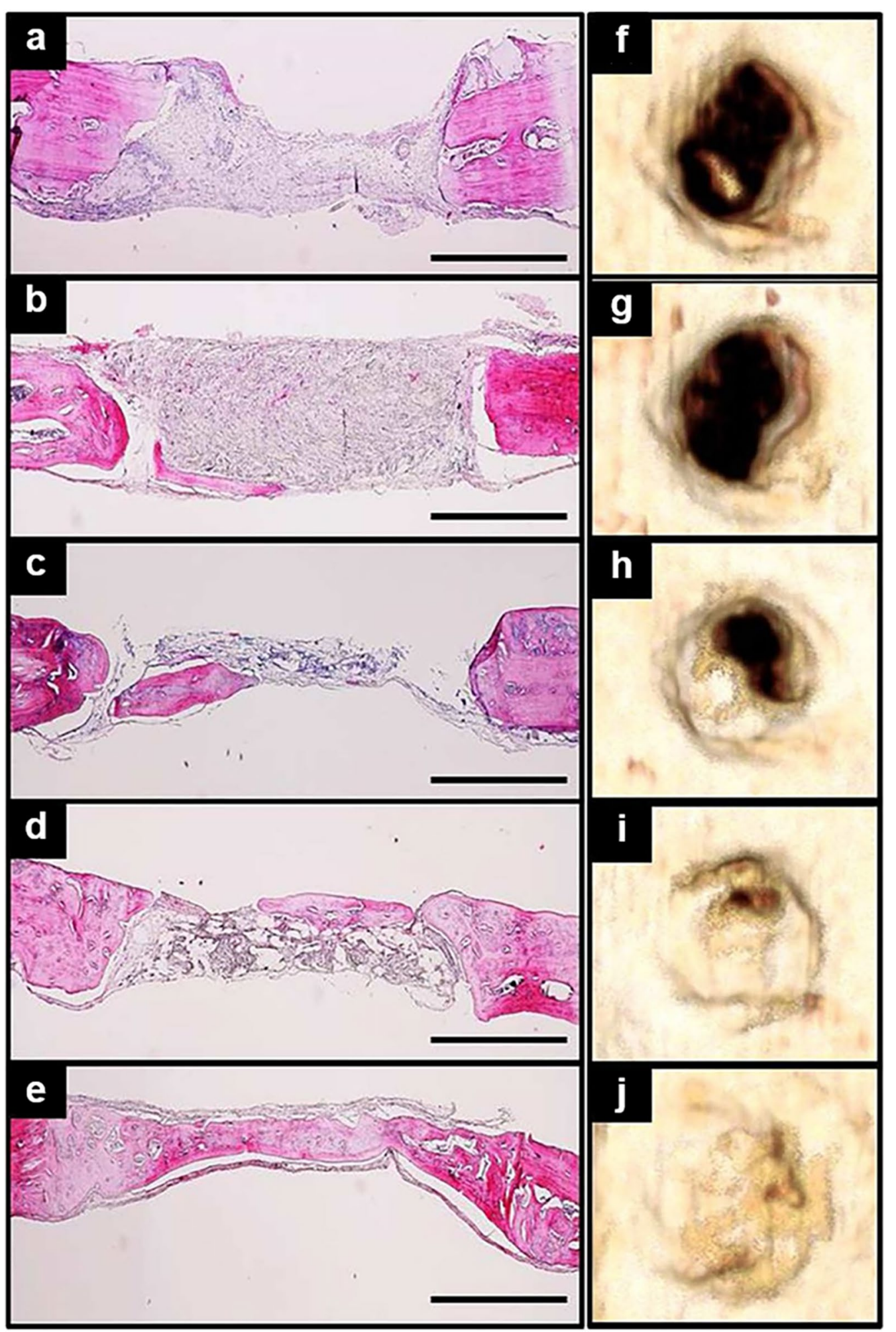

Fig. 7 In vivo bone regeneration performance of different polymer scaffolds. a-e H\&E staining of harvested rat crania in different groups after 4 weeks of implantation (a control; $\mathbf{b}$ silk scaffold; c PLGA scaffold; d PLGA-silk scaffold; e PLGA-silk-HA scaffold). (scale bar, 1 mm). f-j Corresponding micro-CT 3D reconstructed images of crania in different groups (f control; $\mathbf{g}$ silk scaffold; $\mathbf{h}$ PLGA scaffold; i PLGA-silk scaffold; $\mathbf{j}$ PLGA-silk-HA scaffold). [Panels a-j are from Sheikh et al. [221], reprinted with permission. Copyright @ 2015 John Wiley and Sons] 
have been considered promising candidates to mimic the natural hydrated microenvironment for cell growth. The crosslinked microstructure and adjustable architecture of hydrogels also guarantees their structural stability and integrity while being tailored into customized shapes. Moreover, hydrogels exhibit great permeability to nutrients, oxygen, metabolites, and other water-soluble bioactive molecules, making them ideal substrates for supporting cell growth. The degradability of hydrogels is dependent on a variety of factors, such as the composition of the hydrogels and the cross-linking density. It is also worth mentioning that many hydrogels could undergo the sol-to-gel phase transition in response to shifting environmental conditions (e.g., temperature), and the superior injectability of these hydrogels allows them to form custom-tailored shapes for repairing tissue defects [227, 228]. In recent decades, a variety of hydrogel-based biomaterials have been utilized within the field of tissue engineering to fabricate biomimetic tissues, such as skin and cartilage [229-231].

According to the polymer origin, hydrogels fall into three major categories: natural hydrogels, synthetic hydrogels, and hybrid hydrogels [232]. Natural hydrogels are composed of natural polymers (e.g., hyaluronic acid, alginate, fibrin, collagen, silk, gelatin, agarose, and chitosan), and possess numerous advantages such as low toxicity, high biocompatibility, inherent biodegradability, great bioactivity and cell affinity $[229,231,233-236]$. However, the applications of natural hydrogels in the field of bone tissue regeneration are quite limited by their relatively inferior mechanical properties, potential immunogenicity, and their unsatisfactory replicability and processability. To address these limitations, synthetic hydrogels (e.g., PEG-based hydrogels and PLAbased hydrogels) have emerged as alternative candidates for fabricating tissue substitutes [237, 238]. The excellent plasticity and reproducibility of synthetic hydrogels allows precise manipulation of the physiochemical properties of hydrogels during the process of polymerization and subsequent modification (e.g., crosslinking and functionalization), so as to custom-tailor the hydrogel constructs in terms of block structure, viscosity, mechanical properties, and biodegradability. Furthermore, natural/synthetic hybrid hydrogels were designed to bring together the advantages of both types of hydrogels, namely high cell/biomolecule affinity and bioactivity of natural hydrogels as well as better mechanical strength and processability of synthetic hydrogels [227, 228].

A great number of studies have demonstrated hydrogels' favorable effect on supporting cell adherence and ingrowth as well as fostering intercellular interactions [227, 228, 230, 231, 234-236, 239-241]. With regard to bone tissue regeneration, both in vitro and in vivo studies have corroborated that hydrogel-based biomaterials facilitate the process of osteogenesis and calcium biomineralization substantially, and promote angiogenesis as well [236, 239-241]. Hydrogels incorporated with other types of biomaterials, such as calcium phosphates (CaPs) and demineralized bone matrix (DBM), exhibit reinforced mechanical strength and synergistic accelerating effects in bone regeneration [242, 243]. As indicated in many studies, incorporation or encapsulation of various bioactive biomolecules (e.g., RGD, heparin, BMP-2, fibronectin, fibrinogen, bisphosphonate, and growth factors) into hydrogels could potentiate cell adhesion and propagation as well as the osteogenic and angiogenic efficacy of the hybrid scaffolds [233, 236, 238, 243-248]. Notably, the incorporation of some biomolecules, such as heparin and RGD, could alter the mechanical properties of the hydrogels to a large extent $[238,246]$. The heparinfunctionalized hydrogel has emerged as a novel biomaterial for tissue regeneration and drug delivery given the excellent bioactivity of heparin [243-246, 248, 249]. The high electronegative charge of anionic heparin endows it with exceptional affinity to a variety of biomolecules (e.g., BMP-2, growth factors, fibronectin, chemokines, and antithrombin III), which substantially increases the loading dose of the biomolecules while facilitating sustained release at a desirable rate and preserving the biomolecules from denaturation. Subbiah et al. [248] developed an injectable delivery system by immobilizing BMP-2 and VEGF into a heparin-functionalized alginate hydrogel. The high loading efficiency and controlled release pattern of each growth factor were corroborated in vitro. Using this tunable dual growth factor delivery system, three diverse release patterns (i.e., mere BMP-2, simultaneous release of VEGF and BMP-2, sequential release of VEGF and BMP-2) were designed, and the osteogenic

(See figure on next page.)

Fig. 8 Multifunctionality of PDA/PLA scaffolds. a, b Protein expression levels of angiogenic markers (vWF and Ang-1) in hADSCs cultured on different substrates for various time intervals (Symbols: *, statistical significance $(p<0.05)$ compared with DA0). c Antibacterial performance of the PDA/PLA scaffold, evaluated by culturing Staphylococcus aureus on different substrates for 3 and $24 \mathrm{~h}$ (Symbols: *, statistical significance in comparison with DA0). d, e Osteogenic performance of the PDA/PLA scaffold, indicated by ALP activity (d) and osteocalcin secretion (e) from hADSC cultured on different substrates for different time intervals (Symbols: ${ }^{*}$, statistical significance $(p<0.05)$ in comparison with DA0). $\mathbf{f}, \mathbf{g}$ Alizarin red S staining of hDPCs cultured on different substrates for 3 and 7 days and the corresponding quantitative analysis of calcium mineralization. Values that do not share the common letter differ significantly from each other (statistical significance with $\mathrm{p}<0.05$ ). (DAO PLA scaffold without PDA coating; DA1 PLA scaffold with $1 \mathrm{mg} / \mathrm{ml}$ PDA coating; DA2 PLA scaffold with 2 mg/ml PDA coating; Ctl tissue culture plate was used as the control; hDPCs human dental pulp cells) [Panels a-g are from Kao et al. [226], reprinted with permission. Copyright @ 2015 Elsevier] 

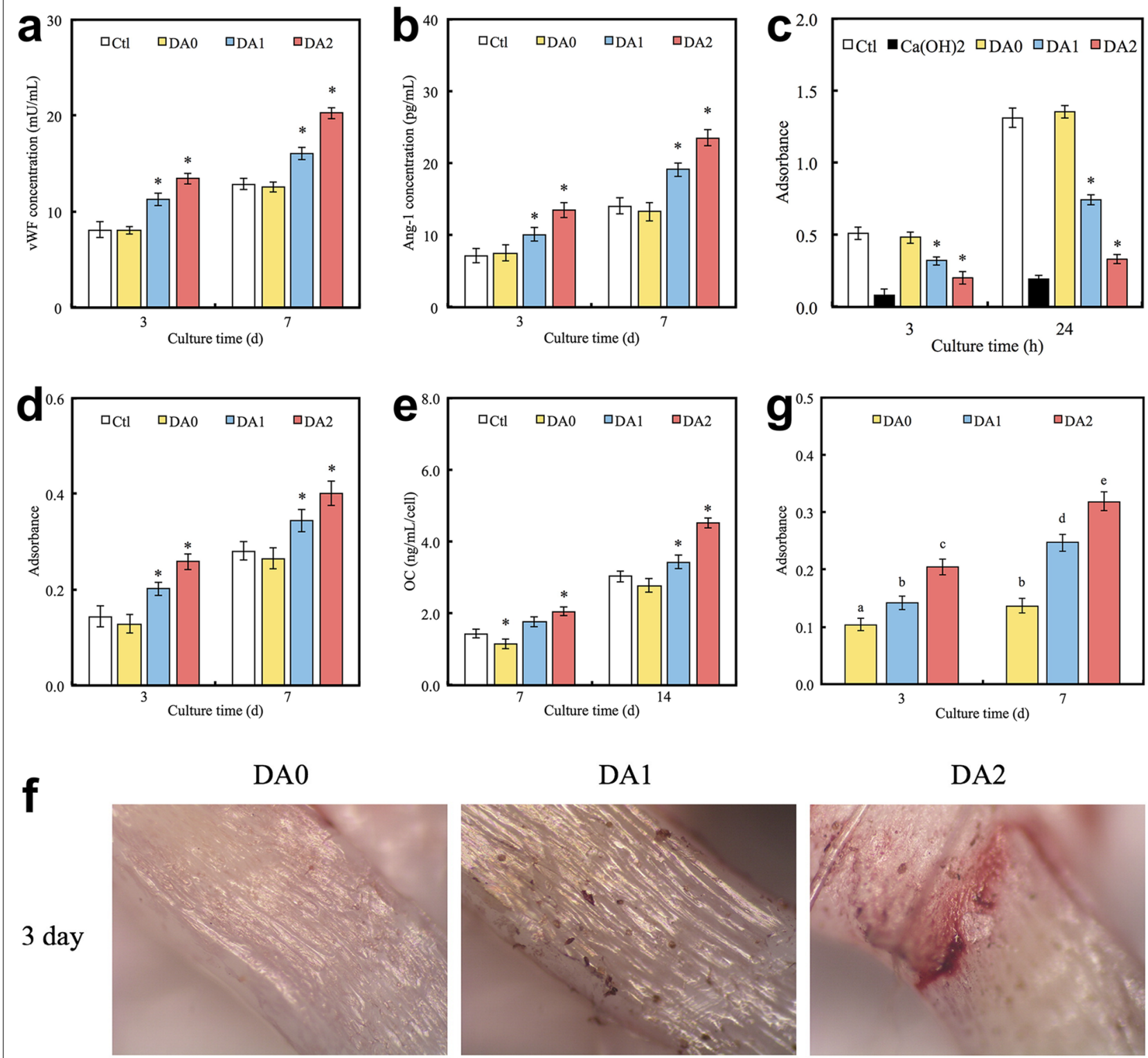

DA1

DA2
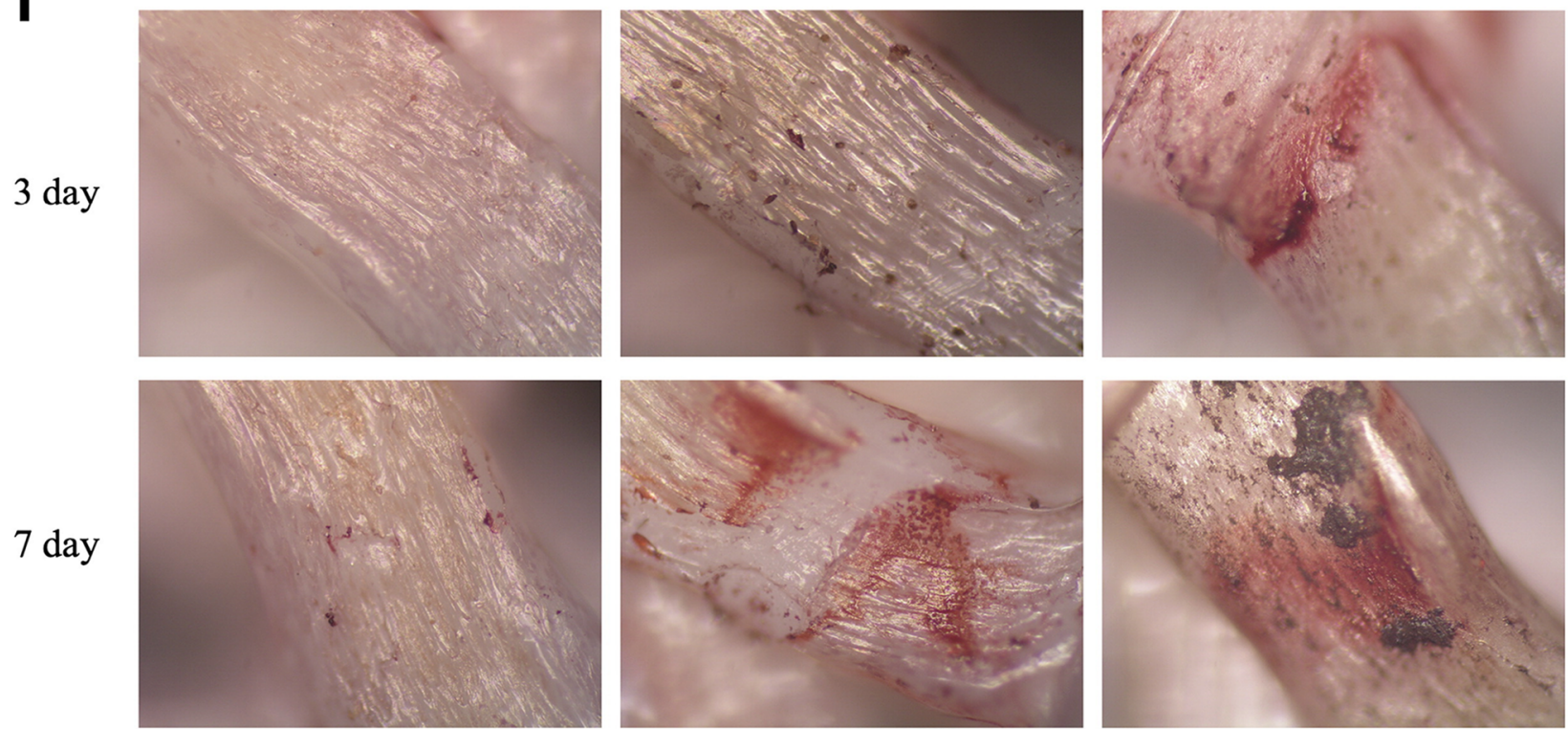

Fig. 8 (See legend on previous page.)

efficacy of each release pattern was examined in the rat femoral bone-muscle composite injury model. Evident bone regeneration was observed in all treatment groups, whereas the sequential release of VEGF and BMP-2 resulted in much more mineralized bone matrix and more developed vascular networks (Fig. 9). 
The growing attention given to hydrogels is partially ascribed to the increased use of 3D bioprinting in regenerative medicine fields. Technically speaking, 3D bioprinting is an emerging technology that utilizes cellladen biocompatible materials, which are also known as bioinks, to design and manufacture living tissue-like structures in an additive layer-by-layer manner. This innovative technology makes it feasible to fabricate living constructs with predesigned structure and geometry, which also allows precise spatial manipulation of the cells and other components within the constructs. Bioinks are mostly composed of suspended cells in tandem with pregel extracellular matrix mimics, which typically contain nutrients and various biomolecules to maximally simulate natural extracellular environments.
Given their excellent biocompatibility, plasticity, and similarity to natural extracellular matrix, hydrogels have been extensively explored as the main components of bioinks [239, 240, 250, 251]. For instance, Kang et al. [239] used hydrogel-based bioinks to fabricate rat cranial bone substitutes and examined their osteogenic capacity in a rat cranial bone defect model. Compared with the untreated defect group, more vascularized bone tissue was observed throughout the bioprinted substitutes at 5 months after implantation (Fig. 10).

In conclusion, three-dimensional materials are intensively utilized as the foundation frameworks for bone substitutes, which are usually combined with a variety of zero-, one-, two-, and other three-dimensional materials to deliver synergistic effects for bone regeneration. The

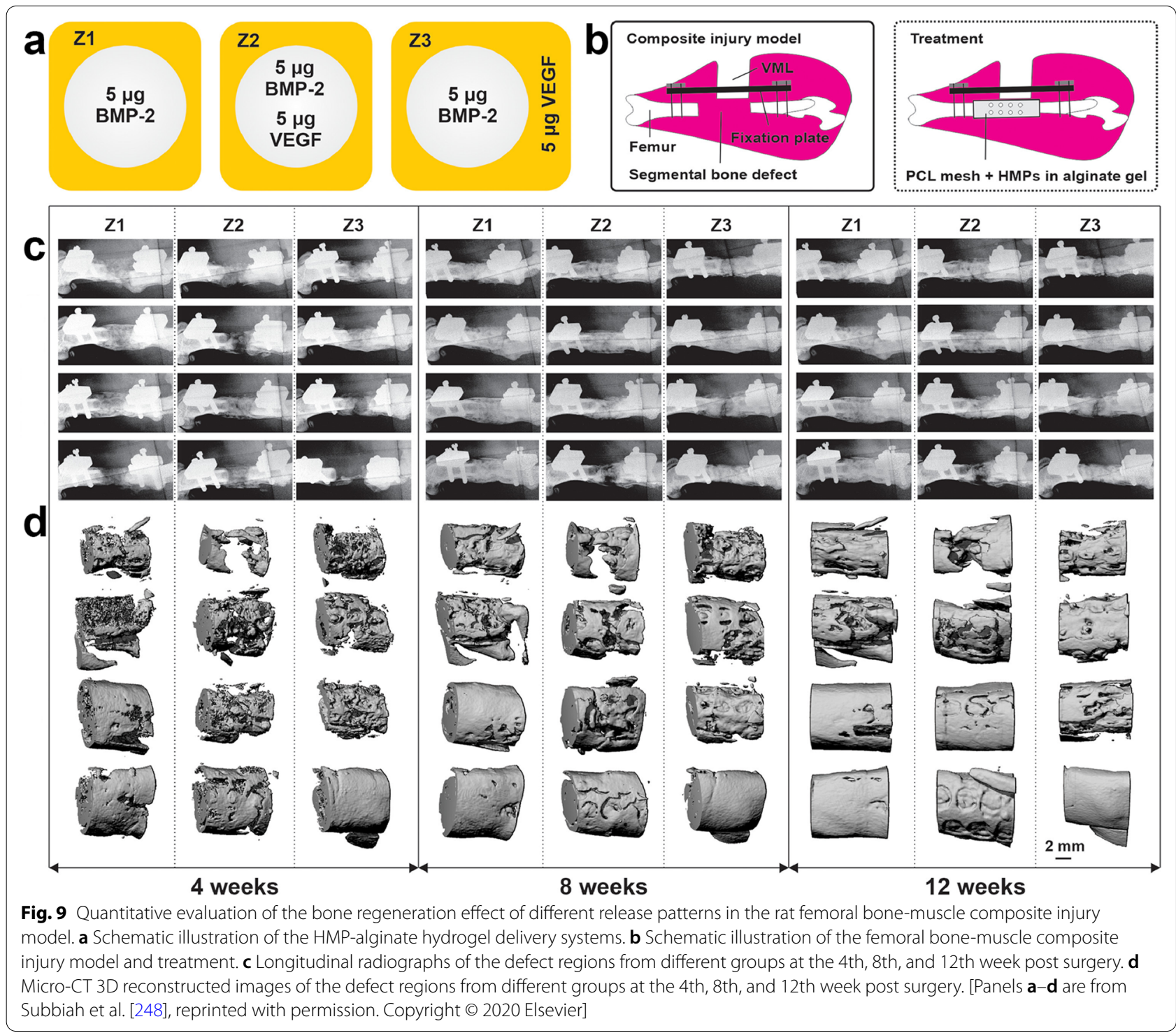


interconnected porous microstructure of 3D scaffolds facilitates the process of osseointegration, neovascularization, and neurotization. 3D scaffolds with hierarchical porous structure (i.e., macropores and micropores) are the optimal choice for bone regeneration. Specifically, the macropores (with diameters of several hundreds of microns) could facilitate cell migration and neovascularization, whereas micropores (with diameters ranging from several microns to several tens of microns) favor the adsorption and retention of various bioactive biomolecules. Surface modification of three-dimensional materials profoundly improves their biological performance, whereas immobilization of diverse biomolecules (e.g., BMP-2, growth factors, and non-steroidal antiinflammatory drugs) endows 3D scaffolds with more alluring properties. Furthermore, the advent of the 3D printing technique paves the way for the detailed design and precise fabrication of cell-laden biomimetic biomaterials, which will certainly be the focus within the field of bone tissue engineering. Selective examples of three-dimensional biomaterials for bone tissue engineering are briefly presented in Table 4.

\section{Four-dimensional biomaterials}

Although the emergence of 3D biomaterials and 3D bioprinting technologies was perceived as dramatic breakthroughs in regenerative medicine, we should not blind ourselves to the limitations of existing biomaterials. Natural tissue regeneration is a highly dynamic and extremely sophisticated process that requires the participation of various biomolecules, cells, and extracellular matrix components in a sequential and precisely controlled manner. Moreover, dynamically reconfigurable microarchitectures with alterable functions are also needed to provide diverse physical and functional support during different phases of tissue conformation. Most traditional biomaterials, however, are designed as inanimate and static substitutes, which fail to cater to the highly dynamic and constantly evolving process of tissue regeneration. To circumvent these limitations,

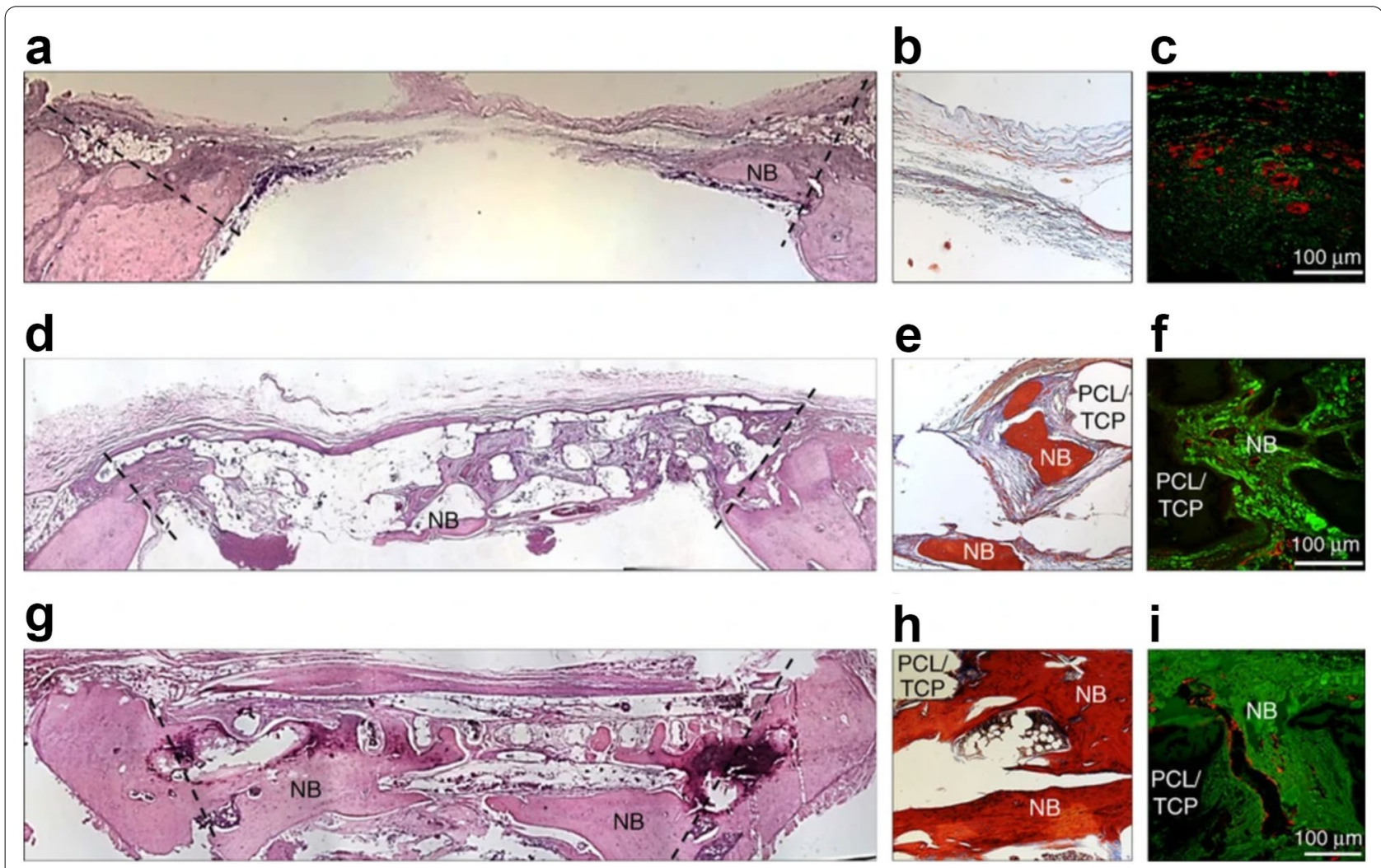

Fig. 10 Qualitative evaluation of bone regeneration after implantation of bioprinted substitutes. a-i Histological and immunohistological staining of rat crania from different groups (a-c, untreated group; $\mathbf{d}-\mathbf{f}$, cell-free scaffold group; $\mathbf{g}-\mathbf{i}$, hAFSCs-laden substitute group) after 5 months of implantation. H\&E staining images $(\mathbf{a}, \mathbf{d}, \mathbf{g})$, modified tetrachrome staining images $(\mathbf{b}, \mathbf{e}, \mathbf{h})$, and VWF immunostaining images $(\mathbf{c}, \mathbf{f}, \mathbf{i})$. In tetrachrome staining images, red areas indicate mature bone, while blue areas indicate the lining of lacunae and osteoids. In vWF immunofluorescent images, red signals indicate blood vessels. (Symbols: NB, newly formed bone; PCL/TCP, the remaining scaffold) (hAFSCs human amniotic fluid-derived stem cells) [Panels a-i are from Kang et al. [239], reprinted with permission. Copyright @ 2016 Springer Nature] 


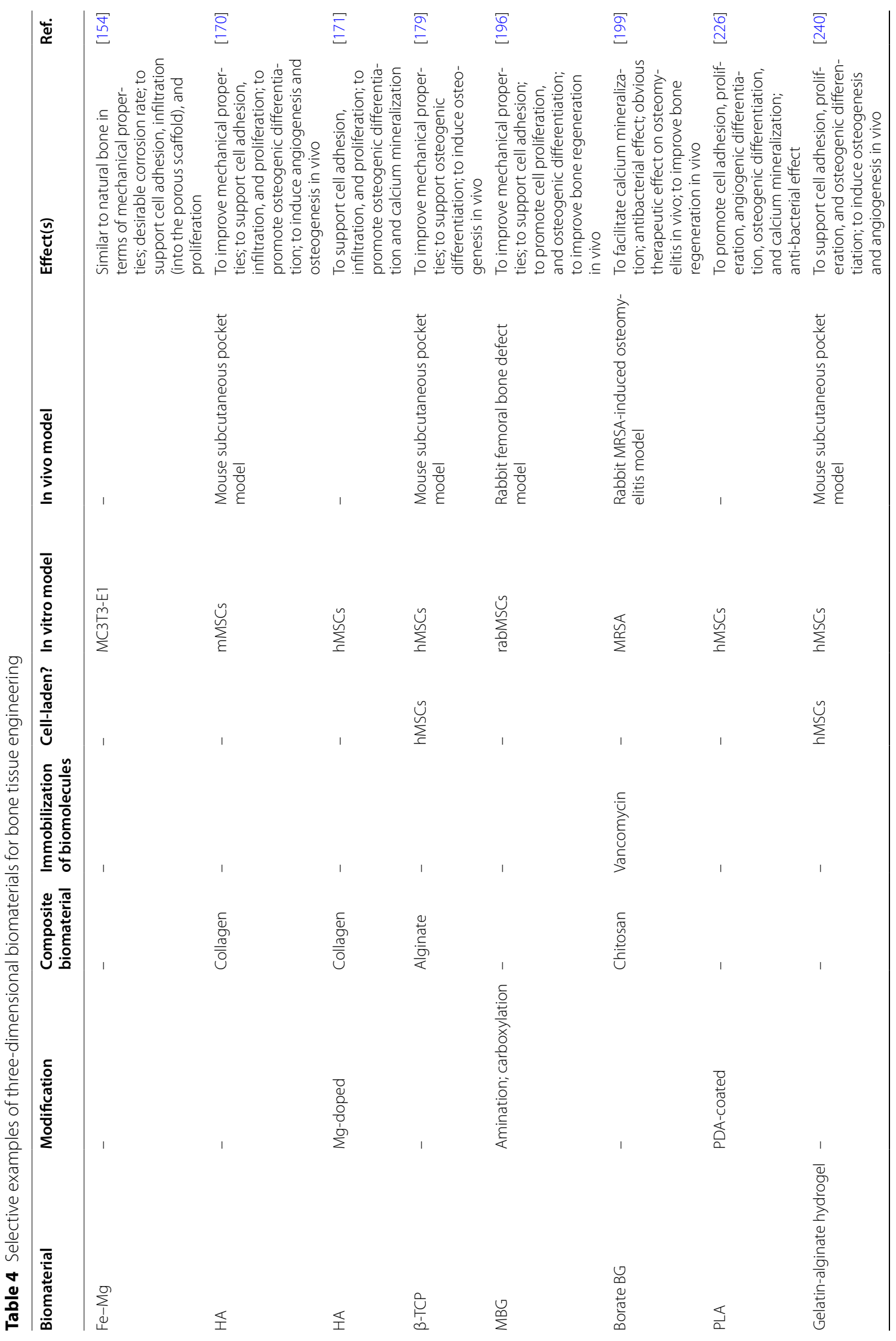




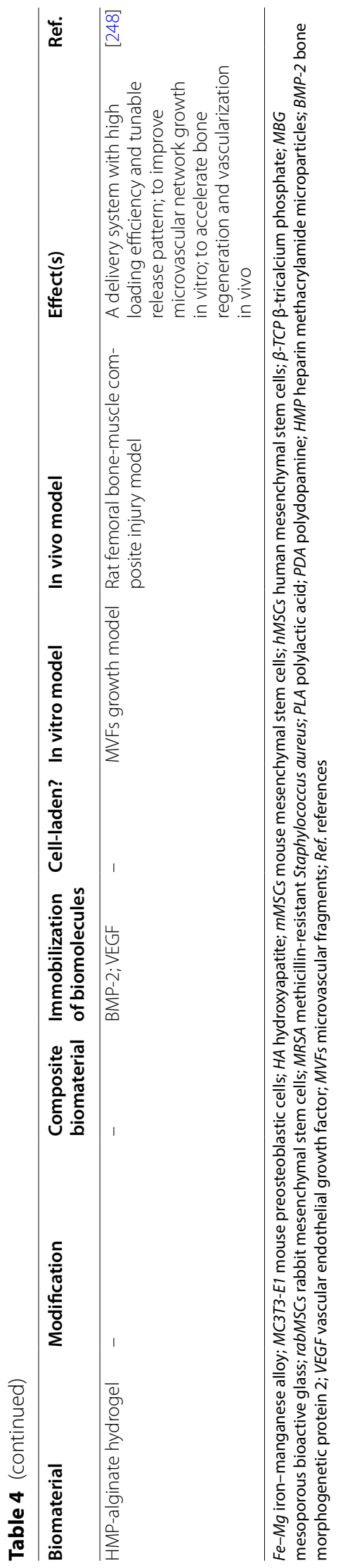


four-dimensional (4D) biomaterials were proposed as the new-generation solution for tissue reconstruction, integrating the conception of time as the fourth dimension [5]. In brief, 4D biomaterials are capable of undergoing self-transformation in the form of shape or functionality upon exposure to predetermined stimuli (e.g., temperature, humidity, osmotic pressure, light, magnetism, electric, and mechanical stimulation) [252]. The dynamic self-remodeling capability and tunable stimuli-responsiveness of $4 \mathrm{D}$ biomaterials allow precise real-time control over the hierarchical architecture and functional transformation of complex biomimetic tissue surrogates, exhibiting unprecedented potential within the field of tissue engineering. According to the patterns of stimuliresponsiveness, $4 \mathrm{D}$ bioprinted materials could be roughly categorized as materials based on shape-transformation mechanisms and those based on functional transformation mechanisms.

The shape-transformation capability of $4 \mathrm{D}$ biomaterials has been extensively investigated, whereas the predetermined stimuli can be further subdivided into physical stimuli (e.g., temperature [253-260], humidity [259, 261], light [262-264], electricity [265], magnetism [266, 267], and acoustic waves [268]), chemical stimuli (e.g., $\mathrm{pH}$ value $[269,270]$ and certain ions [271-274]), and biological stimuli (e.g., cell traction force [275] and enzymes [276]). With regard to bone tissue reconstruction, a variety of thermoresponsive injectable hydrogels, which fit the broad definition of 4D biomaterials, were designed to cater to the need for customized bone defect repair [277-280]. These injectable hydrogels fill in the defects or cracks and undergo sol-gel transition under preset temperatures to achieve dynamic and seamless integration with bone structure, exhibiting distinct superiority in repairing irregularly shaped bone defects. In addition, diverse mineral components (e.g., hydroxyapatite, biphasic calcium phosphate, and mesoporous bioactive glass) were incorporated into thermoresponsive injectable hydrogels to promote the loading-bearing capacity and biological performance of the hybrid hydrogels. For example, hybrid thermoresponsive hydrogels comprising hyaluronic acid-g-chitosan-g-poly $(\mathrm{N}$-isopropylacrylamide) and biphasic calcium phosphate exhibited promoted bioactivity and osteogenic capacity, which is corroborated by improved cell propagation, elevated ALP activity, upregulated gene expression of bone formation markers, accelerated calcium deposition rates, and efficient osteoid formation in a subcutaneous implantation model [277]. In addition to hydrogels, biocompatible polymer scaffolds with tunable thermoresponsive shape memory effects were fabricated using polycaprolactone triol and castor oil [281]. The smart polymer scaffolds exhibited satisfactory mechanical integrity along with superior biocompatibility and osteoinductivity. Full shape recovery of the deformed polymer scaffolds could be achieved at the recovery temperature, which may provide us with a less invasive strategy for implantation of biomimetic bone grafts.

Regarding functional transformation of 4D biomaterials, the tunable functionality of $4 \mathrm{D}$ tissue substitutes enables them to manipulate cell behavior and cell fate in an evolving manner, resembling the functional transition feature of native tissues. One straightforward example to illustrate the concept of functional transformation is a dual-peptide loaded hybrid hydrogel designed by Luo et al. [282]. In this hybrid system, RGD and bone forming peptide-1 (BFP-1)-loaded mesoporous silica nanoparticles were incorporated into the alginate-based hydrogel to form a multifunctional platform for sequential functioning of diverse biomolecules. After MSC adhesion and proliferation were promoted by RGD, BFP-1 loaded on mesoporous silica nanoparticles, which followed a longterm sustained release pattern, started to play a role in guiding MSC differentiation toward the osteogenic lineage (Fig. 11). The favorable osteoinductive effect of the hybrid hydrogel was corroborated in the mouse subcutaneous pocket model. It is also worth mentioning that piezoelectric materials (e.g., barium titanate), which are capable of generating electric charges under mechanical stress, provide a new paradigm for bone tissue reconstruction. In response to the stimulation of applied mechanical stress, piezoelectric biomaterials harness the mechanical force to create an electrical microenvironment, which exerts a favorable influence on cell propagation, osteogenic differentiation, and mineralization of the bone matrix [283]. The exceptional piezoelectric effect of piezoelectric biomaterials presented us with a new strategy for achieving functional transformation of $4 \mathrm{D}$ bioprinted bone substitutes during the post-bioprinting stage. Another great example to elaborate the concept of functional transformation of $4 \mathrm{D}$ biomaterials is the aforementioned BP-reinforced BG scaffolds (BP-BG) [149]. There is no doubt that BP nanosheets should be categorized as two-dimensional biomaterials according to their spatial size in each dimension. However, the multi-functional characteristics and the spontaneous biodegradation process of BP nanosheets make them conform to the broad definition of $4 \mathrm{D}$ biomaterials with functional transition capability. Specifically, the superior photothermal conversion capability of BP nanosheets endows BP-BG with remarkable efficiency in eradicating osteosarcoma under NIR irradiation. Once the photothermal therapy is accomplished and healthy bone tissue starts to regenerate, abundant $\mathrm{PO}_{4}^{3-}$ released from the biodegradation process of $\mathrm{BP}$ nanosheets could rapidly extract $\mathrm{Ca}^{2+}$ ions to form calcium phosphate, which would significantly 


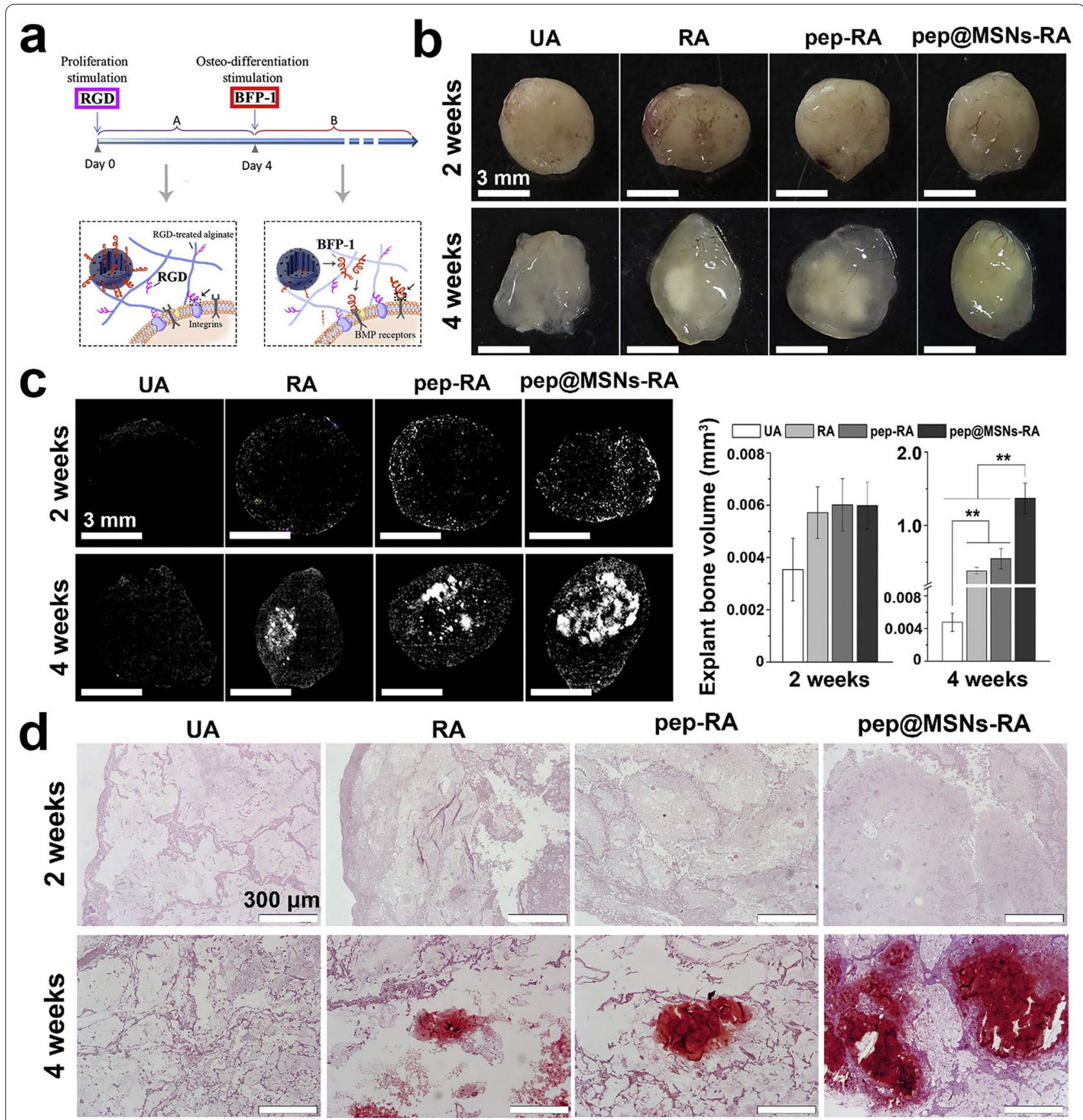

Fig. 11 In vivo bone regeneration performance of different hMSCs-loaded hydrogel-based release systems in the mouse subcutaneous pocket model. a Schematic illustration of the multifunctional hydrogel-based release system. RGD and BFP-1 incorporated in the hybrid system promote hMSC adhesion and osteogenic differentiation, respectively. $\mathbf{b}$ Gross view of the implants from different groups after 2 weeks and 4 weeks of implantation. c Micro-CT reconstructed images of calcium mineralization within the hydrogels and the corresponding quantitative analysis of bone volume after 2 weeks and 4 weeks of implantation. (Symbols: **, statistical significance with $p<0.01$ ) $\mathbf{d}$ Alizarin red $\mathrm{S}$ staining of the implants from different groups after 2 weeks and 4 weeks of implantation. (UA untreated alginate hydrogel; RA RGD-treated alginate hydrogel; pep-RA BFP-1-incorporated RA; pep@MSNs-RA BFP-1-loaded mesoporous silica nanoparticles incorporated into RA) [Panels a-d are from Luo et al. [282], reprinted with permission. Copyright @ 2018 Elsevier] 
facilitate the process of biomineralization and bone regeneration. Importantly, while focusing on bone regeneration, we should never neglect the great essence of vascularization and neurotization during the process of bone tissue reconstruction. Several 4D fabrication strategies have been exploited to facilitate vascularization and nerve regeneration in complex tissue engineering, which are particularly inspiring for the reconstruction of large bone defects [284, 285].

Although 4D biomaterials and 4D fabrication technology are still in their infancy, we have already been excited by the unpredictable potential they have revealed. The 4D fabrication technique offers precise spatiotemporal control over the hierarchical microstructure and functionalities of the fabricated tissue substitutes after implantation in coordination with the dynamic process of tissue regeneration. The increased interest in 4D biomaterials opened the path to manufacture biomimetic tissue surrogates with excellent self-remodeling and functional transition capability, which is sure to garner considerable attention in regenerative medicine.

\section{Conclusions and future perspectives}

Based on the size in each dimension, biomaterials utilized within the field of bone regeneration are categorized as zero-dimensional, one-dimensional, two-dimensional, and three-dimensional biomaterials. The distinct dimensional geometry of each category of biomaterials (i.e., high surface-to-volume ratio of zero-dimensional biomaterials, high length-to-diameter ratio of one-dimensional biomaterials, high diameter-to-thickness ratio of twodimensional biomaterials, hierarchical spatial structure of three-dimensional biomaterials) endows them with unique chemophysical properties and biological performance. Biomaterials from different dimensional categories are usually integrated as hybrid biomaterials, so as to take advantage of each component to provide synergistic effects on supporting cell proliferation and facilitating the process of bone tissue regeneration. Surface modification with chemical groups and functionalization with a variety of biomolecules (e.g., RGD and growth factors) is also an effective method to promote the biocompatibility and bioactivity of biomaterials. Moreover, the rise of 3D bioprinting techniques opened the path for manufacture of cell-laden tissue-like constructs with predesigned structures, whereas the emergence of $4 \mathrm{D}$ fabrication technology made it feasible to manipulate the remodeling and functional transformation of bioprinted bone substitutes during the post-bioprinting stage to coordinate with the highly dynamic process of bone reconstruction. Another trend in the design of biomaterials is to endow them with multifunctionality. Biomaterials with superior tumor eradicating capacity and excellent osteoinductivity could serve as stepwise countermeasures for tumor invasion in bone tissues. Infected nonunion, which still represents thorny challenges for orthopedic surgeons, may also be completely conquered by the application of biomaterials with potent antibacterial property and osteoinductive capability.

Despite numerous studies focusing on bone regeneration, autografts still serve as the "gold standard" treatment in cases of bone defects, especially critical-sized defects. The slow clinical translation of the present biomaterials may be ascribed to several factors, such as relatively low bioactivity, relatively uncontrolled degradation rates, deficiency of sophisticated microstructure (e.g., Haversian canals and microvascular circulation), and the potential immunogenicity of cell-laden materials. It is also worth mentioning that neovascularization and neurotization are two essential processes coupled with bone regeneration, which deserve more attention during the design of biomimetic bone grafts. Herein, we anticipate that 3D and 4D bioprinting technology will be more extensively exploited for fabricating custom-tailored living bone substitutes with dynamic shape adaptation and functional transition capability. More strategies will be proposed to induce synchronous or sequential stimulation of vascularization and neurotization during the process of bone regeneration. Due to the extraordinary bioactivity and regenerative potential of native host cells, biomaterials capable of recruiting diverse host cells will also become the focus of regenerative medicine.

\section{Acknowledgements \\ This work was supported in part by the National Natural Science Foundation of China $(81672143,82072417,82002339)$ and Shanghai Pujiang Program (2020PJD039). Several vector graphics incorporated in the graphic abstract were downloaded from Servier Medical Art (https://smart.servier.com/) and further modified.}

\section{Declarations}

Competing interests

The authors declare that they have no competing interests.

\section{Author details}

${ }^{1}$ Department of Orthopedic Surgery, Shanghai Jiao Tong University Affiliated Sixth People's Hospital, Shanghai, China. ${ }^{2}$ Ningbo Institute of Life and Health Industry, University of Chinese Academy of Science, Ningbo, Zhejiang, China.

Received: 30 September 2021 Accepted: 26 December 2021

Published online: 06 January 2022

\footnotetext{
References

1. Maletis GB, Chen J, Inacio MCS, Love RM, Funahashi TT. Increased risk of revision after anterior cruciate ligament reconstruction with bonepatellar tendon-bone allografts compared with autografts. Am J Sport Med. 2017;45(6):1333-40.

2. Salhotra A, Shah HN, Levi B, Longaker MT. Mechanisms of bone development and repair. Nat Rev Mol Cell Biol. 2020;21(11):696-711.

3. Albrektsson T, Johansson C. Osteoinduction, osteoconduction and osseointegration. Eur Spine J. 2001;10:S96-101.
} 
4. Nersisyan HH, Lee JH, Ding J-R, Kim K-S, Manukyan KV, Mukasyan AS. Combustion synthesis of zero-, one-, two- and three-dimensional nanostructures: current trends and future perspectives. Prog Energy Combust Sci. 2017:63:79-118.

5. Tibbits S. 4D printing: multi-material shape change. Archit Design 2014;84(1):116-21.

6. Kroto HW, Heath JR, O'Brien SC, Curl RF, Smalley RE. C60: buckminsterfullerene. Nature. 1985;318(6042):162-3.

7. Krätschmer W, Lamb LD, Fostiropoulos K, Huffman DR. Solid C60: a new form of carbon. Nature. 1990;347(6291):354-8.

8. Bonifazi D, Enger O, Diederich F. Supramolecular [60]fullerene chemistry on surfaces. Chem Soc Rev. 2007;36(2):390-414.

9. Geim AK, Novoselov KS. The rise of graphene. Nat Mater. 2007;6(3):183-91.

10. Cassell AM, Asplund CL, Tour JM. Self-assembling supramolecular nanostructures from a C(60) derivative: nanorods and vesicles. Angew Chem Int Ed. 1999;38(16):2403-5.

11. Guldi DM, Zerbetto F, Georgakilas V, Prato M. Ordering fullerene materials at nanometer dimensions. Acc Chem Res. 2005;38(1):38-43.

12. Nakanishi T, Schmitt W, Michinobu T, Kurth DG, Ariga K. Hierarchical supramolecular fullerene architectures with controlled dimensionality. Chem Commun. 2005;48:5982-4.

13. Sathish M, Miyazawa K. Size-tunable hexagonal fullerene (C60) nanosheets at the liquid-liquid interface. J Am Chem Soc. 2007;129(45):13816-7.

14. Wakahara T, Sathish M, Miyazawa K, Hu C, Tateyama Y, Nemoto Y, et al. Preparation and optical properties of fullerene/ferrocene hybrid hexagonal nanosheets and large-scale production of fullerene hexagonal nanosheets. J Am Chem Soc. 2009;131(29):9940-4.

15. Krishnan V, Kasuya Y, Ji Q, Sathish M, Shrestha LK, Ishihara S, et al. Vortexaligned fullerene nanowhiskers as a scaffold for orienting cell growth. ACS Appl Mater Interfaces. 2015;7(28):15667-73.

16. Yang X, Li CJ, Wan Y, Smith P, Shang G, Cui Q. Antioxidative fullerol promotes osteogenesis of human adipose-derived stem cells. Int J Nanomed. 2014:9:4023-31.

17. Yamakoshi Y, Umezawa N, Ryu A, Arakane K, Miyata N, Goda Y, et al. Active oxygen species generated from photoexcited fullerene (C60) as potential medicines: O2-* versus 102. J Am Chem Soc. 2003;125(42):12803-9.

18. Osswald S, Yushin G, Mochalin V, Kucheyev SO, Gogotsi Y. Control of $\mathrm{sp} 2 / \mathrm{sp} 3$ carbon ratio and surface chemistry of nanodiamond powders by selective oxidation in air. J Am Chem Soc. 2006;128(35):11635-42.

19. Grausova L, Bacakova L, Kromka A, Potocky S, Vanecek M, Nesladek M, et al. Nanodiamond as promising material for bone tissue engineering. J Nanosci Nanotechnol. 2009;9(6):3524-34.

20. Zhang Q, Mochalin VN, Neitzel I, Knoke IY, Han J, Klug CA, et al. Fluorescent PLLA-nanodiamond composites for bone tissue engineering. Biomaterials. 2011;32(1):87-94.

21. Zhang Q, Mochalin VN, Neitzel I, Hazeli K, Niu J, Kontsos A, et al. Mechanical properties and biomineralization of multifunctional nanodiamond-PLLA composites for bone tissue engineering. Biomaterials. 2012;33(20):5067-75.

22. Parizek M, Douglas TE, Novotna K, Kromka A, Brady MA, Renzing A, et al. Nanofibrous poly(lactide-co-glycolide) membranes loaded with diamond nanoparticles as promising substrates for bone tissue engineering. Int J Nanomed. 2012;7:1931-51.

23. Ponomarenko LA, Schedin F, Katsnelson MI, Yang R, Hill EW, Novoselov $\mathrm{KS}$, et al. Chaotic dirac billiard in graphene quantum dots. Science. 2008;320(5874):356-8.

24. Sun YP, Zhou B, Lin Y, Wang W, Fernando KA, Pathak P, et al. Quantumsized carbon dots for bright and colorful photoluminescence. J Am Chem Soc. 2006;128(24):7756-7.

25. Qiu J, Li D, Mou X, Li J, Guo W, Wang S, et al. Effects of graphene quantum dots on the self-renewal and differentiation of mesenchymal stem cells. Adv Healthc Mater. 2016;5(6):702-10.

26. Shao D, Lu M, Xu D, Zheng X, Pan Y, Song Y, et al. Carbon dots for tracking and promoting the osteogenic differentiation of mesenchymal stem cells. Biomater Sci. 2017:5(9):1820-7.

27. Geng H, Qiu J, Zhu H, Liu X. Achieving stem cell imaging and osteogenic differentiation by using nitrogen doped graphene quantum dots. J Mater Sci Mater Med. 2018;29(6):85.
28. Han Y, Zhang F, Zhang J, Shao D, Wang Y, Li S, et al. Bioactive carbon dots direct the osteogenic differentiation of human bone marrow mesenchymal stem cells. Colloids Surf B. 2019;179:1-8.

29. Yang ST, Cao L, Luo PG, Lu F, Wang X, Wang H, et al. Carbon dots for optical imaging in vivo. J Am Chem Soc. 2009;131(32):11308-9.

30. Li S, Peng Z, Dallman J, Baker J, Othman AM, Blackwelder PL, et al. Crossing the blood-brain-barrier with transferrin conjugated carbon dots: a zebrafish model study. Colloids Surf B. 2016;145:251-6.

31. Khajuria DK, Kumar VB, Karasik D, Gedanken A. Fluorescent nanoparticles with tissue-dependent affinity for live zebrafish imaging. ACS Appl Mater Interfaces. 2017;9(22):18557-65.

32. Gogoi S, Kumar M, Mandal BB, Karak N. A renewable resource based carbon dot decorated hydroxyapatite nanohybrid and its fabrication with waterborne hyperbranched polyurethane for bone tissue engineering. RSC Adv. 2016;6(31):26066-76.

33. Khajuria DK, Kumar VB, Gigi D, Gedanken A, Karasik D. Accelerated bone regeneration by nitrogen-doped carbon dots functionalized with hydroxyapatite nanoparticles. ACS Appl Mater Interfaces. 2018;10(23):19373-85.

34. Lu Y, Li L, Li M, Lin Z, Wang L, Zhang Y, et al. Zero-dimensional carbon dots enhance bone regeneration, osteosarcoma ablation, and clinical bacterial eradication. Bioconjug Chem. 2018;29(9):2982-93.

35. Sarkar C, Chowdhuri AR, Kumar A, Laha D, Garai S, Chakraborty J, et al. One pot synthesis of carbon dots decorated carboxymethyl cellulosehydroxyapatite nanocomposite for drug delivery, tissue engineering and Fe(3+) ion sensing. Carbohydr Polym. 2018;181:710-8.

36. Shafiei S, Omidi M, Nasehi F, Golzar H, Mohammadrezaei D, Rezai Rad $M$, et al. Egg shell-derived calcium phosphate/carbon dot nanofibrous scaffolds for bone tissue engineering: fabrication and characterization. Mater Sci Eng C. 2019;100:564-75.

37. Das B, Dadhich P, Pal P, Dutta J, Dutta A, Srivas PK, et al. Doping of carbon quantum dots (CDs) in calcium phosphate nanorods for inducing ectopic chondrogenesis via activation of the HIF-alpha/SOX-9 pathway. ACS Omega. 2019;4(1):374-86.

38. Yi C, Liu D, Fong CC, Zhang J, Yang M. Gold nanoparticles promote osteogenic differentiation of mesenchymal stem cells through p38 MAPK pathway. ACS Nano. 2010;4(11):6439-48.

39. Zhang R, Lee P, Lui VC, Chen Y, Liu X, Lok CN, et al. Silver nanoparticles promote osteogenesis of mesenchymal stem cells and improve bone fracture healing in osteogenesis mechanism mouse model. Nanomedicine. 2015;11(8):1949-59.

40. Wang Q, Chen B, Cao M, Sun J, Wu H, Zhao P, et al. Response of MAPK pathway to iron oxide nanoparticles in vitro treatment promotes osteogenic differentiation of hBMSCs. Biomaterials. 2016;86:11-20.

41. Wan DQ, Chen DX, Li K, Qu Y, Sun K, Tao K, et al. Gold nanoparticles as a potential cellular probe for tracking of stem cells in bone regeneration using dual-energy computed tomography. ACS Appl Mater Interfaces. 2016;8(47):32241-9.

42. Lu JW, Yang F, Ke QF, Xie XT, Guo YP. Magnetic nanoparticles modifiedporous scaffolds for bone regeneration and photothermal therapy against tumors. Nanomedicine. 2018;14(3):811-22.

43. Jandt KD. Evolutions, revolutions and trends in biomaterials science-a perspective. Adv Eng Mater. 2007:9(12):1035-50.

44. Kim W, Ng JK, Kunitake ME, Conklin BR, Yang P. Interfacing silicon nanowires with mammalian cells. J Am Chem Soc. 2007;129(23):7228-9.

45. Liu D, Yi C, Wang K, Fong CC, Wang Z, Lo PK, et al. Reorganization of cytoskeleton and transient activation of $\mathrm{Ca}^{2+}$ channels in mesenchymal stem cells cultured on silicon nanowire arrays. ACS Appl Mater Interfaces. 2013;5(24):13295-304.

46. Liu D, Yi C, Fong CC, Jin Q, Wang Z, Yu WK, et al. Activation of multiple signaling pathways during the differentiation of mesenchymal stem cells cultured in a silicon nanowire microenvironment. Nanomedicine. 2014;10(6):1153-63.

47. Kim HW, Kim HE, Knowles JC. Production and potential of bioactive glass nanofibers as a next-generation biomaterial. Adv Funct Mater. 2006;16(12):1529-35

48. Lee JH, Rim NG, Jung HS, Shin H. Control of osteogenic differentiation and mineralization of human mesenchymal stem cells on composite nanofibers containing poly[lactic-co-(glycolic acid)] and hydroxyapatite. Macromol Biosci. 2010;10(2):173-82. 
49. Bauer S, Kleber S, Schmuki P. TiO ${ }_{2}$ nanotubes: tailoring the geometry in $\mathrm{H}_{3} \mathrm{PO}_{4} / \mathrm{HF}$ electrolytes. Electrochem Commun. 2006;8(8):1321-5.

50. Park J, Bauer S, von der Mark K, Schmuki P. Nanosize and vitality: $\mathrm{TiO}_{2}$ nanotube diameter directs cell fate. Nano Lett. 2007;7(6):1686-91.

51. Bauer S, Park J, von der Mark K, Schmuki P. Improved attachment of mesenchymal stem cells on super-hydrophobic $\mathrm{TiO}_{2}$ nanotubes. Acta Biomater. 2008;4(5):1576-82.

52. Oh S, Brammer KS, Li YS, Teng D, Engler AJ, Chien S, et al. Stem cell fate dictated solely by altered nanotube dimension. Proc Natl Acad Sci USA. 2009;106(7):2130-5.

53. Bauer S, Park J, Faltenbacher J, Berger S, von der Mark K, Schmuki P. Size selective behavior of mesenchymal stem cells on $\mathrm{ZrO}(2)$ and $\mathrm{TiO}(2)$ nanotube arrays. Integr Biol (Camb). 2009; 1(8-9):525-32.

54. Wang N, Li H, Lu W, Li J, Wang J, Zhang Z, et al. Effects of $\mathrm{TiO}_{2}$ nanotubes with different diameters on gene expression and osseointegration of implants in minipigs. Biomaterials. 2011:32(29):6900-11.

55. lijima S. Carbon nanotubes: past, present, and future. Physica B. 2002:323(1-4):1-5.

56. Peretz $\mathrm{S}$, Regev O. Carbon nanotubes as nanocarriers in medicine. Curr Opin Colloid Interface Sci. 2012;17(6):360-8.

57. Janas D, Vilatela AC, Koziol KKK. Performance of carbon nanotube wires in extreme conditions. Carbon. 2013;62:438-46.

58. An KH, Kim WS, Park YS, Moon JM, Bae DJ, Lim SC, et al. Electrochemical properties of high-power supercapacitors using single-walled carbon nanotube electrodes. Adv Funct Mater. 2001;11(5):387-92.

59. Rinzler AG, Hafner JH, Nikolaev P, Nordlander P, Colbert DT, Smalley RE, et al. Unraveling nanotubes: field emission from an atomic wire. Science. 1995;269(5230):1550-3.

60. Toprakci O, Toprakci HA, Ji L, Xu G, Lin Z, Zhang X. Carbon nanotubeloaded electrospun $\mathrm{LiFePO}_{4} /$ carbon composite nanofibers as stable and binder-free cathodes for rechargeable lithium-ion batteries. ACS Appl Mater Interfaces. 2012;4(3):1273-80.

61. Wong SS, Joselevich E, Woolley AT, Cheung CL, Lieber CM. Covalently functionalized nanotubes as nanometre-sized probes in chemistry and biology. Nature. 1998;394(6688):52-5.

62. Hirata E, Menard-Moyon C, Venturelli E, Takita H, Watari F, Bianco A, et al. Carbon nanotubes functionalized with fibroblast growth factor accelerate proliferation of bone marrow-derived stromal cells and bone formation. Nanotechnology. 2013;24(43):435101.

63. Zhao B, Hu H, Mandal SK, Haddon RC. A bone mimic based on the selfassembly of hydroxyapatite on chemically functionalized single-walled carbon nanotubes. Chem Mater. 2005;17(12):3235-41.

64. Akasaka T, Watari F, Sato Y, Tohji K. Apatite formation on carbon nanotubes. Mater Sci Eng C. 2006;26(4):675-8

65. Matsuoka M, Akasaka T, Totsuka Y, Watari F. Strong adhesion of Saos-2 cells to multi-walled carbon nanotubes. Mater Sci Eng B. 2010;173(1-3):182-6.

66. Usui Y, Aoki K, Narita N, Murakami N, Nakamura I, Nakamura K, et al. Carbon nanotubes with high bone-tissue compatibility and boneformation acceleration effects. Small. 2008;4(2):240-6.

67. Sitharaman B, Shi XF, Walboomers XF, Liao HB, Cuijpers V, Wilson LJ, et al. In vivo biocompatibility of ultra-short single-walled carbon nanotube/ biodegradable polymer nanocomposites for bone tissue engineering. Bone. 2008:43(2):362-70.

68. Hahn BD, Lee JM, Park DS, Choi JJ, Ryu J, Yoon WH, et al. Mechanical and in vitro biological performances of hydroxyapatite-carbon nanotube composite coatings deposited on Ti by aerosol deposition. Acta Biomater. 2009;5(8):3205-14.

69. Xu JL, Khor KA, Sui JJ, Chen WN. Preparation and characterization of a novel hydroxyapatite/carbon nanotubes composite and its interaction with osteoblast-like cells. Mater Sci Eng C. 2009;29(1):44-9.

70. Lahiri D, Benaduce AP, Rouzaud F, Solomon J, Keshri AK, Kos L, et al. Wear behavior and in vitro cytotoxicity of wear debris generated from hydroxyapatite-carbon nanotube composite coating. J Biomed Mater Res A. 2011;96a(1):1-12.

71. Khalid P, Hussain MA, Rekha PD, Arun AB. Carbon nanotube-reinforced hydroxyapatite composite and their interaction with human osteoblast in vitro. Hum Exp Toxicol. 2015;34(5):548-56.

72. Kaur T, Thirugnanam A. Tailoring in vitro biological and mechanical properties of polyvinyl alcohol reinforced with threshold carbon nanotube concentration for improved cellular response. RSC Adv. 2016;6(46):39982-92.

73. Li HP, Zhao QY, Li BE, Kang JL, Yu ZY, Li YX, et al. Fabrication and properties of carbon nanotube-reinforced hydroxyapatite composites by a double in situ synthesis process. Carbon. 2016;101:159-67.

74. Rodrigues BVM, Silva AS, Melo GFS, Vasconscellos LMR, Marciano FR, Lobo AO. Influence of low contents of superhydrophilic MWCNT on the properties and cell viability of electrospun poly (butylene adipate-coterephthalate) fibers. Mater Sci Eng C. 2016;59:782-91.

75. Gholami F, Ismail S, Noor AFM. Development of carboxylated multiwalled carbon nanotubes and bovine serum albumin reinforced hydroxyapatite for bone substitute applications. J Aust Ceram Soc. 2017:53(1):117-27.

76. Rajesh R, Ravichandran YD. Development of a new carbon nanotubealginate-hydroxyapatite tricomponent composite scaffold for application in bone tissue engineering. Int J Nanomed. 2015;10(Suppl 1):7-15.

77. Shokri S, Movahedi B, Rafieinia M, Salehi H. A new approach to fabrication of $\mathrm{Cs} / \mathrm{BG} / \mathrm{CNT}$ nanocomposite scaffold towards bone tissue engineering and evaluation of its properties. Appl Surf Sci. 2015;357:1758-64.

78. Rajesh R, Ravichandran YD, Reddy MJK, Ryu SH, Shanmugharaj AM. Development of functionalized multi-walled carbon nanotube-based polysaccharide-hydroxyapatite scaffolds for bone tissue engineering. RSC Adv. 2016;6(85):82385-93.

79. Valverde TM, Castro EG, Cardoso MHS, Martins PA, Souza LMO, Silva PP, et al. A novel 3D bone-mimetic scaffold composed of collagen/ MTA/MWCNT modulates cell migration and osteogenesis. Life Sci. 2016;162:115-24.

80. Lin CJ, Han HJ, Zhang F, Li AM. Electrophoretic deposition of HA MWNTs composite coating for biomaterial applications. J Mater Sci Mater Med. 2008:19(7):2569-74.

81. Bai Y, Neupane MP, Park IS, Lee MH, Bae TS, Watari F, et al. Electrophoretic deposition of carbon nanotubes-hydroxyapatite nanocomposites on titanium substrate. Mater Sci Eng C. 2010;30(7):1043-9.

82. Abarrategi A, Gutierrez MC, Moreno-Vicente C, Hortiguela MJ, Ramos V, Lopez-Lacomba JL, et al. Multiwall carbon nanotube scaffolds for tissue engineering purposes. Biomaterials. 2008;29(1):94-102.

83. Bhattacharya M, Wutticharoenmongkol-Thitiwongsawet $\mathrm{P}$, Hamamoto DT, Lee D, Cui TH, Prasad HS, et al. Bone formation on carbon nanotube composite. J Biomed Mater Res A. 2011;96a(1):75-82.

84. Park S, Park J, Jo I, Cho SP, Sung D, Ryu S, et al. In situ hybridization of carbon nanotubes with bacterial cellulose for three-dimensional hybrid bioscaffolds. Biomaterials. 2015;58:93-102.

85. Chen WY, Yang RC, Wang HM, Zhang L, Hu KK, Li CH, et al. Selfassembled heterojunction carbon nanotubes synergizing with photoimmobilized IGF-1 inhibit cellular senescence. Adv Healthc Mater. 2016;5(18):2413-26.

86. Supronowicz PR, Ajayan PM, Ullmann KR, Arulanandam BP, Metzger DW Bizios R. Novel current-conducting composite substrates for exposing osteoblasts to alternating current stimulation. J Biomed Mater Res. 2002;59(3):499-506.

87. Shao SJ, Zhou SB, Li L, Li JR, Luo C, Wang JX, et al. Osteoblast function on electrically conductive electrospun PLA/MWCNTs nanofibers. Biomaterials. 2011;32(11):2821-33.

88. Liu D, Yi C, Zhang D, Zhang J, Yang M. Inhibition of proliferation and differentiation of mesenchymal stem cells by carboxylated carbon nanotubes. ACS Nano. 2010:4(4):2185-95.

89. Zhang Y, Xu Y, Li Z, Chen T, Lantz SM, Howard PC, et al. Mechanistic toxicity evaluation of uncoated and PEGylated single-walled carbon nanotubes in neuronal PC12 cells. ACS Nano. 2011;5(9):7020-33.

90. Novoselov KS, Geim AK, Morozov SV, Jiang D, Zhang Y, Dubonos $\mathrm{SV}$, et al. Electric field effect in atomically thin carbon films. Science. 2004;306(5696):666-9.

91. Shin SR, Li YC, Jang HL, Khoshakhlagh P, Akbari M, Nasajpour A, et al. Graphene-based materials for tissue engineering. Adv Drug Deliv Rev. 2016;105(Pt B):255-74.

92. Novoselov KS, Fal'ko VI, Colombo L, Gellert PR, Schwab MG, Kim K. A roadmap for graphene. Nature. 2012;490(7419):192-200.

93. Li X, Cai W, An J, Kim S, Nah J, Yang D, et al. Large-area synthesis of high-quality and uniform graphene films on copper foils. Science. 2009:324(5932):1312-4. 
94. Kalbacova M, Broz A, Kong J, Kalbac M. Graphene substrates promote adherence of human osteoblasts and mesenchymal stromal cells. Carbon. 2010;48(15):4323-9.

95. Aryaei A, Jayatissa AH, Jayasuriya AC. The effect of graphene substrate on osteoblast cell adhesion and proliferation. J Biomed Mater Res A 2014;102(9):3282-90.

96. Lee WC, Lim CH, Shi H, Tang LA, Wang Y, Lim CT, et al. Origin of enhanced stem cell growth and differentiation on graphene and graphene oxide. ACS Nano. 2011:5(9):7334-41.

97. Nayak TR, Andersen H, Makam VS, Khaw C, Bae S, Xu X, et al. Graphene for controlled and accelerated osteogenic differentiation of human mesenchymal stem cells. ACS Nano. 2011;5(6):4670-8.

98. Crowder SW, Prasai D, Rath R, Balikov DA, Bae H, Bolotin Kl, et al. Threedimensional graphene foams promote osteogenic differentiation of human mesenchymal stem cells. Nanoscale. 2013;5(10):4171-6.

99. Gao C, Liu T, Shuai C, Peng S. Enhancement mechanisms of graphene in nano-58S bioactive glass scaffold: mechanical and biological performance. Sci Rep. 2014;4:4712.

100. Jakus AE, Shah RN. Multi and mixed 3D-printing of graphenehydroxyapatite hybrid materials for complex tissue engineering. J Biomed Mater Res A. 2017;105(1):274-83.

101. Luo JJ, Zhang X, Machuki JO, Dai CB, Li Y, Guo KJ, et al. Three-dimensionally $\mathrm{N}$-doped graphene-hydroxyapatite/agarose as an osteoinductive scaffold for enhancing bone regeneration. ACS Appl Bio Mater. 2019;2(1):299-310.

102. Boehm HP. Graphene-how a laboratory curiosity suddenly became extremely interesting. Angew Chem Int Ed. 2010;49(49):9332-5.

103. Akhavan O, Ghaderi E, Shahsavar M. Graphene nanogrids for selective and fast osteogenic differentiation of human mesenchymal stem cells. Carbon. 2013;59:200-11.

104. Liu H, Cheng J, Chen F, Bai D, Shao C, Wang J, et al. Gelatin functionalized graphene oxide for mineralization of hydroxyapatite: biomimetic and in vitro evaluation. Nanoscale. 2014;6(10):5315-22.

105. Liu H, Cheng J, Chen F, Hou F, Bai D, Xi P, et al. Biomimetic and cellmediated mineralization of hydroxyapatite by carrageenan functionalized graphene oxide. ACS Appl Mater Interfaces. 2014;6(5):3132-40.

106. Elkhenany $\mathrm{H}$, Amelse L, Lafont A, Bourdo S, Caldwell M, Neilsen N, et al. Graphene supports in vitro proliferation and osteogenic differentiation of goat adult mesenchymal stem cells: potential for bone tissue engineering. J Appl Toxicol. 2015;35(4):367-74.

107. Zhao CH, Lu XZ, Zanden C, Liu JH. The promising application of graphene oxide as coating materials in orthopedic implants: preparation, characterization and cell behavior. Biomed Mater. 2015;10(1):015019.

108. Qi YY, Tai ZX, Sun DF, Chen JT, Ma HB, Yan XB, et al. Fabrication and characterization of poly(vinyl alcohol)/graphene oxide nanofibrous biocomposite scaffolds. J Appl Polym Sci. 2013;127(3):1885-94.

109. Kang S, Park JB, Lee TJ, Ryu S, Bhang SH, La WG, et al. Covalent conjugation of mechanically stiff graphene oxide flakes to three-dimensional collagen scaffolds for osteogenic differentiation of human mesenchymal stem cells. Carbon. 2015;83:162-72.

110. Diez-Pascual AM, Diez-Vicente AL. Poly(propylene fumarate)/polyethylene glycol-modified graphene oxide nanocomposites for tissue engineering. ACS Appl Mater Interfaces. 2016:8(28):17902-14.

111. Liu C, Wong HM, Yeung KWK, Tjong SC. Novel electrospun polylactic acid nanocomposite fiber mats with hybrid graphene oxide and nanohydroxyapatite reinforcements having enhanced biocompatibility. Polymers-Basel. 2016;8(8):287.

112. Shao WL, He JX, Sang F, Wang Q, Chen L, Cui SZ, et al. Enhanced bone formation in electrospun poly(L-lactic-co-glycolic acid)-tussah silk fibroin ultrafine nanofiber scaffolds incorporated with graphene oxide. Mater Sci Eng C. 2016;62:823-34.

113. Xie CM, Lu X, Han L, Xu JL, Wang ZM, Jiang LL, et al. Biomimetic mineralized hierarchical graphene oxide/chitosan scaffolds with adsorbability for immobilization of nanoparticles for biomedical applications. ACS Appl Mater Interfaces. 2016;8(3):1707-17.

114. Natarajan J, Madras G, Chatterjee K. Development of graphene oxide-/galactitol polyester-based biodegradable composites for biomedical applications. ACS Omega. 2017;2(9):5545-56.

115. Paz E, Forriol F, Del Real JC, Dunne N. Graphene oxide versus graphene for optimisation of PMMA bone cement for orthopaedic applications. Mater Sci Eng C. 2017;77:1003-11.
116. Peng SP, Feng P, Wu P, Huang W, Yang YW, Guo W, et al. Graphene oxide as an interface phase between polyetheretherketone and hydroxyapatite for tissue engineering scaffolds. Sci Rep. 2017;7:46604.

117. Zhou T, Li G, Lin S, Tian T, Ma Q, Zhang Q, et al. Electrospun poly(3hydroxybutyrate-co-4-hydroxybutyrate)/graphene oxide scaffold: enhanced properties and promoted in vivo bone repair in rats. ACS Appl Mater Interfaces. 2017;9(49):42589-600.

118. Liang CY, Luo YC, Yang GD, Xia D, Liu L, Zhang XM, et al. Graphene oxide hybridized $\mathrm{nHAC/PLGA}$ scaffolds facilitate the proliferation of MC3T3-E1 cells. Nanoscale Res Lett. 2018;13:15.

119. Liu YX, Fang N, Liu B, Song LN, Wen BY, Yang DZ. Aligned porous chitosan/graphene oxide scaffold for bone tissue engineering. Mater Lett. 2018:233:78-81.

120. Pahlevanzadeh F, Bakhsheshi-Rad HR, Hamzah E. In-vitro biocompatibility, bioactivity, and mechanical strength of PMMA-PCL polymer containing fluorapatite and graphene oxide bone cements. J Mech Behav Biomed. 2018;82:257-67.

121. Sivashankari PR, Moorthi A, Abudhahir KM, Prabaharan M. Preparation and characterization of three-dimensional scaffolds based on hydroxypropyl chitosan-graft-graphene oxide. Int J Biol Macromol. 2018;110:522-30

122. Zhang YD, Wang C, Fu L, Ye S, Wang M, Zhou YM. Fabrication and application of novel porous scaffold in situ-loaded graphene oxide and osteogenic peptide by cryogenic 3D printing for repairing critical-sized bone defect. Molecules. 2019;24(9):1699.

123. Luo $Y$, Shen H, Fang $Y$, Cao $Y$, Huang J, Zhang M, et al. Enhanced proliferation and osteogenic differentiation of mesenchymal stem cells on graphene oxide-incorporated electrospun poly(lacticco-glycolic acid) nanofibrous mats. ACS Appl Mater Interfaces. 2015:7(11):6331-9.

124. Depan D, Misra RDK. The interplay between nanostructured carbongrafted chitosan scaffolds and protein adsorption on the cellular response of osteoblasts: structure-function property relationship. Acta Biomater. 2013:9(4):6084-94.

125. Nair M, Nancy D, Krishnan AG, Anjusree GS, Vadukumpully S, Nair SV. Graphene oxide nanoflakes incorporated gelatin-hydroxyapatite scaffolds enhance osteogenic differentiation of human mesenchymal stem cells. Nanotechnology. 2015;26(16):161001.

126. Wu C, Xia L, Han P, Xu M, Fang B, Wang J, et al. Graphene-oxide-modified $\beta$-tricalcium phosphate bioceramics stimulate in vitro and in vivo osteogenesis. Carbon. 2015:93:116-29.

127. Kumar S, Raj S, Sarkar K, Chatterjee K. Engineering a multi-biofunctional composite using poly(ethylenimine) decorated graphene oxide for bone tissue regeneration. Nanoscale. 2016;8(12):6820-36.

128. Zhang Y, Zhai D, Xu M, Yao Q, Chang J, Wu C. 3D-printed bioceramic scaffolds with a $\mathrm{Fe}_{3} \mathrm{O}_{4}$ /graphene oxide nanocomposite interface for hyperthermia therapy of bone tumor cells. J Mater Chem B. 2016;4(17):2874-86

129. Unnithan AR, Sasikala ARK, Park CH, Kim CS. A unique scaffold for bone tissue engineering: an osteogenic combination of graphene oxide-hyaluronic acid-chitosan with simvastatin. J Ind Eng Chem. 2017:46:182-91.

130. Tatavarty R, Ding H, Lu G, Taylor RJ, Bi X. Synergistic acceleration in the osteogenesis of human mesenchymal stem cells by graphene oxide-calcium phosphate nanocomposites. Chem Commun (Camb). 2014:50(62):8484-7

131. La WG, Park S, Yoon HH, Jeong GJ, Lee TJ, Bhang SH, et al. Delivery of a therapeutic protein for bone regeneration from a substrate coated with graphene oxide. Small. 2013;9(23):4051-60.

132. Stankovich S, Dikin DA, Piner RD, Kohlhaas KA, Kleinhammes A, Jia Y, et al. Synthesis of graphene-based nanosheets via chemical reduction of exfoliated graphite oxide. Carbon. 2007;45(7):1558-65.

133. Shin HJ, Kim KK, Benayad A, Yoon SM, Park HK, Jung IS, et al. Efficient reduction of graphite oxide by sodium borohydride and its effect on electrical conductance. Adv Funct Mater. 2009;19(12):1987-92.

134. Chen H, Muller MB, Gilmore KJ, Wallace GG, Li D. Mechanically strong, electrically conductive, and biocompatible graphene paper. Adv Mater. 2008;20(18):3557-61.

135. Lu JY, He YS, Cheng C, Wang Y, Qiu L, Li D, et al. Self-supporting graphene hydrogel film as an experimental platform to evaluate 
the potential of graphene for bone regeneration. Adv Funct Mater. 2013;23(28):3494-502.

136. Cheng J, Liu HY, Zhao BJ, Shen R, Liu D, Hong JP, et al. MC3T3-E1 preosteoblast cell-mediated mineralization of hydroxyapatite by poly-dopamine-functionalized graphene oxide. J Bioact Compat Polym. 2015;30(3):289-301.

137. Lu JY, Cheng C, He YS, Lyu CQ, Wang YF, Yu J, et al. Multilayered graphene hydrogel membranes for guided bone regeneration. Adv Mater. 2016:28(21):4025-31.

138. Liu HY, Xi PX, Xie GQ, Shi YJ, Hou FP, Huang L, et al. Simultaneous reduction and surface functionalization of graphene oxide for hydroxyapatite mineralization. J Phys Chem C. 2012;116(5):3334-41.

139. Kumar $\mathrm{S}$, Chatterjee K. Strontium eluting graphene hybrid nanoparticles augment osteogenesis in a 3D tissue scaffold. Nanoscale. 2015;7(5):2023-33.

140. Lee JH, Shin YC, Jin OS, Kang SH, Hwang YS, Park JC, et al. Reduced graphene oxide-coated hydroxyapatite composites stimulate spontaneous osteogenic differentiation of human mesenchymal stem cells. Nanoscale. 2015;7(27):11642-51.

141. Lee JH, Shin YC, Lee SM, Jin OS, Kang SH, Hong SW, et al. Enhanced osteogenesis by reduced graphene oxide/hydroxyapatite nanocomposites. Sci Rep. 2015;5:18833.

142. Sasidharan A, Panchakarla LS, Chandran P, Menon D, Nair S, Rao CN, et al. Differential nano-bio interactions and toxicity effects of pristine versus functionalized graphene. Nanoscale. 2011;3(6):2461-4.

143. Chang YL, Yang ST, Liu JH, Dong E, Wang YW, Cao AN, et al. In vitro toxicity evaluation of graphene oxide on A549 cells. Toxicol Lett. 2011;200(3):201-10.

144. Wang A, Pu K, Dong B, Liu Y, Zhang L, Zhang Z, et al. Role of surface charge and oxidative stress in cytotoxicity and genotoxicity of graphene oxide towards human lung fibroblast cells. J Appl Toxicol. 2013;33(10):1156-64.

145. Yang K, Wan JM, Zhang SA, Zhang YJ, Lee ST, Liu ZA. In vivo pharmacokinetics, long-term biodistribution, and toxicology of PEGylated graphene in mice. ACS Nano. 2011;5(1):516-22.

146. Curran JM, Chen R, Hunt JA. The guidance of human mesenchymal stem cell differentiation in vitro by controlled modifications to the cell substrate. Biomaterials. 2006;27(27):4783-93.

147. Muller P, Bulnheim U, Diener A, Luthen F, Teller M, Klinkenberg ED, et al. Calcium phosphate surfaces promote osteogenic differentiation of mesenchymal stem cells. J Cell Mol Med. 2008;12(1):281-91.

148. Dimitrievska S, Bureau MN, Antoniou J, Mwale F, Petit A, Lima RS, et al. Titania-hydroxyapatite nanocomposite coatings support human mesenchymal stem cells osteogenic differentiation. J Biomed Mater Res A. 2011;98(4):576-88.

149. Yang BW, Yin JH, Chen Y, Pan SS, Yao HL, Gao YS, et al. 2D-black-phosphorus-reinforced 3D-printed scaffolds: a stepwise countermeasure for osteosarcoma. Adv Mater. 2018;30(10):1705611.

150. Lhotka C, Szekeres T, Steffan I, Zhuber K, Zweymuller K. Four-year study of cobalt and chromium blood levels in patients managed with two different metal-on-metal total hip replacements. J Orthop Res. 2003;21 (2):189-95.

151. Huiskes $R$, Weinans $H$, Rietbergen $B$. The relationship between stress shielding and bone resorption around total hip stems and the effects of flexible materials. Clin Orthop Relat Res. 1992;274:124-34.

152. Lopez-Heredia MA, Sohier J, Gaillard C, Quillard S, Dorget M, Layrolle P. Rapid prototyped porous titanium coated with calcium phosphate as a scaffold for bone tissue engineering. Biomaterials. 2008;29(17):2608-15.

153. Wu SL, Liu XM, Hu T, Chu PK, Ho JPY, Chan YL, et al. A biomimetic hierarchical scaffold: natural growth of nanotitanates on three-dimensional microporous Ti-based metals. Nano Lett. 2008;8(11):3803-8.

154. Chou DT, Wells D, Hong D, Lee B, Kuhn H, Kumta PN. Novel processing of iron-manganese alloy-based biomaterials by inkjet 3-D printing. Acta Biomater. 2013;9(10):8593-603.

155. Chen HJ, Wang CL, Zhu XD, Zhang K, Fan YJ, Zhang XD. Fabrication of porous titanium scaffolds by stack sintering of microporous titanium spheres produced with centrifugal granulation technology. Mater Sci Eng C. 2014;43:182-8.

156. Vaithilingam J, Kilsby S, Goodridge RD, Christie SD, Edmondson S, Hague RJ. Functionalisation of Ti6AI4V components fabricated using selective laser melting with a bioactive compound. Mater Sci Eng C. 2015;46:52-61.

157. Gopi D, Murugan N, Ramya S, Kavitha L. Electrodeposition of a porous strontium-substituted hydroxyapatite/zinc oxide duplex layer on AZ91 magnesium alloy for orthopedic applications. J Mater Chem B. 2014;2(34):5531-40.

158. Dorozhkin SV. Bioceramics of calcium orthophosphates. Biomaterials. 2010;31(7):1465-85.

159. Ebrahimi M, Botelho MG, Dorozhkin SV. Biphasic calcium phosphates bioceramics (HA/TCP): concept, physicochemical properties and the impact of standardization of study protocols in biomaterials research. Mater Sci Eng C. 2017;71:1293-312.

160. Yu W, Sun X, Meng HY, Sun BC, Chen P, Liu XJ, et al. 3D printed porous ceramic scaffolds for bone tissue engineering: a review. Biomater Sci. 2017;5(9):1690-8

161. Suchanek W, Yoshimura M. Processing and properties of hydroxyapatite-based biomaterials for use as hard tissue replacement implants. J Mater Res. 1998;13(1):94-117.

162. Ko CL, Chen WC, Chen JC, Wang YH, Shih CJ, Tyan YC, et al. Properties of osteoconductive biomaterials: calcium phosphate cement with different ratios of platelet-rich plasma as identifiers. Mater Sci Eng C. 2013;33(6):3537-44.

163. Fuchs RK, Thompson WR, Warden SJ. Bone biology. In: Bone repair biomaterials. Cambridge: Woodhead Publishing Ltd; 2019. p. 15-52.

164. Kim SS, Park MS, Jeon O, Choi CY, Kim BS. Poly(lactide-co-glycolide)/ hydroxyapatite composite scaffolds for bone tissue engineering. Biomaterials. 2006;27(8):1399-409.

165. Li CM, Vepari C, Jin HJ, Kim HJ, Kaplan DL. Electrospun silk-BMP-2 scaffolds for bone tissue engineering. Biomaterials. 2006;27(16):3115-24.

166. Nie HM, Wang CH. Fabrication and characterization of PLGA/HAp composite scaffolds for delivery of BMP-2 plasmid DNA. J Control Release. 2007;120(1-2):111-21.

167. Woodard JR, Hilldore AJ, Lan SK, Park CJ, Morgan AW, Eurell JAC, et al. The mechanical properties and osteoconductivity of hydroxyapatite bone scaffolds with multi-scale porosity. Biomaterials. 2007;28(1):45-54.

168. Warnke PH, Seitz H, Warnke F, Becker ST, Sivananthan S, Sherry E, et al. Ceramic scaffolds produced by computer-assisted 3D printing and sintering: characterization and biocompatibility investigations. J Biomed Mater Res B. 2010;93b(1):212-7.

169. Peng F, Yu XH, Wei M. In vitro cell performance on hydroxyapatite particles/poly(L-lactic acid) nanofibrous scaffolds with an excellent particle along nanofiber orientation. Acta Biomater. 2011;7(6):2585-92.

170. Kane RJ, Weiss-Bilka HE, Meagher MJ, Liu YX, Gargac JA, Niebur GL, et al. Hydroxyapatite reinforced collagen scaffolds with improved architecture and mechanical properties. Acta Biomater. 2015;17:16-25.

171. Calabrese G, Giuffrida R, Fabbi C, Figallo E, Lo Furno D, Gulino R, et al. Collagen-hydroxyapatite scaffolds induce human adipose derived stem cells osteogenic differentiation in vitro. PLoS ONE. 2016;1 1(3):e0151181.

172. Goncalves EM, Oliveira FJ, Silva RF, Neto MA, Fernandes MH, Amaral M, et al. Three-dimensional printed PCL-hydroxyapatite scaffolds filled with CNTs for bone cell growth stimulation. J Biomed Mater Res B. 2016;104(6):1210-9.

173. Carrodeguas RG, De Aza S. alpha-Tricalcium phosphate: synthesis, properties and biomedical applications. Acta Biomater. 2011;7(10):3536-46.

174. Egli RJ, Gruenenfelder S, Doebelin N, Hofstetter W, Luginbuehl R, Bohner $\mathrm{M}$. Thermal treatments of calcium phosphate biomaterials to tune the physico-chemical properties and modify the in vitro osteoclast response. Adv Eng Mater. 2011;13(3):B102-7.

175. Raynaud S, Champion E, Lafon JP, Bernache-Assollant D. Calcium phosphate apatites with variable $\mathrm{Ca} / \mathrm{P}$ atomic ratio III. Mechanical properties and degradation in solution of hot pressed ceramics. Biomaterials. 2002;23(4):1081-9.

176. Kyriazis V, Tzaphlidou M. Skeletal calcium/phosphorus ratio measuring techniques and results. I. Microscopy and microtomography. Sci World J. 2004;4:1027-34.

177. Vlad MD, Gomez S, Barraco M, Lopez J, Fernandez E. Effect of the calcium to phosphorus ratio on the setting properties of calcium phosphate bone cements. J Mater Sci Mater Med. 2012;23(9):2081-90.

178. Tarafder S, Balla VK, Davies NM, Bandyopadhyay A, Bose S. Microwavesintered 3D printed tricalcium phosphate scaffolds for bone tissue engineering. J Tissue Eng Regen Med. 2013;7(8):631-41. 
179. Matsuno T, Hashimoto Y, Adachi S, Omata K, Yoshitaka Y, Ozeki Y, et al. Preparation of injectable 3D-formed beta-tricalcium phosphate bead/alginate composite for bone tissue engineering. Dent Mater J. 2008;27(6):827-34.

180. Rakovsky A, Gotman I, Rabkin E, Gutmanas EY. beta-TCP-polylactide composite scaffolds with high strength and enhanced permeability prepared by a modified salt leaching method. J Mech Behav Biomed Mater. 2014;32:89-98.

181. Tarafder S, Bose S. Polycaprolactone-coated 3D printed tricalcium phosphate scaffolds for bone tissue engineering: in vitro alendronate release behavior and local delivery effect on in vivo osteogenesis. ACS Appl Mater Interfaces. 2014;6(13):9955-65.

182. Mohseni M, Jahandideh A, Abedi G, Akbarzadeh A, Hesaraki S. Assessment of tricalcium phosphate/collagen (TCP/collagene)nanocomposite scaffold compared with hydroxyapatite (HA) on healing of segmental femur bone defect in rabbits. Artif Cell Nanomed Biotechnol. 2018;46(2):242-9.

183. Hench LL. Biomaterials: a forecast for the future. Biomaterials. 1998;19(16):1419-23.

184. Hench LL. The story of bioglass (R). J Mater Sci Mater Med. 2006;17(11):967-78.

185. Reck R, Storkel S, Meyer A. Bioactive glass-ceramics in middle ear surgery. An 8-year review. Ann N Y Acad Sci. 1988;523:100-6.

186. Ilharreborde B, Morel E, Fitoussi F, Presedo A, Souchet P, Pennecot GF, et al. Bioactive glass as a bone substitute for spinal fusion in adolescent idiopathic scoliosis: a comparative study with lliac crest autograft. J Pediatr Orthop. 2008;28(3):347-51.

187. Baino F, Vitale-Brovarone C. Three-dimensional glass-derived scaffolds for bone tissue engineering: current trends and forecasts for the future. J Biomed Mater Res A. 2011;97a(4):514-35.

188. Hench LL, Splinter RJ, Allen WC. Bonding mechanisms at the interface of ceramic prosthetic materials. J Biomed Mater Res. 1971;5:117-41.

189. Baino F, Vitale-Brovarone C. Mechanical properties and reliability of glass-ceramic foam scaffolds for bone repair. Mater Lett. 2014:118:27-30.

190. Oki A, Parveen B, Hossain S, Adeniji S, Donahue H. Preparation and in vitro bioactivity of zinc containing sol-gel-derived bioglass materials. J Biomed Mater Res A. 2004;69a(2):216-21.

191. Balamurugan A, Balossier G, Kannan S, Michel J, Rebelo AHS, Ferreira JMF. Development and in vitro characterization of sol-gel derived $\mathrm{CaO}-\mathrm{P}_{2} \mathrm{O}_{5}-\mathrm{SiO}_{2}-\mathrm{ZnO}$ bioglass. Acta Biomater. 2007;3(2):255-62.

192. Zhong JP, Greenspan DC. Processing and properties of sol-gel bioactive glasses. J Biomed Mater Res. 2000;53(6):694-701.

193. Sepulveda P, Jones JR, Hench LL. In vitro dissolution of melt-derived $45 \mathrm{~S} 5$ and sol-gel derived $58 \mathrm{~S}$ bioactive glasses. J Biomed Mater Res. 2002:61(2):301-11.

194. Eqtesadi S, Motealleh A, Pajares A, Guiberteau F, Miranda P. Improving mechanical properties of 13-93 bioactive glass robocast scaffold by poly(lactic acid) and poly(epsilon-caprolactone) melt infiltration. J NonCryst Solids. 2016;432:111-9.

195. Vergnol G, Ginsac N, Rivory P, Meille S, Chenal JM, Balvay S, et al. In vitro and in vivo evaluation of a polylactic acid-bioactive glass composite for bone fixation devices. J Biomed Mater Res B. 2016;104(1):180-91.

196. Zhang XD, Zeng DL, Li N, Wen J, Jiang XQ, Liu CS, et al. Functionalized mesoporous bioactive glass scaffolds for enhanced bone tissue regeneration. Sci Rep. 2016;6:19361.

197. Lopez-Noriega A, Arcos D, Vallet-Regi M. Functionalizing mesoporous bioglasses for long-term anti-osteoporotic drug delivery. Chem Eur J. 2010;16(35):10879-86.

198. Jiang SX, Zhang Y, Shu Y, Wu ZN, Cao WJ, Huang WX. Amino-functionalized mesoporous bioactive glass for drug delivery. Biomed Mater. 2017;12(2):025017.

199. Ding H, Zhao CJ, Cui X, Gu YF, Jia WT, Rahaman MN, et al. A novel injectable borate bioactive glass cement as an antibiotic delivery vehicle for treating osteomyelitis. PLOS ONE. 2014;9(1):e85472.

200. Zhang YD, Cui X, Zhao SC, Wang H, Rahaman MN, Liu ZT, et al. Evaluation of injectable strontium-containing borate bioactive glass cement with enhanced osteogenic capacity in a critical-sized rabbit femoral condyle defect model. ACS Appl Mater Interfaces. 2015;7(4):2393-403.
201. Cui X, Zhang YD, Wang H, Gu YF, Li L, Zhou J, et al. An injectable borate bioactive glass cement for bone repair: preparation, bioactivity and setting mechanism. J Non-Cryst Solids. 2016;432:150-7.

202. Liu XH, Ma PX. Polymeric scaffolds for bone tissue engineering. Ann Biomed Eng. 2004;32(3):477-86.

203. Hench LL, Polak JM. Third-generation biomedical materials. Science. 2002;295(5557):1014-7.

204. Charulatha V, Rajaram A. Influence of different crosslinking treatments on the physical properties of collagen membranes. Biomaterials. 2003;24(5):759-67.

205. Elbjeirami WM, Yonter EO, Starcher BC, West JL. Enhancing mechanical properties of tissue-engineered constructs via lysyl oxidase crosslinking activity. J Biomed Mater Res A. 2003;66a(3):513-21.

206. Brinkman WT, Nagapudi K, Thomas BS, Chaikof EL. Photo-crosslinking of type I collagen gels in the presence of smooth muscle cells: mechanical properties, cell viability, and function. Biomacromolecules. 2003;4(4):890-5.

207. Hirai J, Matsuda T. Self-organized, tubular hybrid vascular tissue composed of vascular cells and collagen for low-pressure-loaded venous system. Cell Transplant. 1995;4(6):597-608.

208. Hu YH, Grainger DW, Winn SR, Hollinger JO. Fabrication of poly(alphahydroxy acid) foam scaffolds using multiple solvent systems. J Biomed Mater Res. 2002;59(3):563-72.

209. Oh SH, Kang SG, Kim ES, Cho SH, Lee JH. Fabrication and characterization of hydrophilic poly(lactic-co-glycolic acid)/poly(vinyl alcohol) blend cell scaffolds by melt-molding particulate-leaching method. Biomaterials. 2003;24(22):4011-21.

210. Thadavirul N, Pavasant P, Supaphol P. Development of polycaprolactone porous scaffolds by combining solvent casting, particulate leaching, and polymer leaching techniques for bone tissue engineering. J Biomed Mater Res A. 2014;102(10):3379-92.

211. Salerno A, Fernandez-Gutierrez M, del Barrio JSR, Domingo C. Bio-safe fabrication of PLA scaffolds for bone tissue engineering by combining phase separation, porogen leaching and scCO(2) drying. J Supercrit Fluid. 2015:97:238-46.

212. Ma PX, Choi JW. Biodegradable polymer scaffolds with well-defined interconnected spherical pore network. Tissue Eng. 2001;7(1):23-33.

213. Tan QG, Li SG, Ren J, Chen C. Fabrication of porous scaffolds with a controllable microstructure and mechanical properties by porogen fusion technique. Int J Mol Sci. 2011:12(2):890-904.

214. Prabhakaran MP, Venugopal J, Ramakrishna S. Electrospun nanostructured scaffolds for bone tissue engineering. Acta Biomater. 2009;5(8):2884-93.

215. Park SH, Park DS, Shin JW, Kang YG, Kim HK, Yoon TR, et al. Scaffolds for bone tissue engineering fabricated from two different materials by the rapid prototyping technique: PCL versus PLGA. J Mater Sci Mater Med. 2012;23(11):2671-8.

216. Mondrinos MJ, Dembzynski R, Lu L, Byrapogu VKC, Wootton DM, Lelkes $\mathrm{PI}$, et al. Porogen-based solid freeform fabrication of polycaprolactonecalcium phosphate scaffolds for tissue engineering. Biomaterials. 2006;27(25):4399-408.

217. Intranuovo F, Gristina R, Brun F, Mohammadi S, Ceccone G, Sardella E, et al. Plasma modification of PCL porous scaffolds fabricated by solventcasting/particulate leaching for tissue engineering. Plasma Process Polym. 2014;11(2):184-95.

218. von Arx T, Cochran DL, Schenk RK, Buser D. Evaluation of a prototype trilayer membrane (PTLM) for lateral ridge augmentation: an experimental study in the canine mandible. Int J Oral Max Surg. 2002;31(2):190-9.

219. Maquet V, Boccaccini AR, Pravata L, Notingher I, Jerome R. Porous poly(alpha-hydroxyacid)/bioglass composite scaffolds for bone tissue engineering. I: preparation and in vitro characterisation. Biomaterials. 2004;25(18):4185-94.

220. Shikinami Y, Matsusue Y, Nakamura T. The complete process of bioresorption and bone replacement using devices made of forged composites of raw hydroxyapatite particles/poly L-lactide (F-u-HA/ PLLA). Biomaterials. 2005;26(27):5542-51.

221. Sheikh FA, Ju HW, Moon BM, Lee OJ, Kim JH, Park HJ, et al. Hybrid scaffolds based on PLGA and silk for bone tissue engineering. J Tissue Eng Regen Med. 2016;10(3):209-21. 
222. Lei Y, Xu ZL, Ke QF, Yin WJ, Chen YX, Zhang CQ, et al. Strontium hydroxyapatite/chitosan nanohybrid scaffolds with enhanced osteoinductivity for bone tissue engineering. Mater Sci Eng C. 2017;72:134-42.

223. Huang BY, Caetano G, Vyas C, Blaker JJ, Diver C, Bartolo P. Polymerceramic composite scaffolds: the effect of hydroxyapatite and beta-tricalcium phosphate. Materials. 2018;11(1):129.

224. Backes EH, Fernandes EM, Diogo GS, Marques CF, Silva TH, Costa LC, et al. Engineering 3D printed bioactive composite scaffolds based on the combination of aliphatic polyester and calcium phosphates for bone tissue regeneration. Mater Sci Eng C. 2021;122:111928.

225. Yamaoka T, Hotta Y, Kobayashi K, Kimura Y. Synthesis and properties of malic acid-containing functional polymers. Int J Biol Macromol. 1999:25(1-3):265-71.

226. Kao CT, Lin CC, Chen YW, Yeh CH, Fang HY, Shie MY. Poly(dopamine) coating of 3D printed poly(lactic acid) scaffolds for bone tissue engineering. Mater Sci Eng C. 2015;56:165-73.

227. Chen JP, Cheng TH. Thermo-responsive chitosan-graft-poly(N-isopropylacrylamide) injectable hydrogel for cultivation of chondrocytes and meniscus cells. Macromol Biosci. 2006;6(12):1026-39.

228. Tan HP, Ramirez CM, Miljkovic N, Li H, Rubin JP, Marra KG. Thermosensitive injectable hyaluronic acid hydrogel for adipose tissue engineering. Biomaterials. 2009;30(36):6844-53.

229. Boucard N, Viton C, Agay D, Mari E, Roger T, Chancerelle Y, et al. The use of physical hydrogels of chitosan for skin regeneration following thirddegree burns. Biomaterials. 2007;28(24):3478-88.

230. Vilela CA, Correia C, da Silva MA, Santos TC, Gertrudes AC, Moreira ES, et al. In vitro and in vivo performance of methacrylated gellan gum hydrogel formulations for cartilage repair. J Biomed Mater Res A. 2018;106(7):1987-96.

231. Weitkamp JT, Woltje M, Nusspickel B, Schmidt FN, Aibibu D, Bayer A, et al. Silk fiber-reinforced hyaluronic acid-based hydrogel for cartilage tissue engineering. Int J Mol Sci. 2021;22(7):3635.

232. Zhu J, Marchant RE. Design properties of hydrogel tissue-engineering scaffolds. Expert Rev Med Devices. 2011;8(5):607-26.

233. Kim J, Kim IS, Cho TH, Lee KB, Hwang SJ, Tae G, et al. Bone regeneration using hyaluronic acid-based hydrogel with bone morphogenic protein-2 and human mesenchymal stem cells. Biomaterials. 2007;28(10):1830-7.

234. Sakai S, Hirose K, Taguchi K, Ogushi Y, Kawakami K. An injectable, in situ enzymatically gellable, gelatin derivative for drug delivery and tissue engineering. Biomaterials. 2009;30(20):3371-7.

235. Tabriz AG, Hermida MA, Leslie NR, Shu WM. Three-dimensional bioprinting of complex cell laden alginate hydrogel structures. Biofabrication. 2015;7(4):045012.

236. Wang YJ, Zhu W, Xiao K, Li Z, Ma Q, Li WF, et al. Self-healing and injectable hybrid hydrogel for bone regeneration of femoral head necrosis and defect. Biochem Biophys Res Commun. 2019;508(1):25-30.

237. Deshmukh M, Singh Y, Gunaseelan S, Gao DY, Stein S, Sinko PJ. Biodegradable poly(ethylene glycol) hydrogels based on a self-elimination degradation mechanism. Biomaterials. 2010;31(26):6675-84.

238. Zustiak SP, Leach JB. Hydrolytically degradable poly(ethylene glycol) hydrogel scaffolds with tunable degradation and mechanical properties. Biomacromolecules. 2010;11(5):1348-57.

239. Kang HW, Lee SJ, Ko IK, Kengla C, Yoo JJ, Atala A. A 3 D bioprinting system to produce human-scale tissue constructs with structural integrity. Nat Biotechnol. 2016;34(3):312-9.

240. Wang XF, Song Y, Liu YS, Sun YC, Wang YG, Wang Y, et al. Osteogenic differentiation of three-dimensional bioprinted constructs consisting of human adipose-derived stem cells in vitro and in vivo. PLOS ONE. 2016;11(6):e0157214.

241. Qiu PC, Li MB, Chen K, Fang B, Chen PF, Tang ZB, et al. Periosteal matrixderived hydrogel promotes bone repair through an early immune regulation coupled with enhanced angio- and osteogenesis. Biomaterials. 2020;227:119552.

242. Fellah BH, Weiss P, Gauthier O, Rouillon T, Pilet P, Daculsi G, et al. Bone repair using a new injectable self-crosslinkable bone substitute. J Orthop Res. 2006;24(4):628-35.

243. Kim S, Fan JB, Lee CS, Chen C, Bubukina K, Lee M. Heparinized chitosan stabilizes the bioactivity of BMP-2 and potentiates the osteogenic efficacy of demineralized bone matrix. J Biol Eng. 2020;14(1):6.
244. Benoit DSW, Anseth KS. Heparin functionalized PEG gels that modulate protein adsorption for hMSC adhesion and differentiation. Acta Biomater. 2005;1(4):461-70.

245. Benoit DSW, Durney AR, Anseth KS. The effect of heparin-functionalized PEG hydrogels on three-dimensional human mesenchymal stem cell osteogenic differentiation. Biomaterials. 2007;28(1):66-77.

246. Tae G, Kim YJ, Choi WI, Kim M, Stayton PS, Hoffman AS. Formation of a novel heparin-based hydrogel in the presence of heparin-binding biomolecules. Biomacromolecules. 2007;8(6):1979-86.

247. Kim HJ, You SJ, Yang DH, Eun J, Park HK, Kim MS, et al. Injectable hydrogels based on MPEG-PCL-RGD and BMSCs for bone tissue engineering. Biomater Sci. 2020;8(15):4334-45

248. Subbiah R, Cheng A, Ruehle MA, Hettiaratchi MH, Bertassoni LE, Guldberg RE. Effects of controlled dual growth factor delivery on bone regeneration following composite bone-muscle injury. Acta Biomater. 2020;114:63-75.

249. Peng J, Zhao H, Tu CZ, Xu ZQ, Ye L, Zhao L, et al. In situ hydrogel dressing loaded with heparin and basic fibroblast growth factor for accelerating wound healing in rat. Mater Sci Eng C. 2020;116:111169.

250. Li C, Faulkner-Jones A, Dun AR, Jin J, Chen P, Xing YZ, et al. Rapid formation of a supramolecular polypeptide-DNA hydrogel for in situ three-dimensional multilayer bioprinting. Angew Chem Int Ed. 2015;54(13):3957-61.

251. Ding HZ, Tourlomousis F, Chang RC. Bioprinting multidimensional constructs: a quantitative approach to understanding printed cell density and redistribution phenomena. Biomed Phys Eng Express. 2017;3(3):035016

252. Campbell TA, Tibbits S, Garrett B. The next wave: 4D printing programming the material world. The Atlantic Council of the United States. 2014.

253. Skrzeszewska PJ, Jong LN, de Wolf FA, Stuart MAC, van der Gucht J. Shape-memory effects in biopolymer networks with collagen-like transient nodes. Biomacromolecules. 2011;12(6):2285-92.

254. Stroganov V, Al-Hussein M, Sommer JU, Janke A, Zakharchenko S, Ionov L. Reversible thermosensitive biodegradable polymeric actuators based on confined crystallization. Nano Lett. 2015;15(3):1786-90.

255. Senatov FS, Niaza KV, Zadorozhnyy MY, Maksimkin AV, Kaloshkin SD, Estrin YZ. Mechanical properties and shape memory effect of 3D-printed PLA-based porous scaffolds. J Mech Behav Biomed. 2016;57:139-48.

256. Wang T, Chen LM, Shen TT, Wu DY. Preparation and properties of a novel thermo-sensitive hydrogel based on chitosan/hydroxypropyl methylcellulose/glycerol. Int J Biol Macromol. 2016;93:775-82.

257. Apsite I, Stoychev G, Zhang WZ, Jehnichen D, Xie J, Ionov L. Porous stimuli-responsive self-folding electrospun mats for 4D biofabrication. Biomacromolecules. 2017:18(10):3178-84.

258. Hendrikson WJ, Rouwkema J, Clementi F, van Blitterswijk CA, Fare S, Moroni L. Towards 4D printed scaffolds for tissue engineering: exploiting 3D shape memory polymers to deliver time-controlled stimulus on cultured cells. Biofabrication. 2017;9(3):031001.

259. Naficy S, Gately R, Gorkin R, Xin H, Spinks GM. 4D Printing of reversible shape morphing hydrogel structures. Macromol Mater Eng. 2017:302(1):1600212.

260. Graham S, Marina PF, Blencowe A. Thermoresponsive polysaccharides and their thermoreversible physical hydrogel networks. Carbohydr Polym. 2019;207:143-59.

261. Zhang LD, Liang HR, Jacob J, Naumov P. Photogated humidity-driven motility. Nat Commun. 2015;6:7429.

262. Griffin DR, Kasko AM. Photodegradable macromers and hydrogels for live cell encapsulation and release. J Am Chem Soc. 2012;134(31):13103-7.

263. Qin YP, Chen J, Bi Y, Xu XH, Zhou H, Gao JM, et al. Near-infrared light remote-controlled intracellular anti-cancer drug delivery using thermo/ pH sensitive nanovehicle. Acta Biomater. 2015;17:201-9.

264. Arakawa CK, Badeau BA, Zheng Y, DeForest CA. Multicellular vascularized engineered tissues through user-programmable biomaterial photodegradation. Adv Mater. 2017;29(37):1703156.

265. Servant A, Leon V, Jasim D, Methven L, Limousin P, FernandezPacheco EV, et al. Graphene-based electroresponsive scaffolds as polymeric implants for on-demand drug delivery. Adv Healthc Mater. 2014;3(8):1334-43. 
266. Lalitha K, Prasad YS, Sridharan V, Maheswari CU, John G, Nagarajan S. A renewable resource-derived thixotropic self-assembled supramolecular gel: magnetic stimuli responsive and real-time self-healing behaviour. RSC Adv. 2015;5(95):77589-94

267. Zhang LN, Zuo XQ, Li SJ, Sun M, Xie HM, Zhang K, et al. Synergistic therapy of magnetism-responsive hydrogel for soft tissue injuries. Bioact Mater. 2019;4:160-6.

268. Huebsch N, Kearney CJ, Zhao XH, Kim J, Cezar CA, Suo ZG, et al. Ultrasound-triggered disruption and self-healing of reversibly crosslinked hydrogels for drug delivery and enhanced chemotherapy. Proc Natl Acad Sci USA. 2014;111(27):9762-7.

269. Eldin MSM, Kamoun EA, Sofan MA, Elbayomi SM. L-Arginine grafted alginate hydrogel beads: a novel $\mathrm{pH}$-sensitive system for specific protein delivery. Arab J Chem. 2015;8(3):355-65.

270. Nadgorny M, Xiao ZY, Chen C, Connal LA. Three-dimensional printing of $\mathrm{pH}$-responsive and functional polymers on an affordable desktop printer. ACS Appl Mater Interfaces. 2016;8(42):28946-54.

271. Bai T, Han YJ, Zhang P, Wang W, Liu WG. Zinc ion-triggered two-way macro-/microscopic shape changing and memory effects in high strength hydrogels with pre-programmed unilateral patterned surfaces. Soft Matter. 2012;8(25):6846-52.

272. Nan WJ, Wang W, Gao H, Liu WG. Fabrication of a shape memory hydrogel based on imidazole-zinc ion coordination for potential cellencapsulating tubular scaffold application. Soft Matter. 2013;9(1):132-7.

273. Ren ZQ, Zhang YY, Li YM, Xu B, Liu WG. Hydrogen bonded and ionically crosslinked high strength hydrogels exhibiting $\mathrm{Ca}^{2+}$-triggered shape memory properties and volume shrinkage for cell detachment. J Mater Chem B. 2015;3(30):6347-54.

274. Kirillova A, Maxson R, Stoychev G, Gomillion CT, Ionov L. 4D biofabrication using shape-morphing hydrogels. Adv Mater. 2017;29(46):1703443.

275. Kuribayashi-Shigetomi K, Onoe H, Takeuchi S. Cell origami: self-folding of three-dimensional cell-laden microstructures driven by cell traction force. PLoS ONE. 2012;7(12):e51085.

276. Kim J, Park Y, Tae G, Lee KB, Hwang SJ, Kim IS, et al. Synthesis and characterization of matrix metalloprotease sensitive-low molecular weight hyaluronic acid based hydrogels. J Mater Sci Mater Med. 2008;19(11):3311-8

277. Chen JP, Tsai MJ, Liao HT. Incorporation of biphasic calcium phosphate microparticles in injectable thermoresponsive hydrogel modulates bone cell proliferation and differentiation. Colloids Surf B. 2013;110:120-9.

278. Chen XH, Zhao YB, Geng SN, Miron RJ, Zhang Q, Wu CT, et al. In vivo experimental study on bone regeneration in critical bone defects using $\mathrm{PIB}$ nanogels/boron-containing mesoporous bioactive glass composite scaffold. Int J Nanomed. 2015;10:839-46.

279. Demirtas TT, Irmak G, Gumusderelioglu M. A bioprintable form of chitosan hydrogel for bone tissue engineering. Biofabrication. 2017;9(3):035003.

280. Parameswaran-Thankam A, Parnell CM, Watanabe F, RanguMagar AB, Chhetri BP, Szwedo PK, et al. Guar-based injectable thermoresponsive hydrogel as a scaffold for bone cell growth and controlled drug delivery. ACS Omega. 2018;3(11):15158-67.

281. Miao SD, Zhu W, Castro NJ, Leng JS, Zhang LG. Four-dimensional printing hierarchy scaffolds with highly biocompatible smart polymers for tissue engineering applications. Tissue Eng C. 2016;22(10):952-63.

282. Luo ZY, Zhang SQ, Pan JJ, Shi R, Liu H, Lyu YL, et al. Time-responsive osteogenic niche of stem cells: a sequentially triggered, dual-peptide loaded, alginate hybrid system for promoting cell activity and osteodifferentiation. Biomaterials. 2018;163:25-42.

283. Tang YF, Wu C, Wu ZX, Hu L, Zhang W, Zhao K. Fabrication and in vitro biological properties of piezoelectric bioceramics for bone regeneration. Sci Rep. 2017;7:43360.

284. Devillard CD, Mandon CA, Lambert SA, Blum LJ, Marquette CA. Bioinspired multi-activities 4D printing objects: a new approach toward complex tissue engineering. Biotechnol J. 2018;13(12):1800098.

285. Miao S, Cui H, Nowicki M, Xia L, Zhou X, Lee SJ, et al. Stereolithographic 4D bioprinting of multiresponsive architectures for neural engineering. Adv Biosyst. 2018;2(9):1800101.

\section{Publisher's Note}

Springer Nature remains neutral with regard to jurisdictional claims in published maps and institutional affiliations.
Ready to submit your research? Choose BMC and benefit from:

- fast, convenient online submission

- thorough peer review by experienced researchers in your field

- rapid publication on acceptance

- support for research data, including large and complex data types

- gold Open Access which fosters wider collaboration and increased citations

- maximum visibility for your research: over $100 \mathrm{M}$ website views per year

At BMC, research is always in progress.

Learn more biomedcentral.com/submissions 